Supporting Information for

\title{
Half-sandwich Ruthenium Complexes With Schiff Base Ligands: Syntheses, Characterization and Catalytic Activities for the Reduction of Nitroarenes
}

Wei-Guo Jia*, Hui Zhang, Tai Zhang, Dong Xie, Shuo Ling, En-Hong Sheng

College of Chemistry and Materials Science, Center for Nano Science and Technology, The Key Laboratory of Functional Molecular Solids, Ministry of Education, Anhui Laboratory of Molecular-Based Materials, Anhui Normal University, Wuhu, 241000, China

*Corresponding author. Tel.: +86-0553-3883513; Fax: +86-0553-3869302

E-mail address: wgjiasy@mail.ahnu.edu.cn (W. -G. Jia)

\section{Contents}

1. Copies of ${ }^{1} \mathrm{H},{ }^{13} \mathrm{C}$ NMR Spectra of schiff-base 1a-1l (FigureS1-FigureS20).

2. Copies of ${ }^{1} \mathrm{H},{ }^{13} \mathrm{C}$ NMR Spectra of half-sandwich ruthenium complex 2a-2l (FigureS21-FigureS44).

3. Copies of ${ }^{1} \mathrm{H}$ Spectra of aromatic anilines compounds in Table $\mathbf{5}$ (FigureS45-FigureS68).

4. Copies of ${ }^{1} \mathrm{H}$ Spectra of NMR in situ (FigureS69). 


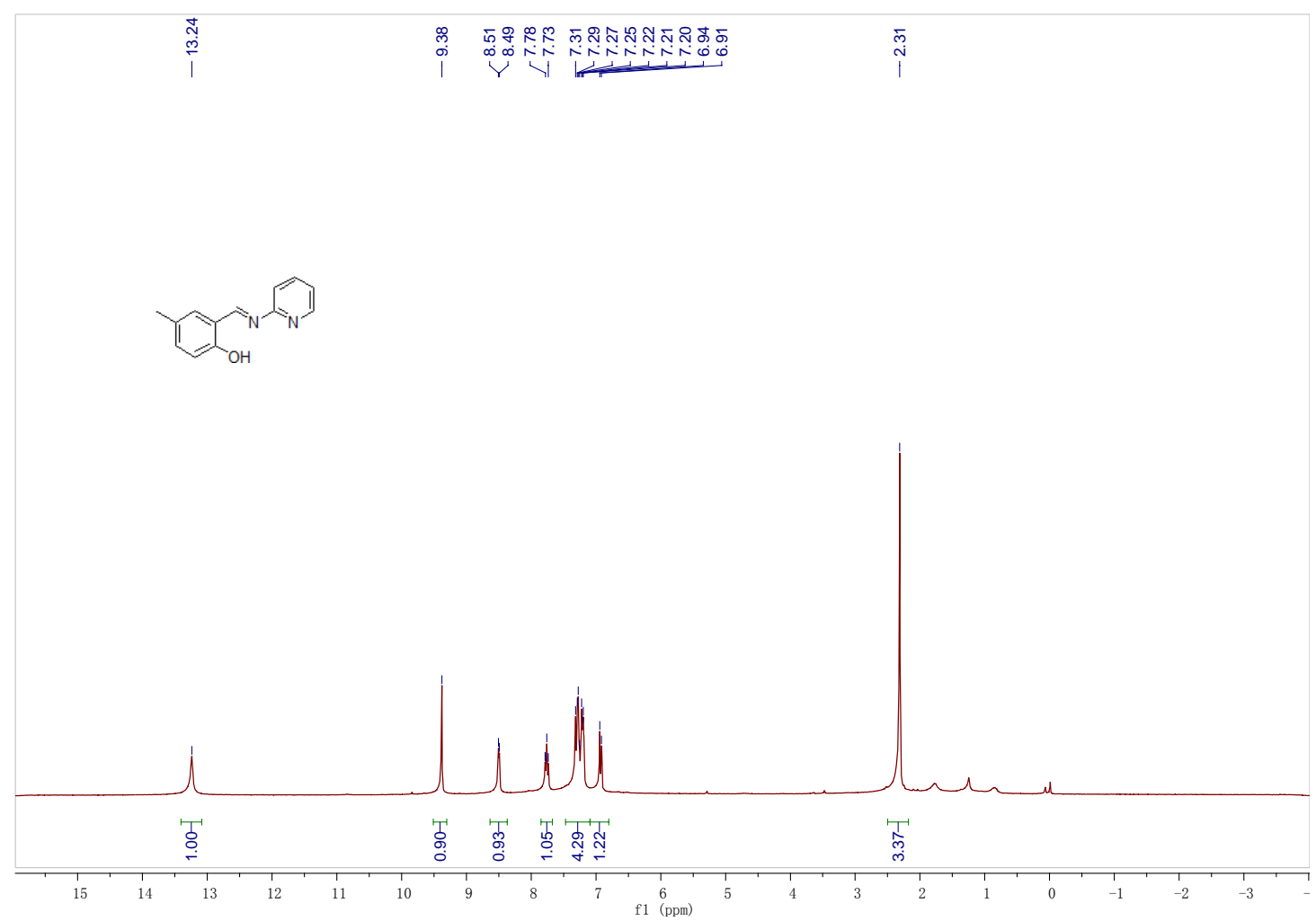

Figure S1. The ${ }^{1} \mathrm{H}$ NMR of Schiff-base 1a

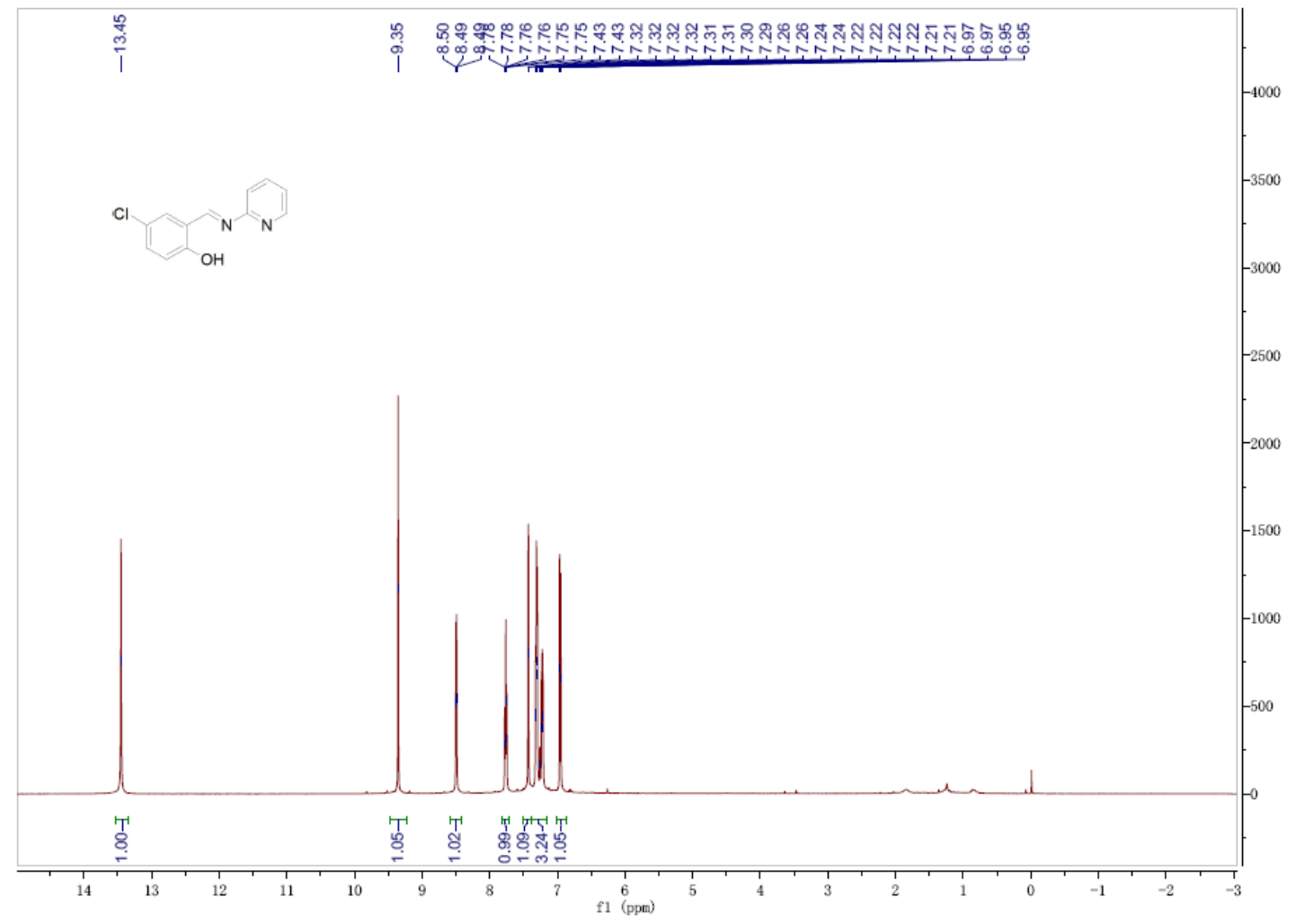

Figure S2. The ${ }^{1} \mathrm{H}$ NMR of Schiff-base $\mathbf{1 b}$ 


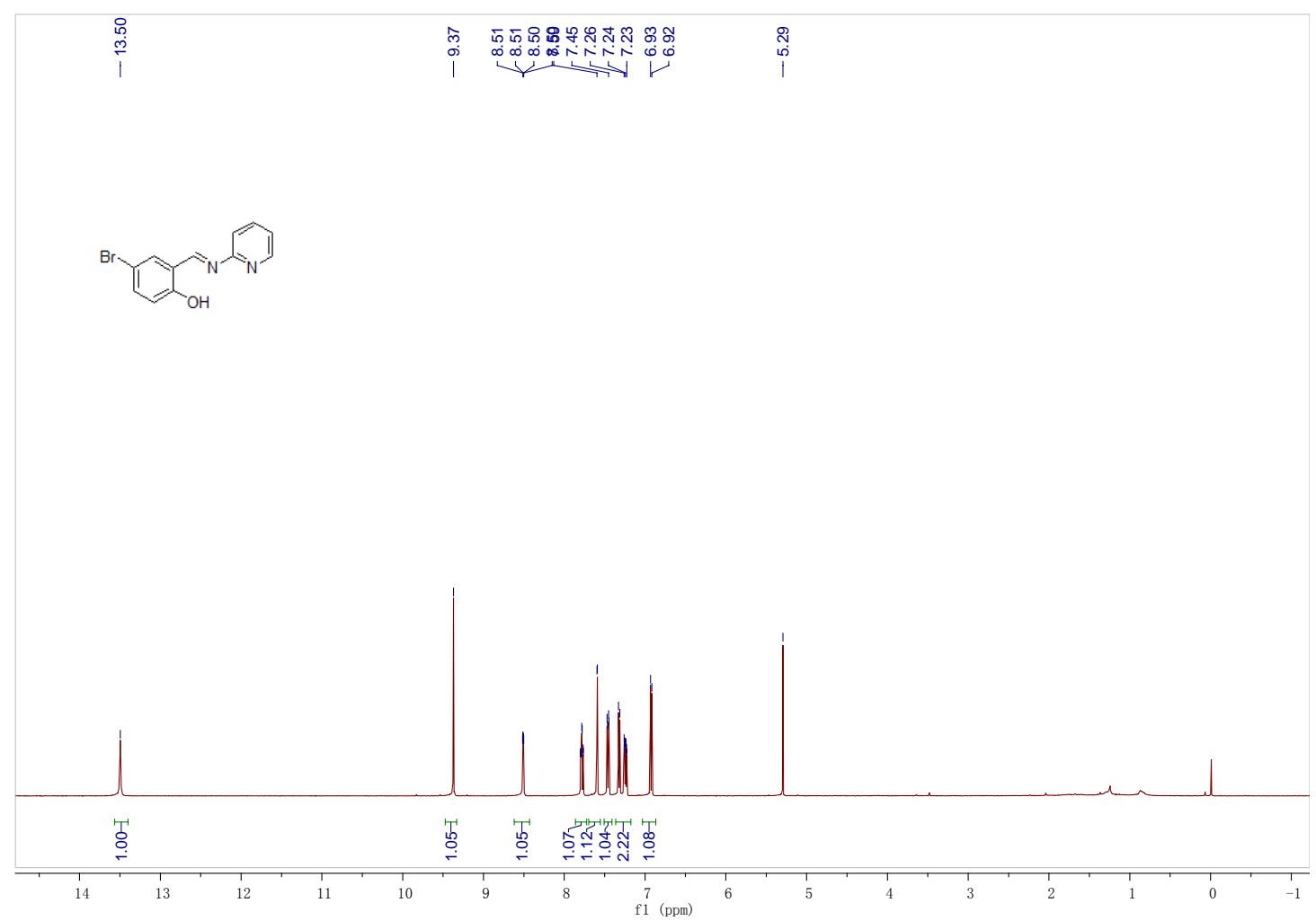

Figure S3. The ${ }^{1} \mathrm{H}$ NMR of Schiff-base 1c

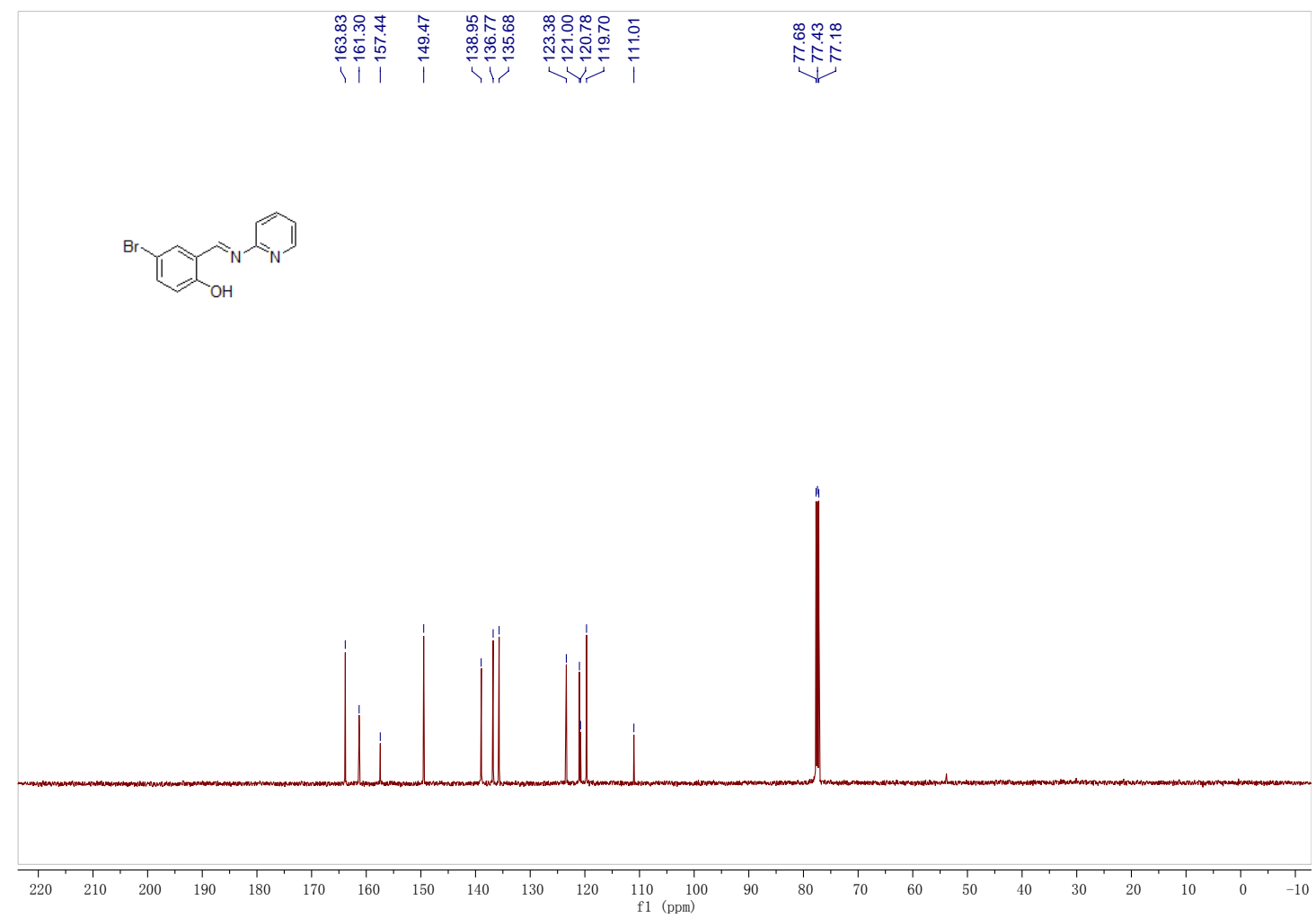

Figure S4. The ${ }^{13} \mathrm{C}$ NMR of Schiff-base 1c 


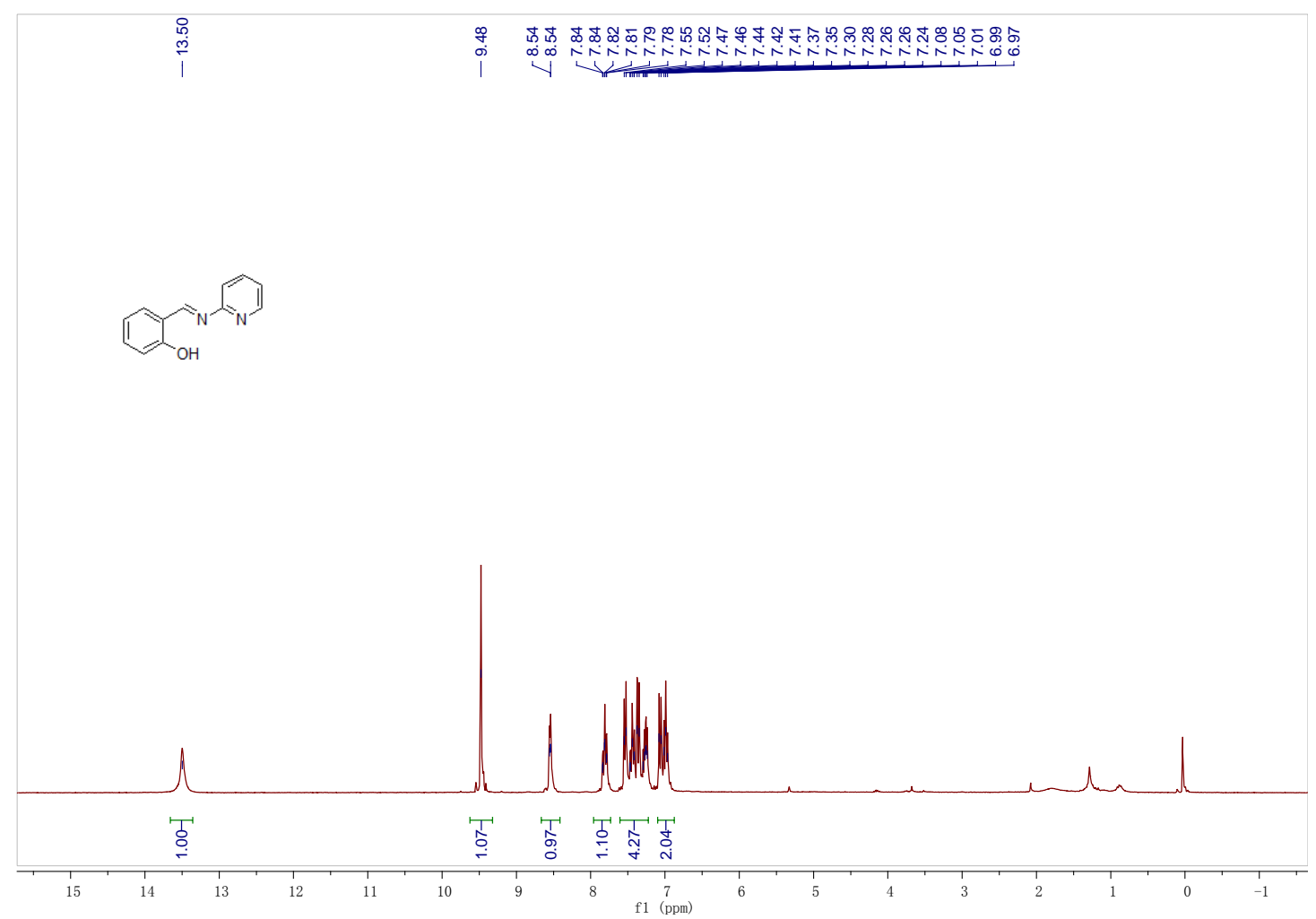

Figure S5. The ${ }^{1} \mathrm{H}$ NMR of Schiff-base 1d

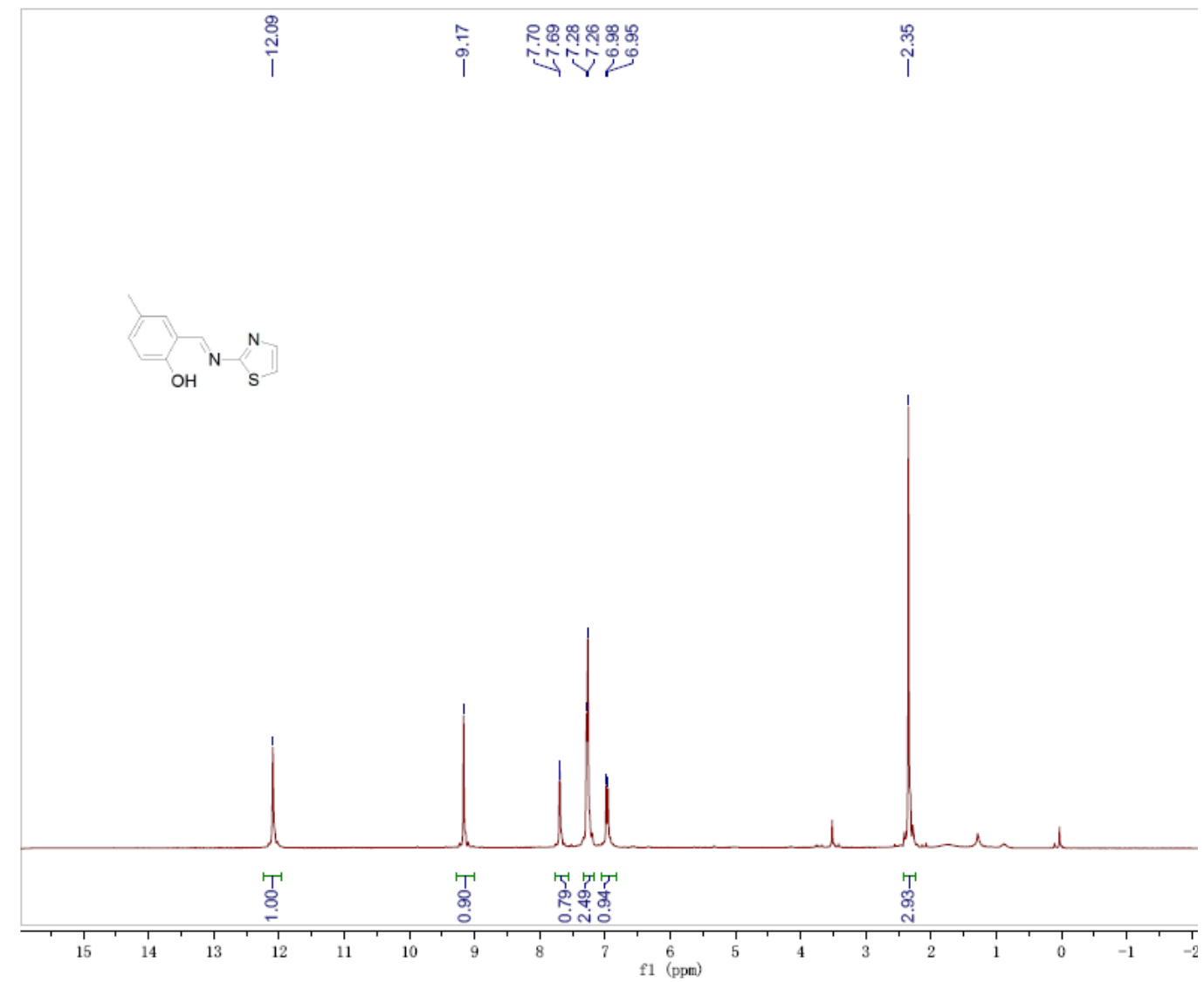

Figure S6. The ${ }^{1} \mathrm{H}$ NMR of Schiff-base 1e 


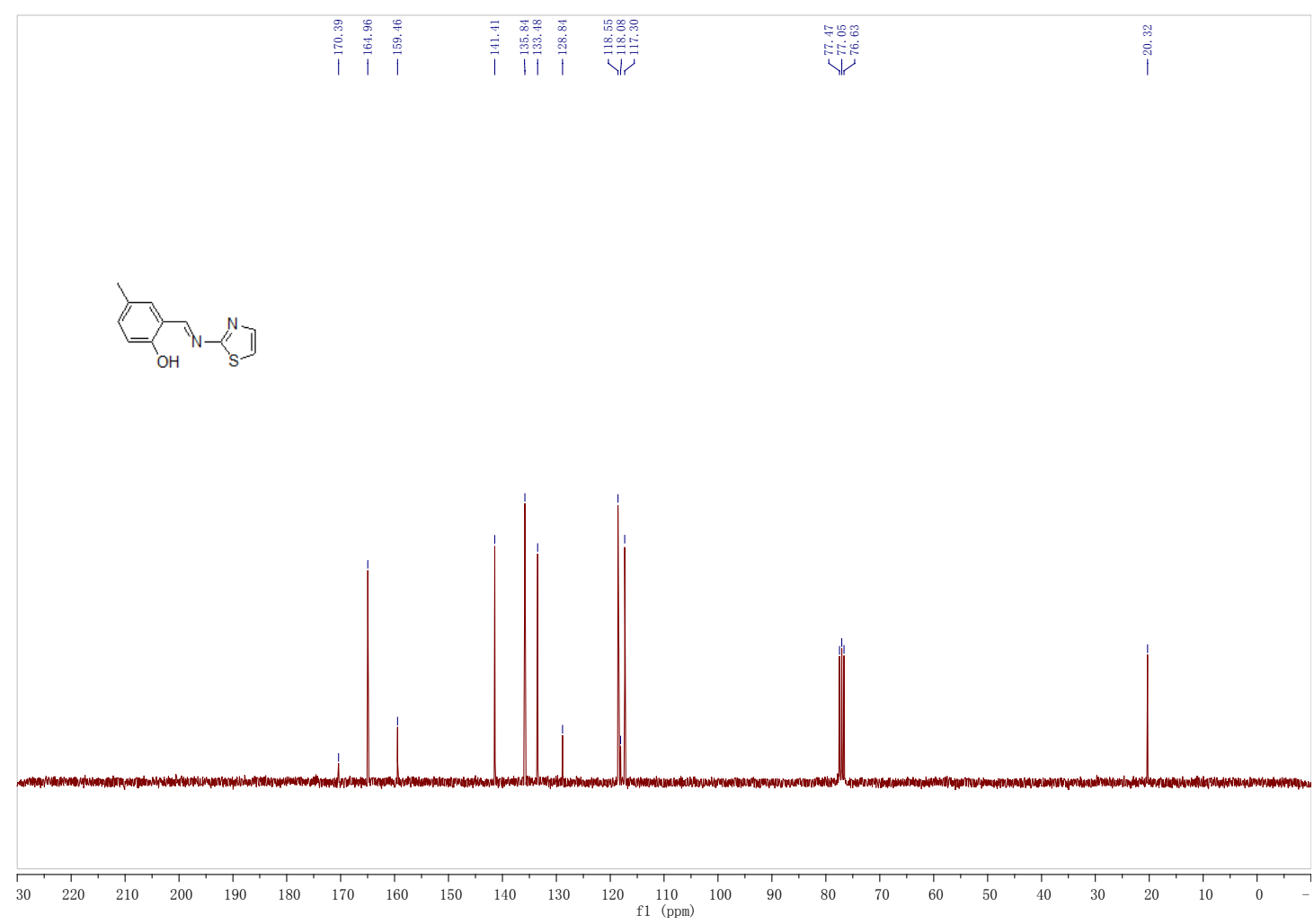

Figure S7. The ${ }^{13} \mathrm{C}$ NMR of Schiff-base 1e

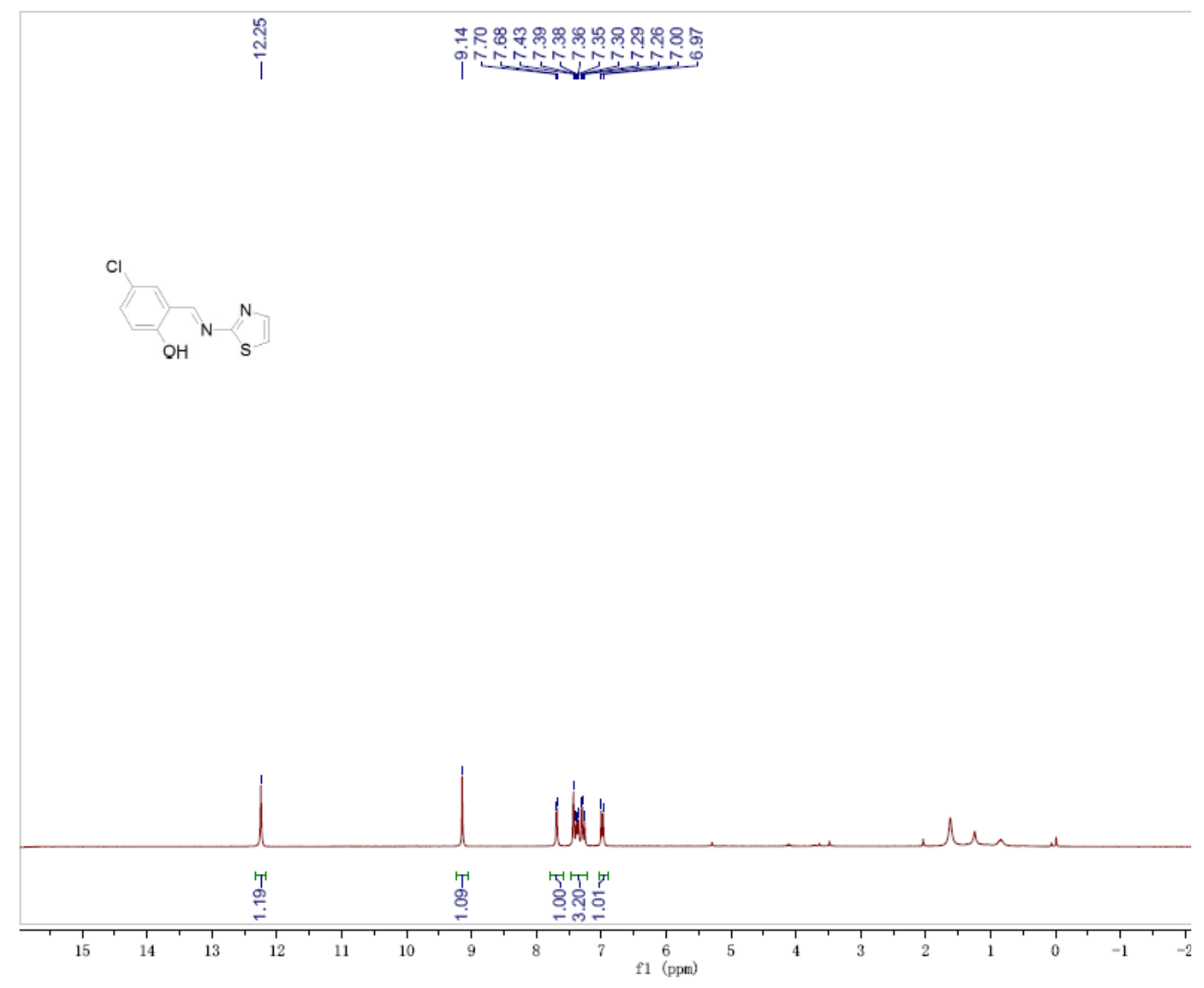

Figure S8. The ${ }^{1} \mathrm{H}$ NMR of Schiff-base $\mathbf{1 f}$ 


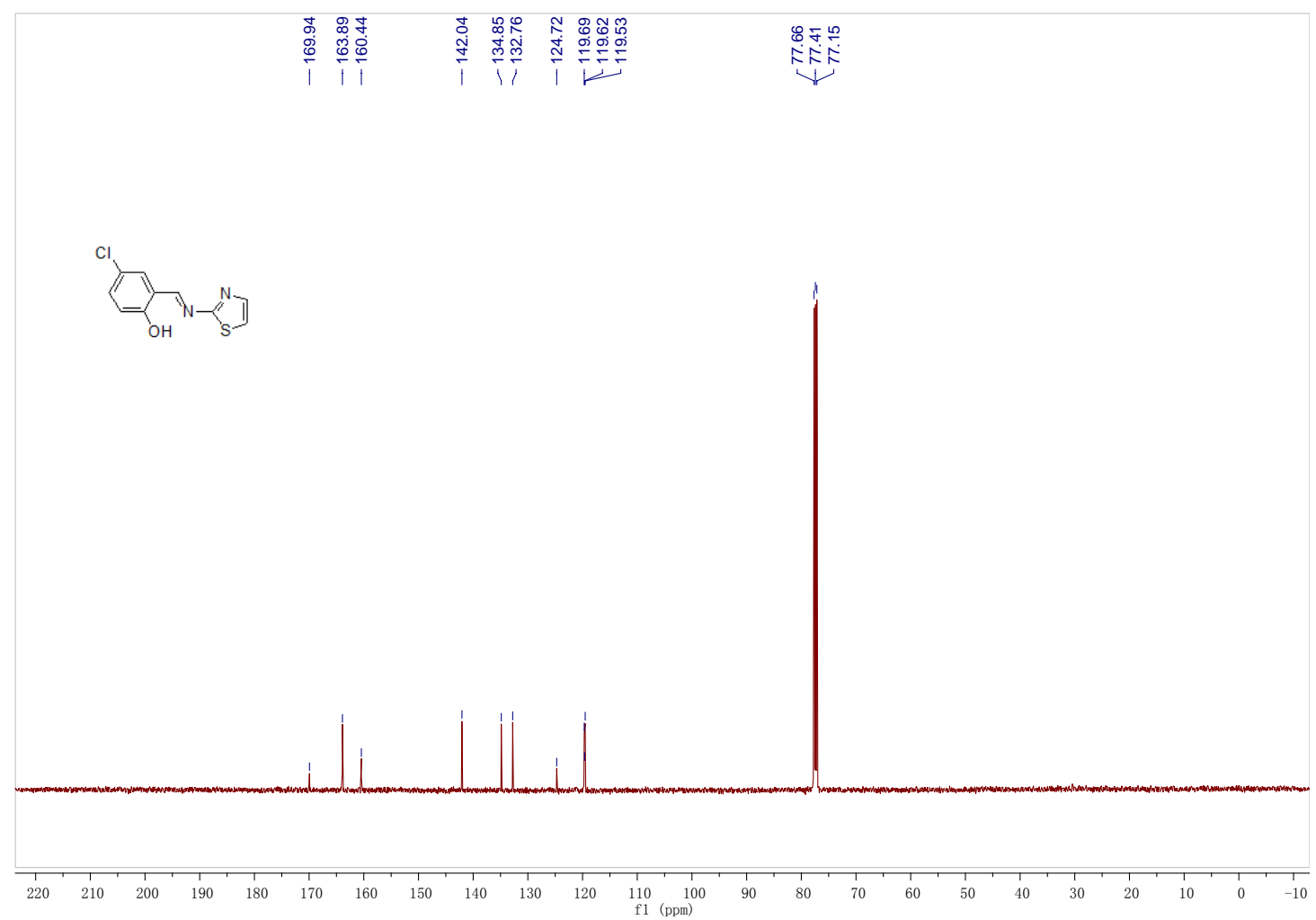

Figure S9. The ${ }^{13} \mathrm{C}$ NMR of Schiff-base $\mathbf{1 f}$

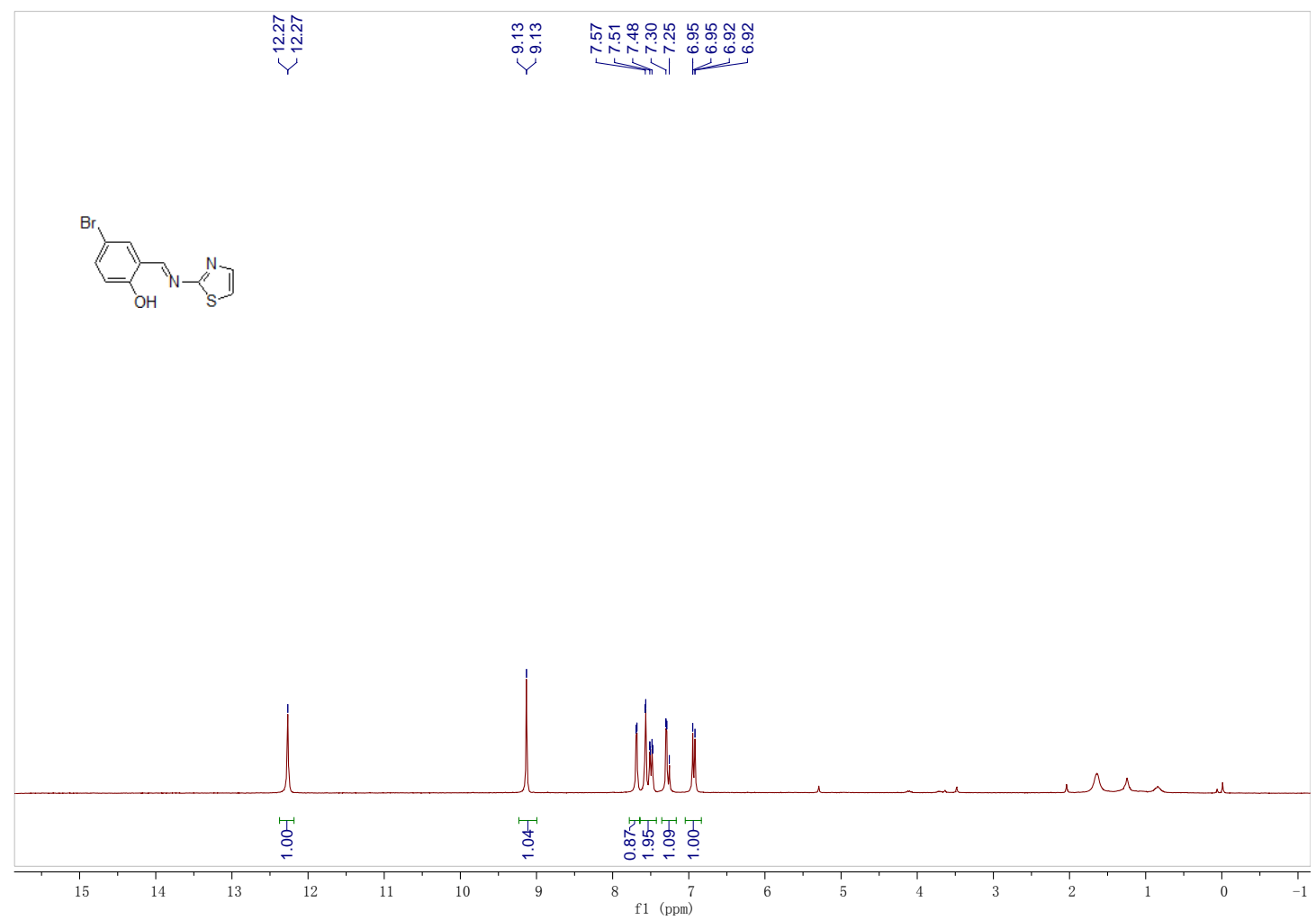

Figure S10. The ${ }^{1} \mathrm{H}$ NMR of Schiff-base $\mathbf{1 g}$ 


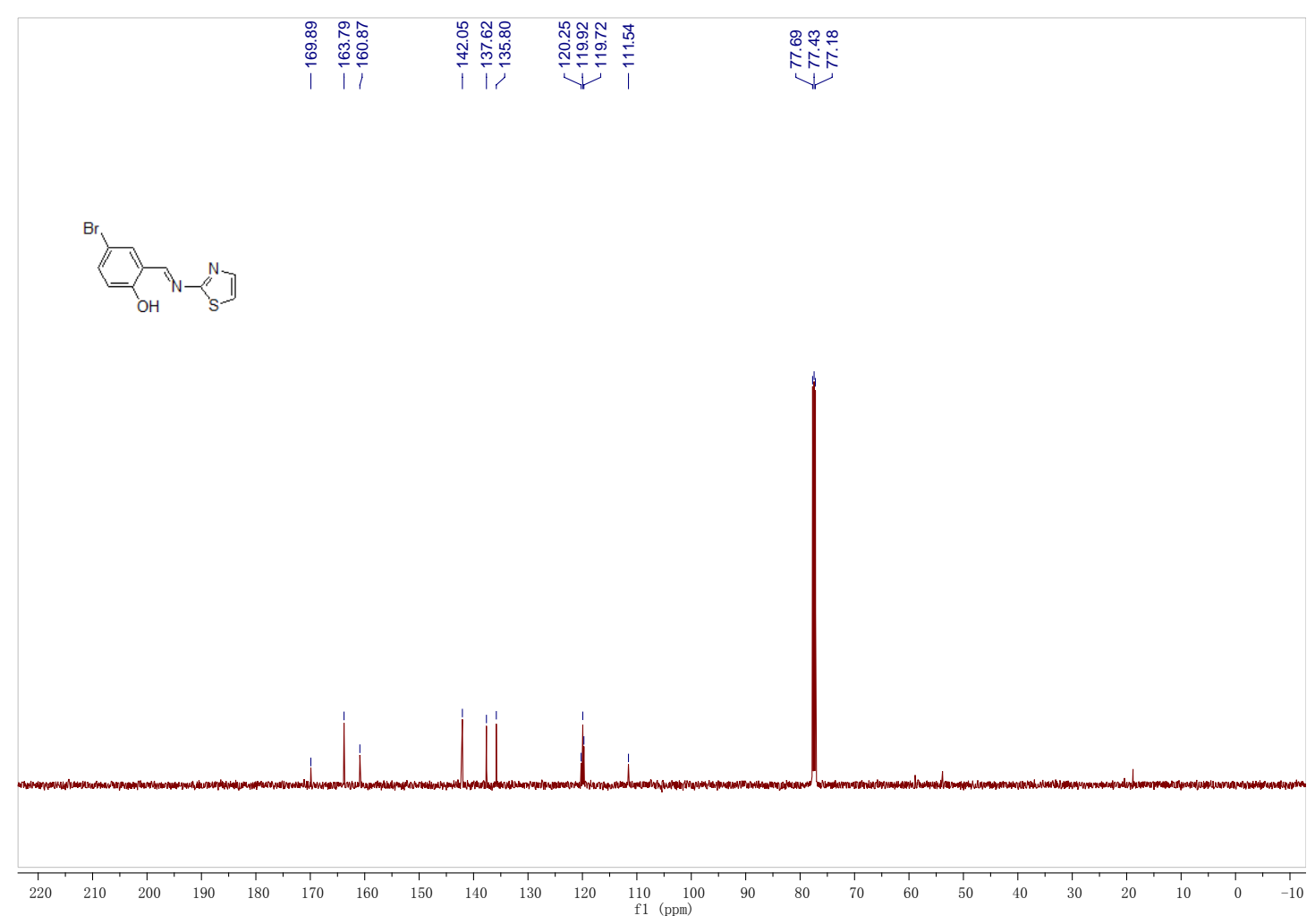

Figure S11. The ${ }^{13} \mathrm{C}$ NMR of Schiff-base $\mathbf{1 g}$

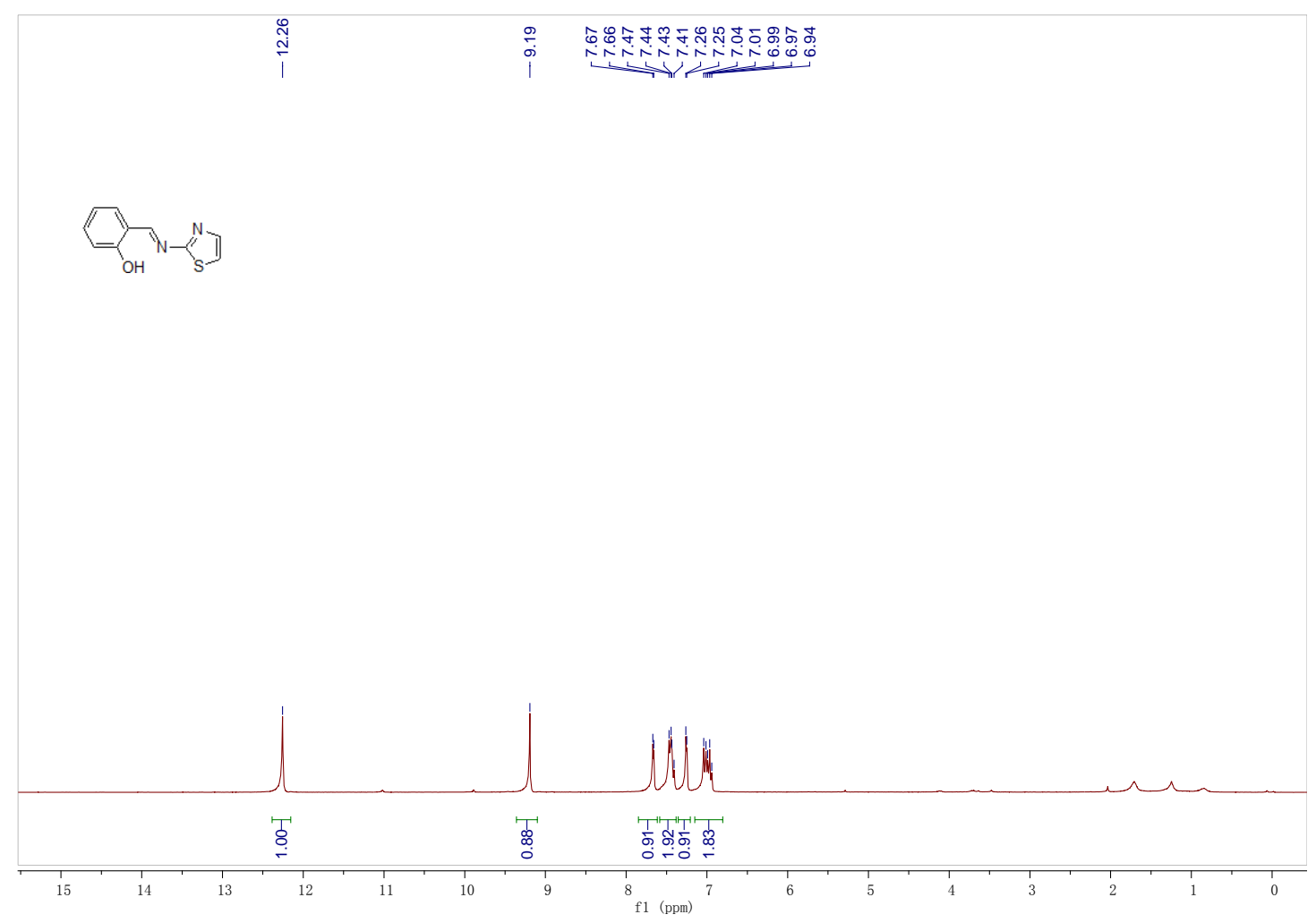

Figure S12. The ${ }^{1} \mathrm{H}$ NMR of Schiff-base $\mathbf{1 h}$ 


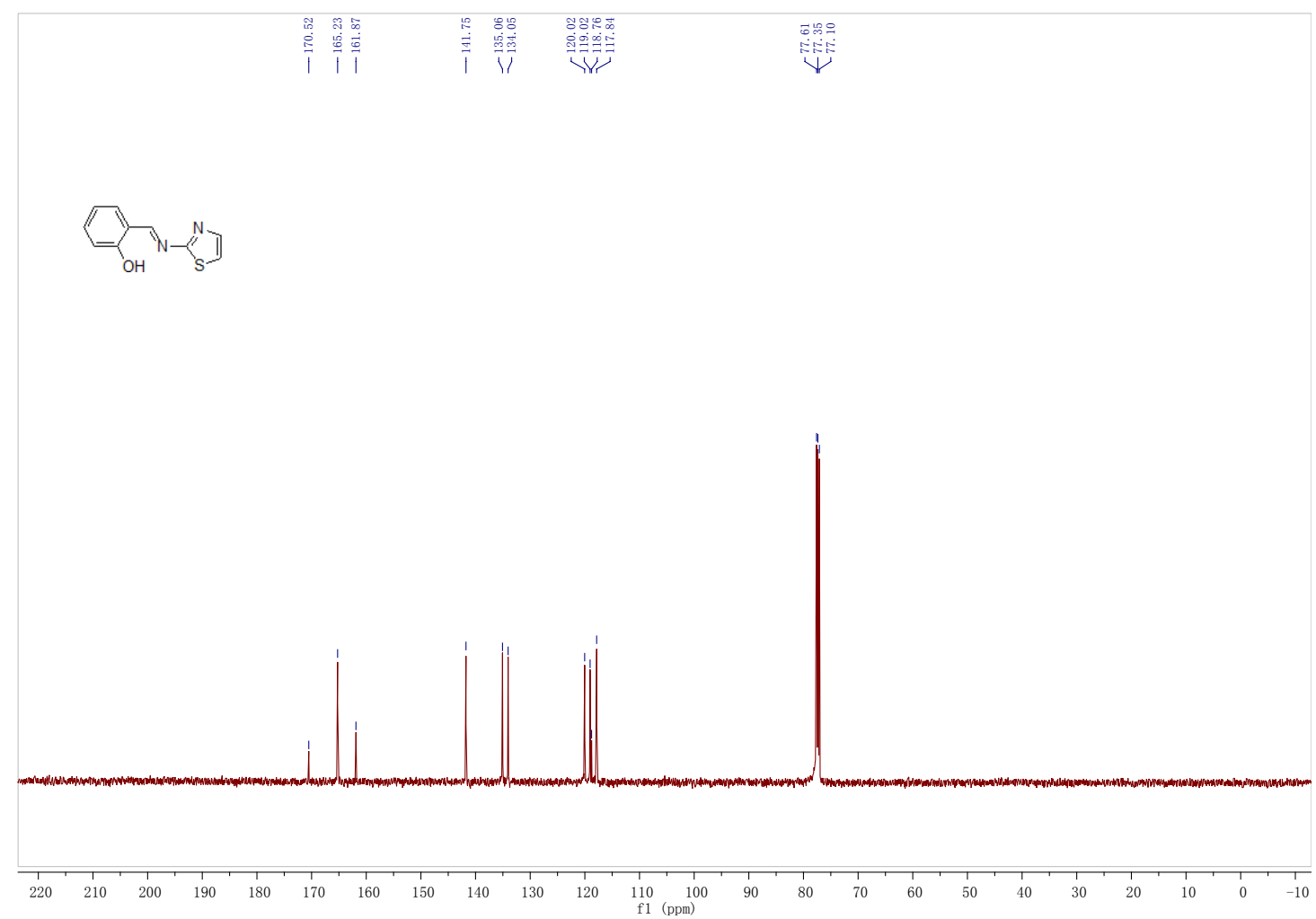

Figure S13. The ${ }^{13} \mathrm{C}$ NMR of Schiff-base $\mathbf{1 h}$
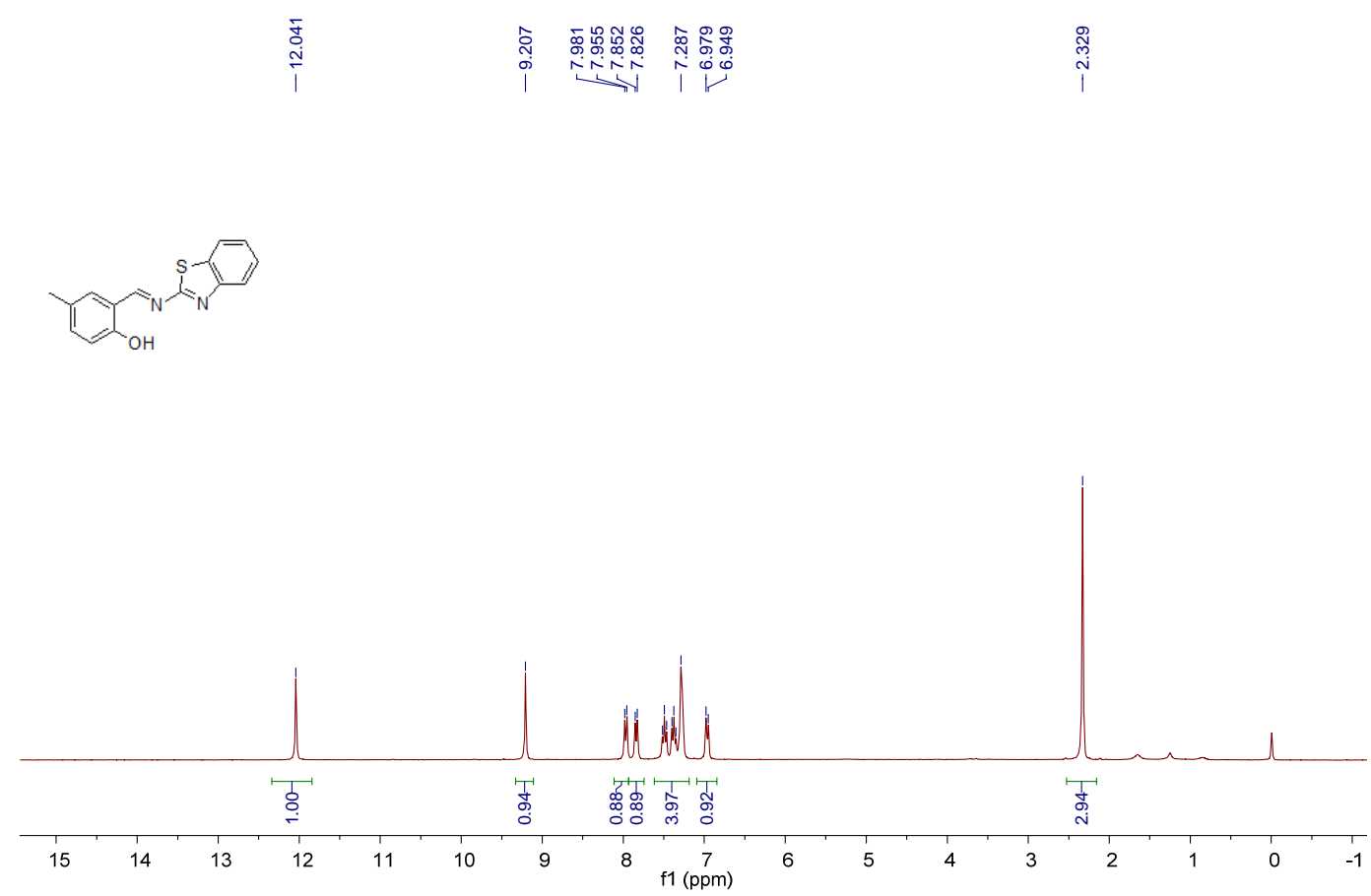

Figure S14. The ${ }^{1} \mathrm{H}$ NMR of Schiff-base 1i 


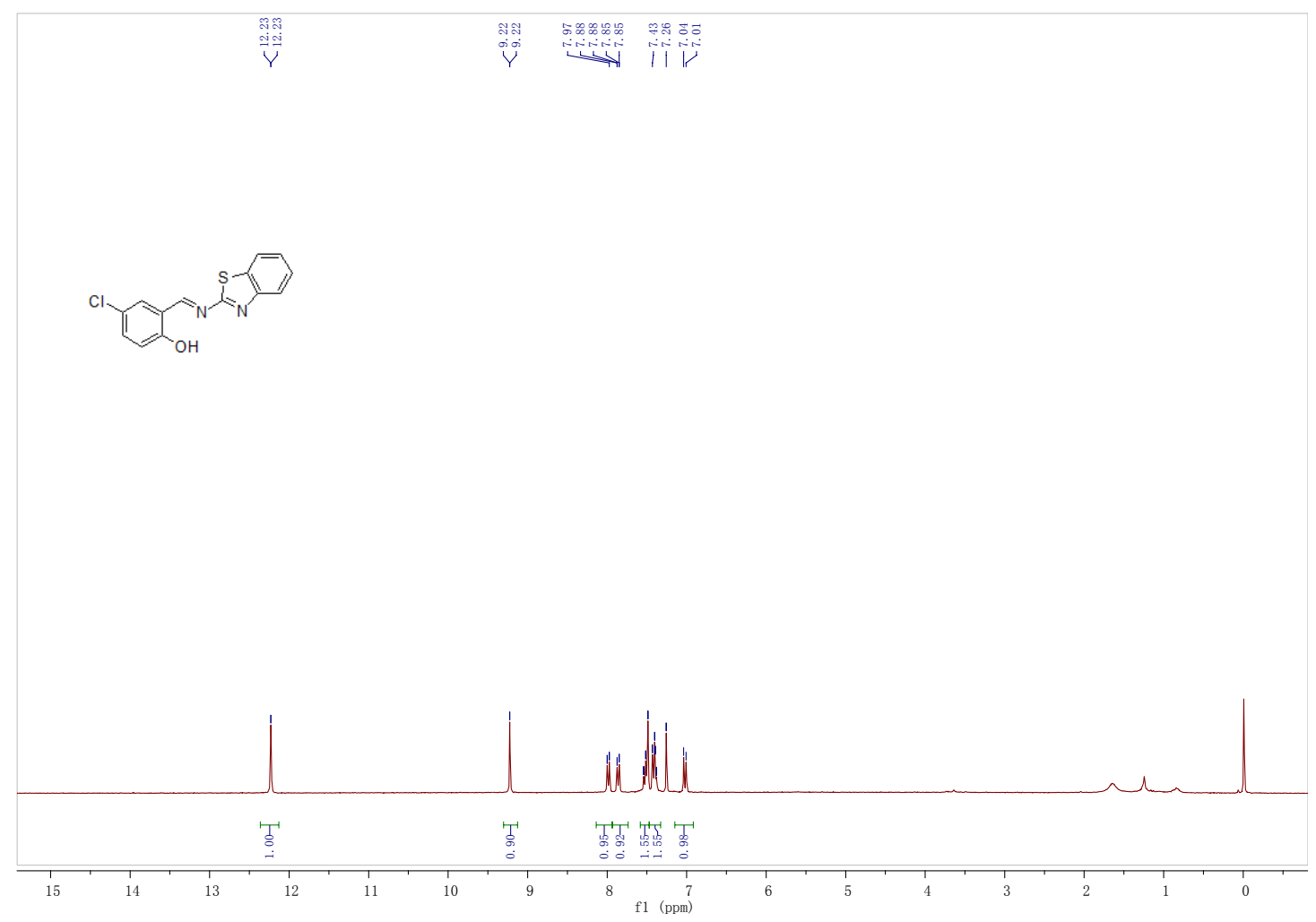

Figure S15. The ${ }^{1} \mathrm{H}$ NMR of Schiff-base $\mathbf{1 j}$

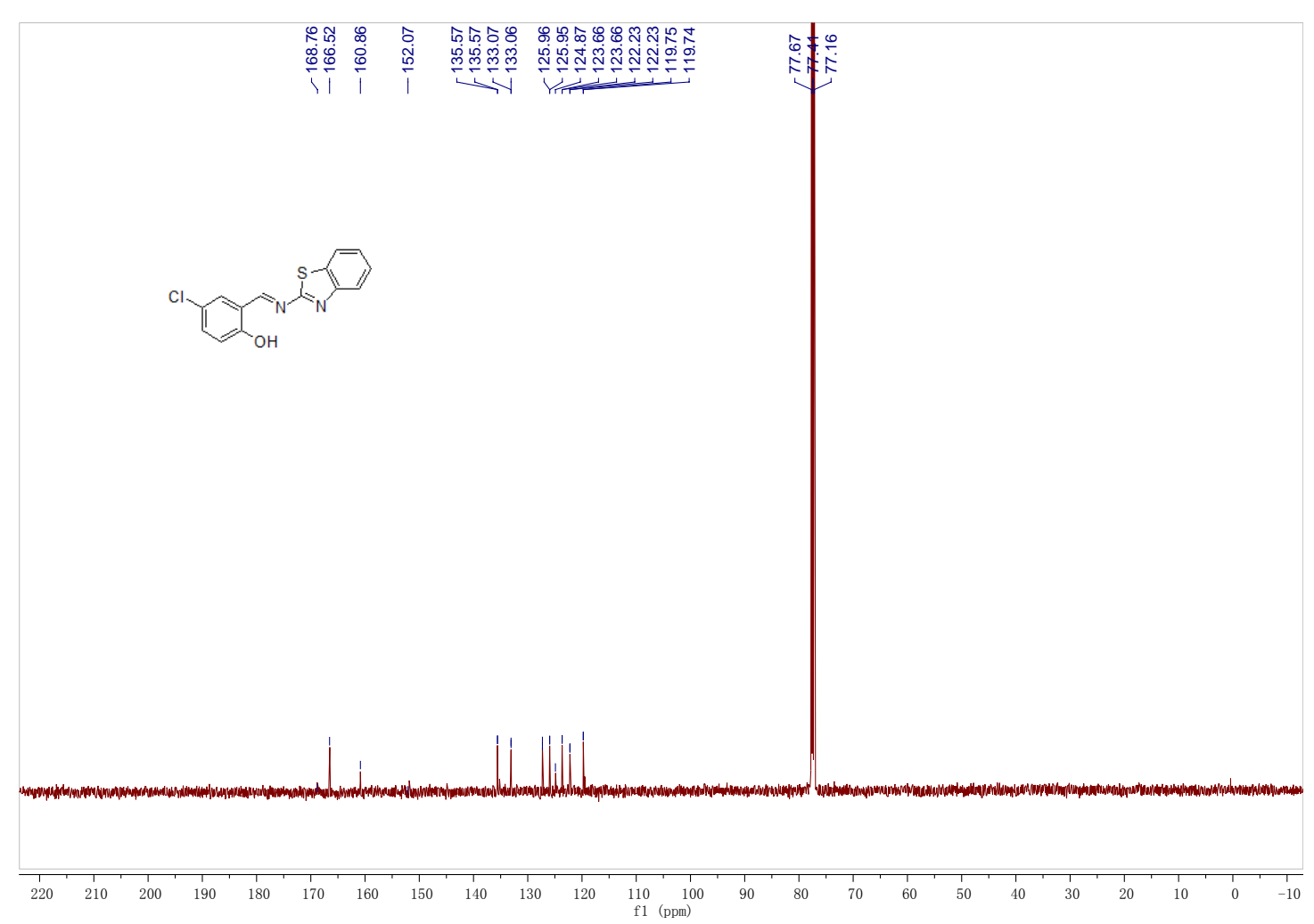

Figure S16. The ${ }^{13} \mathrm{C}$ NMR of Schiff-base $\mathbf{1 j}$ 


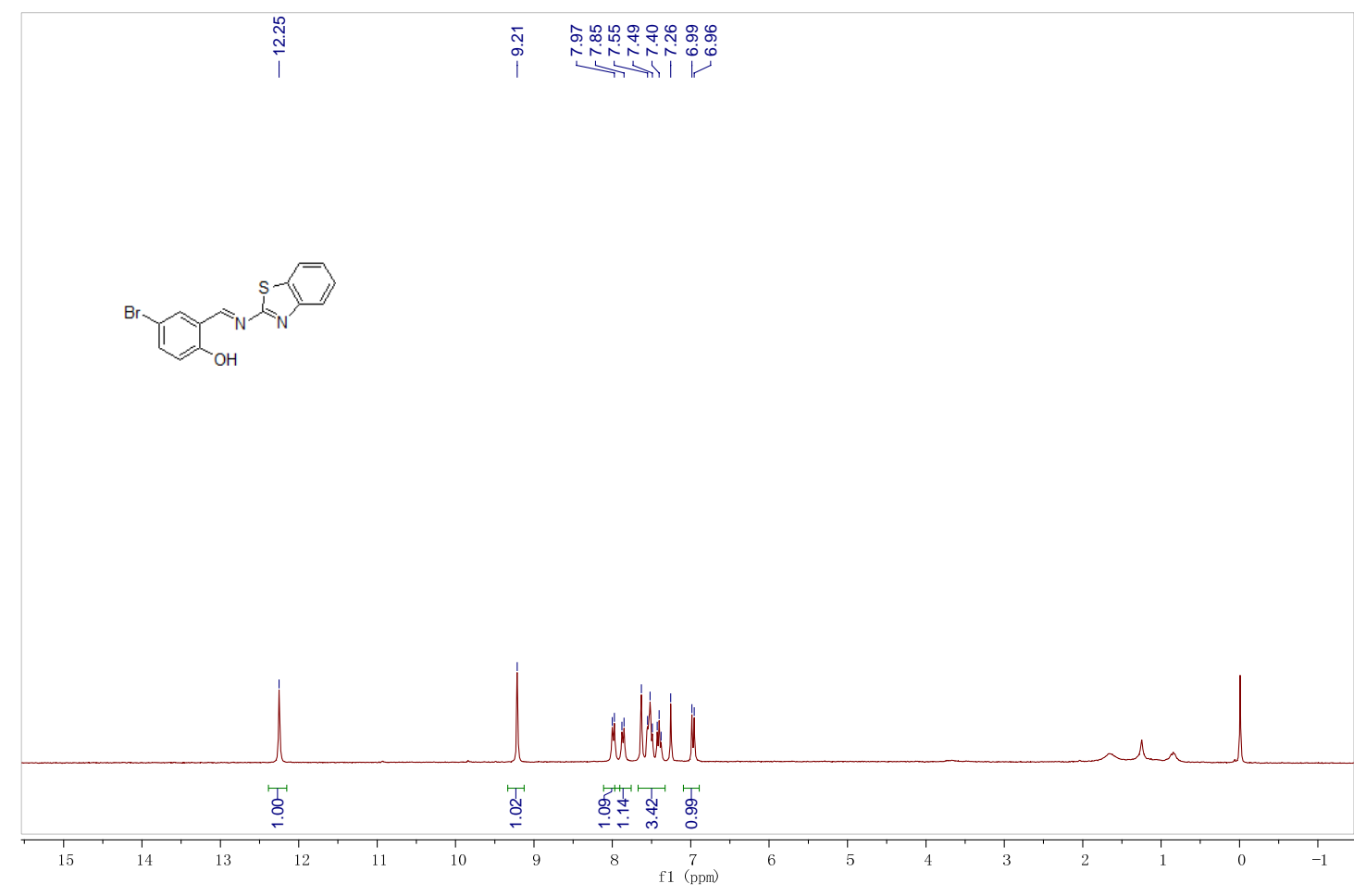

Figure S17. The ${ }^{1} \mathrm{H}$ NMR of Schiff-base $\mathbf{1 k}$

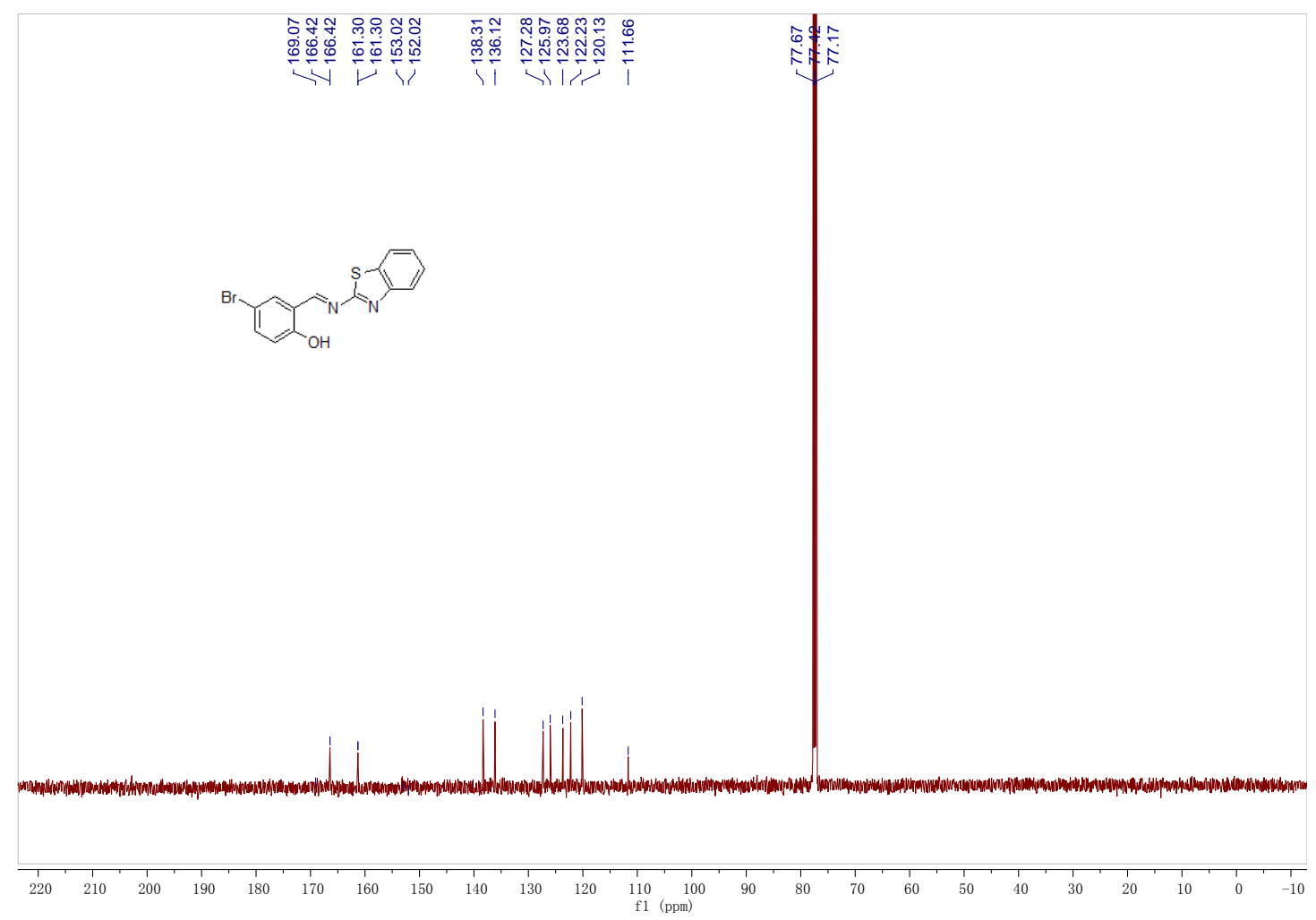

Figure S18. The ${ }^{13} \mathrm{C}$ NMR of Schiff-base $\mathbf{1 k}$ 

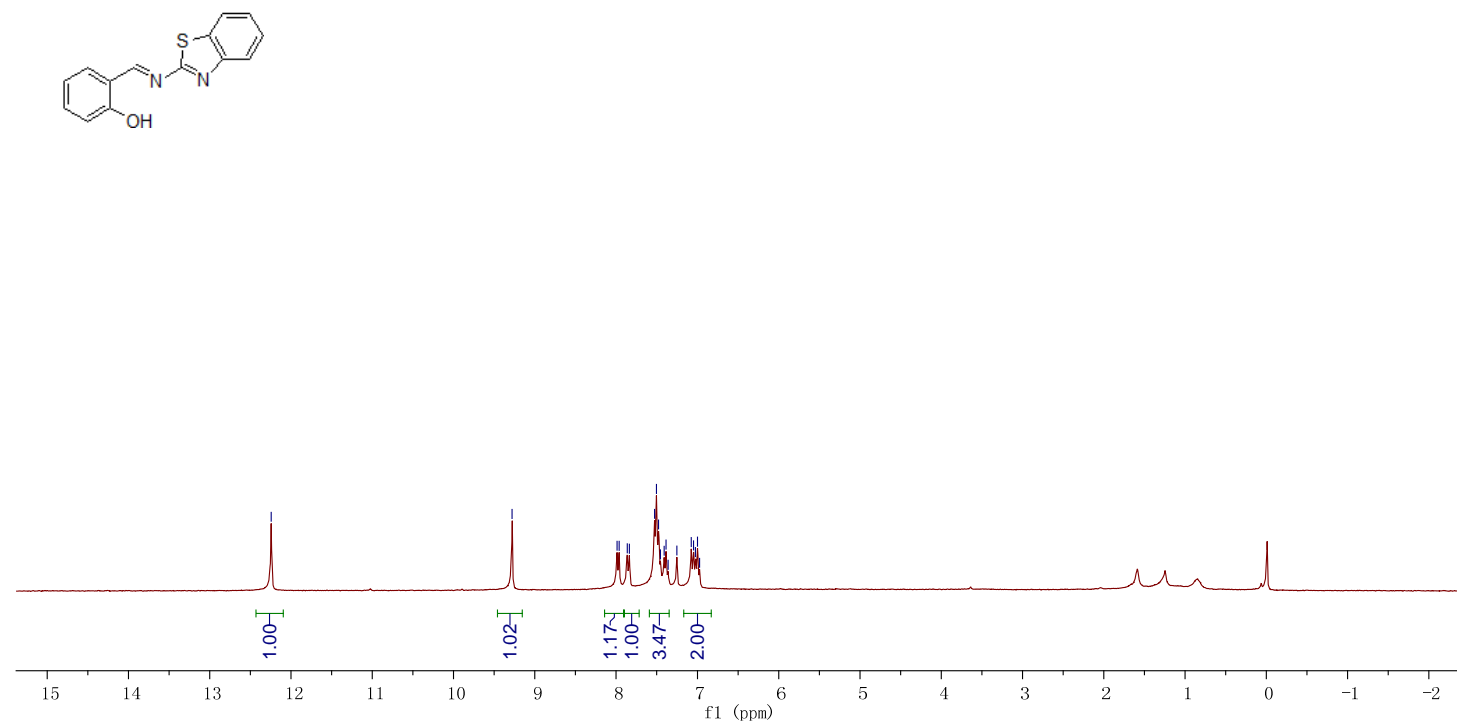

Figure S19. The ${ }^{1} \mathrm{H}$ NMR of Schiff-base 11

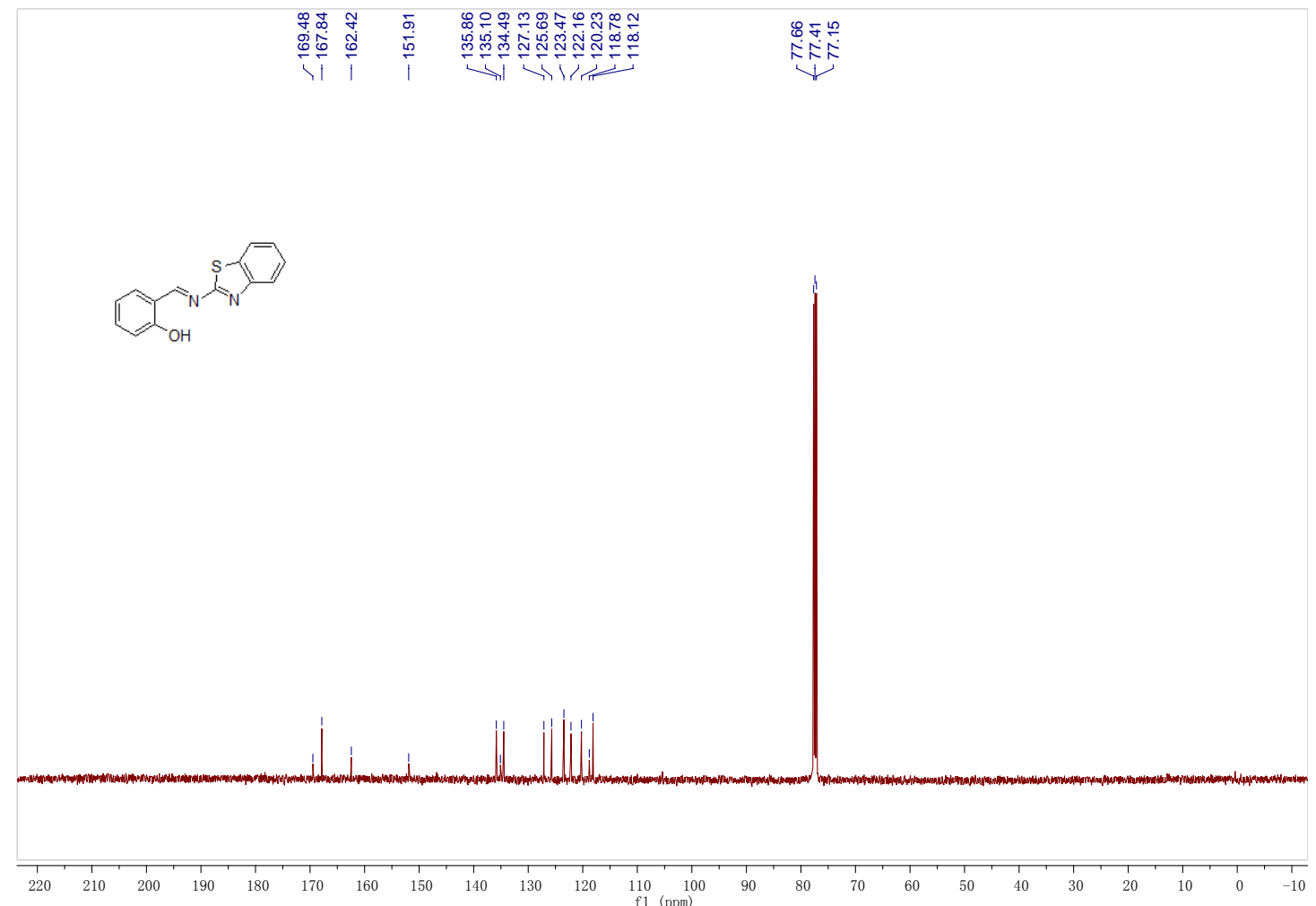

Figure S20. The ${ }^{13} \mathrm{C}$ NMR of Schiff-base $\mathbf{1 l}$ 


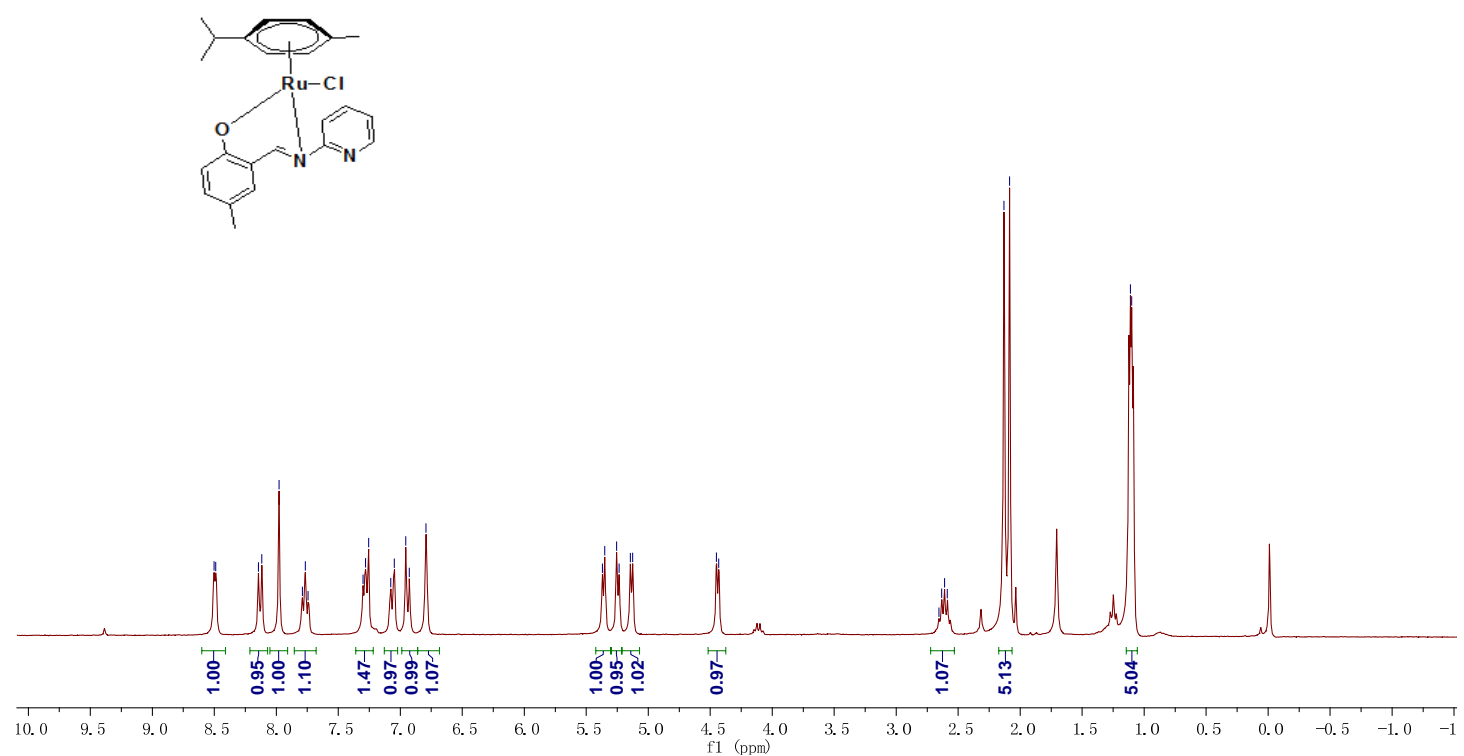

Figure S21. The ${ }^{1} \mathrm{H}$ NMR of half-sandwich ruthenium complex 2a

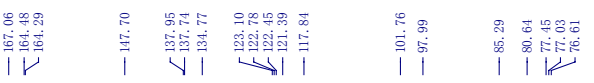
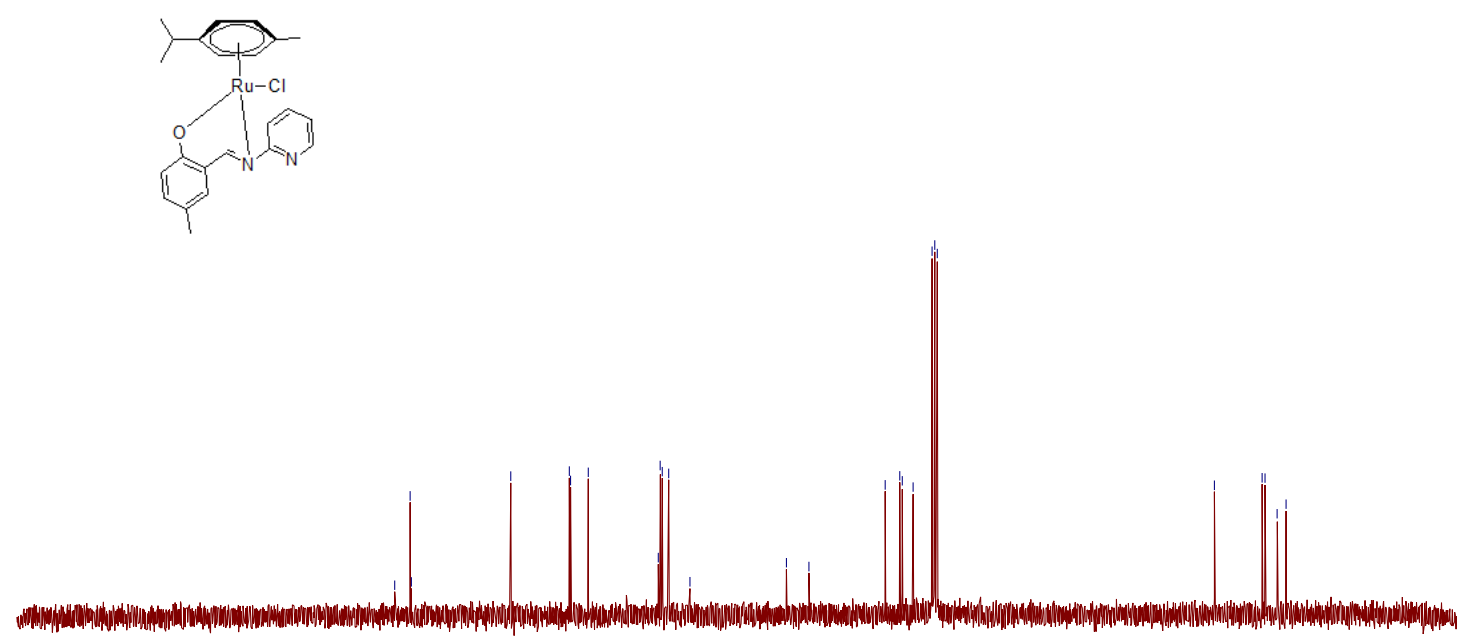

$\begin{array}{lll}30 & 220 & 210\end{array}$

Figure S22. The ${ }^{13} \mathrm{C}$ NMR of half-sandwich ruthenium complex 2a 

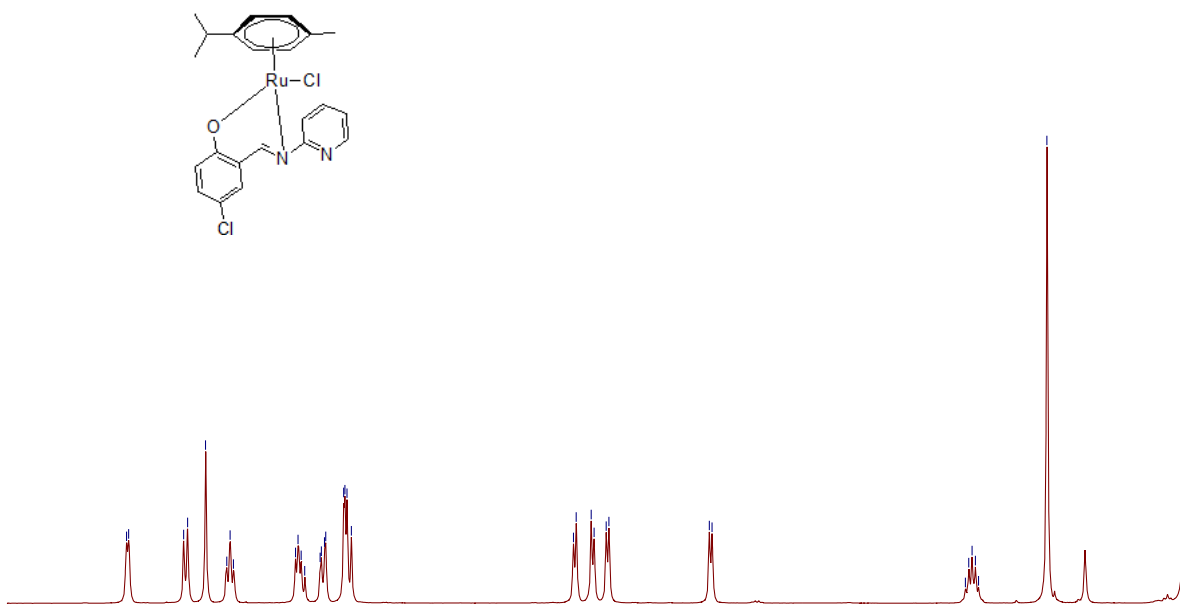

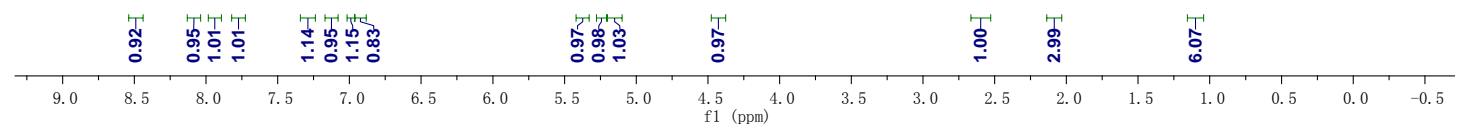

Figure S23. The ${ }^{1} \mathrm{H}$ NMR of half-sandwich ruthenium complex $\mathbf{2 b}$
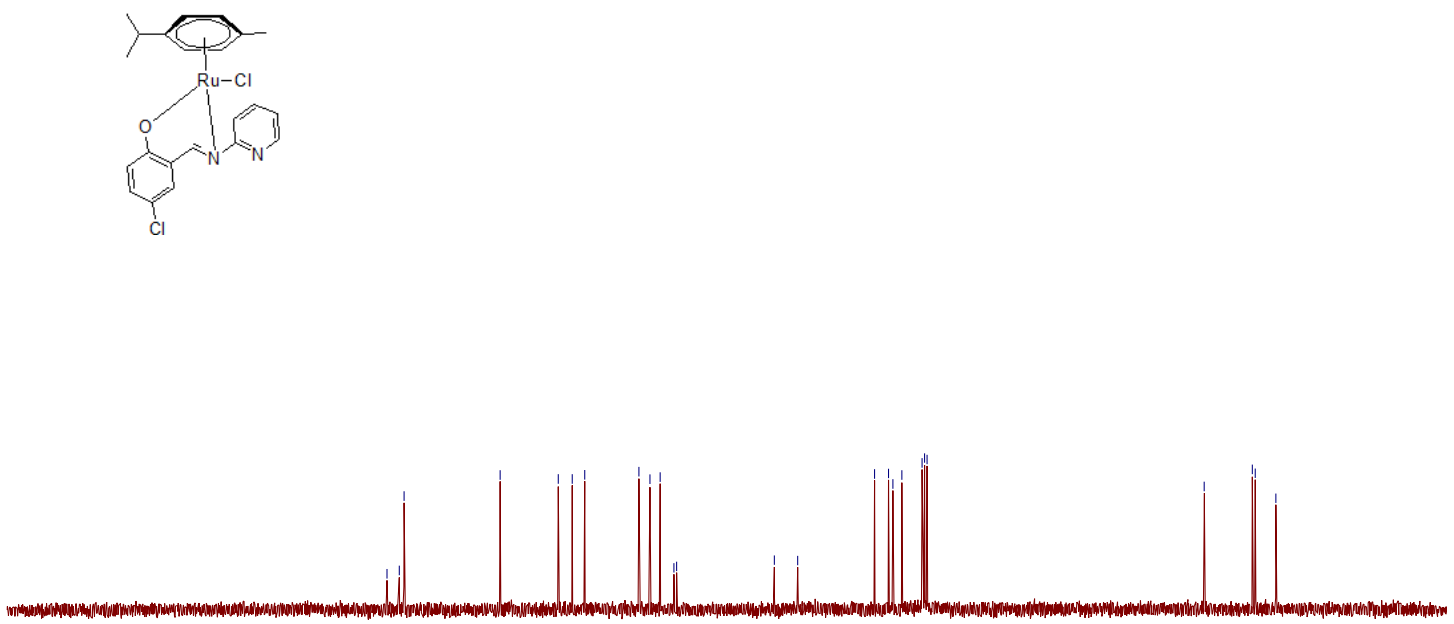

Figure S24. The ${ }^{13} \mathrm{C}$ NMR of half-sandwich ruthenium complex $\mathbf{2 b}$ 

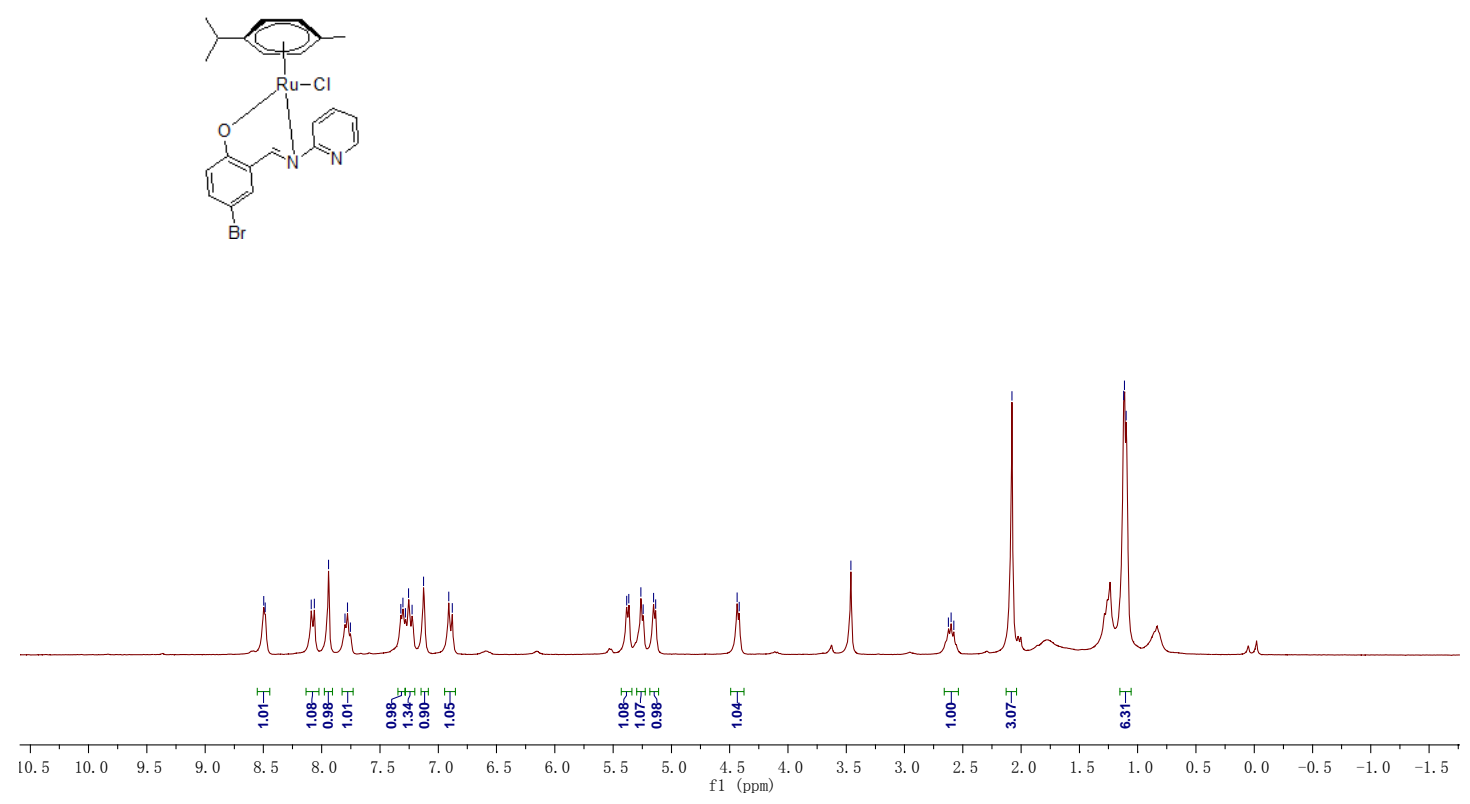

Figure S25. The ${ }^{1} \mathrm{H}$ NMR of half-sandwich ruthenium complex 2c

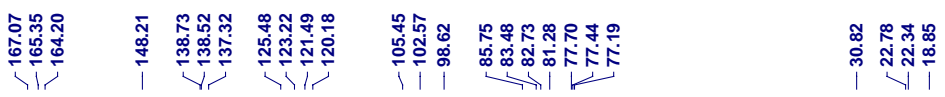
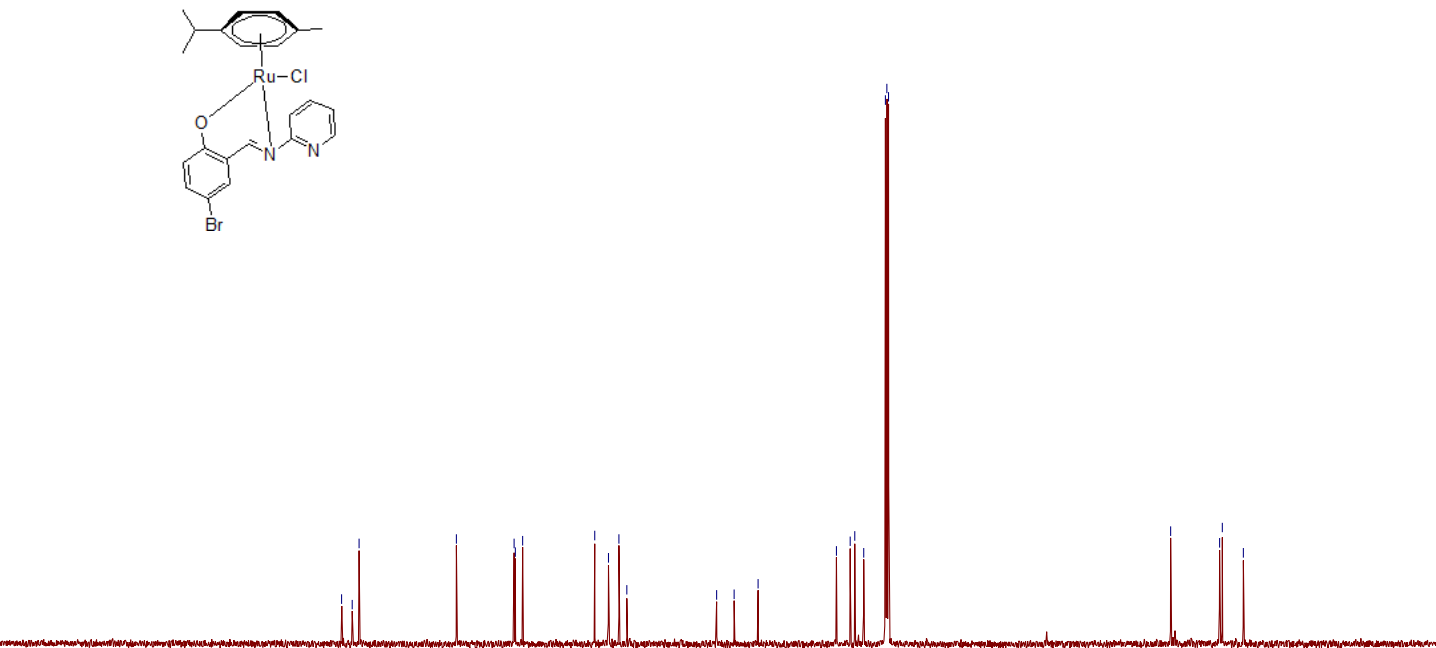

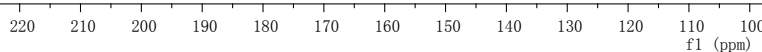

Figure S26. The ${ }^{13} \mathrm{C}$ NMR of half-sandwich ruthenium complex 2c 

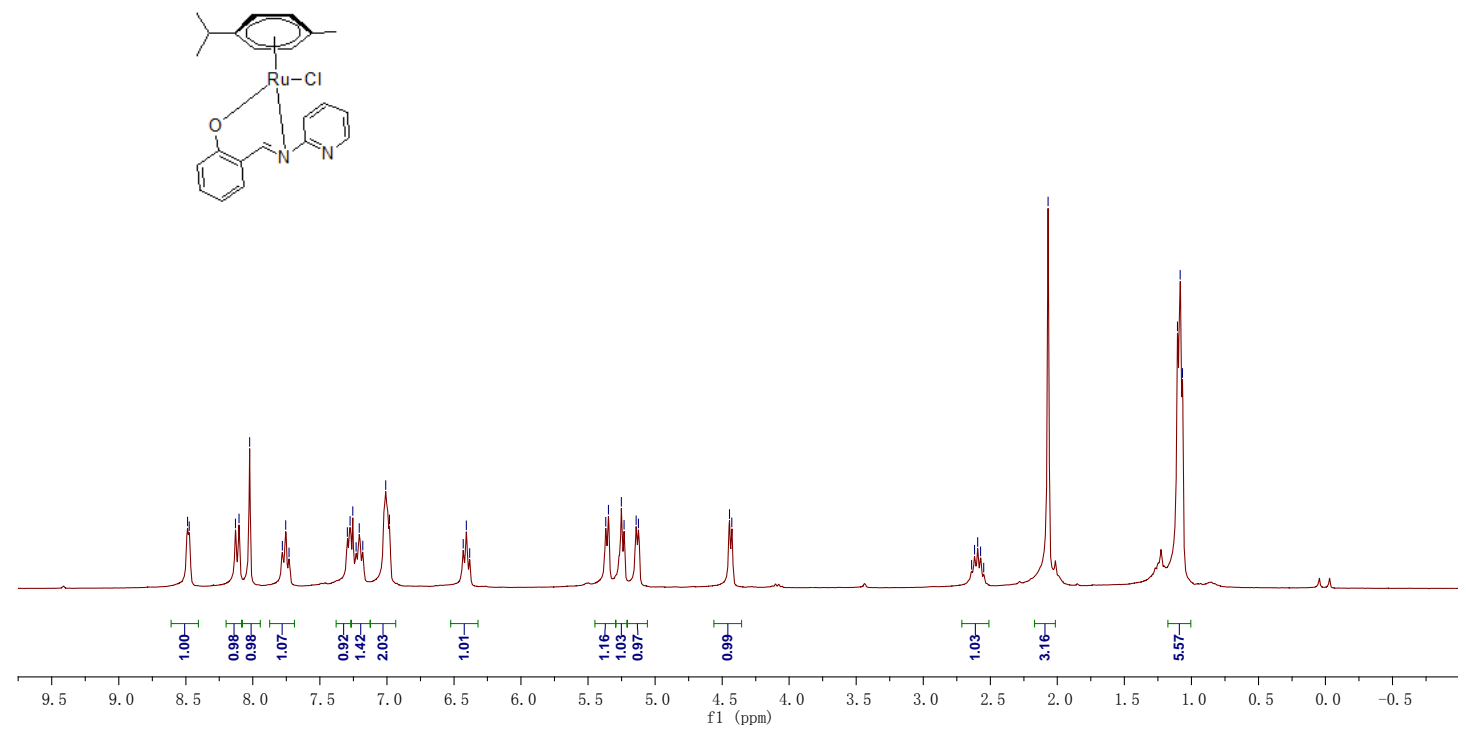

Figure S27. The ${ }^{1} \mathrm{H}$ NMR of half-sandwich ruthenium complex $2 \mathbf{d}$

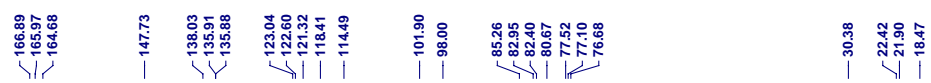
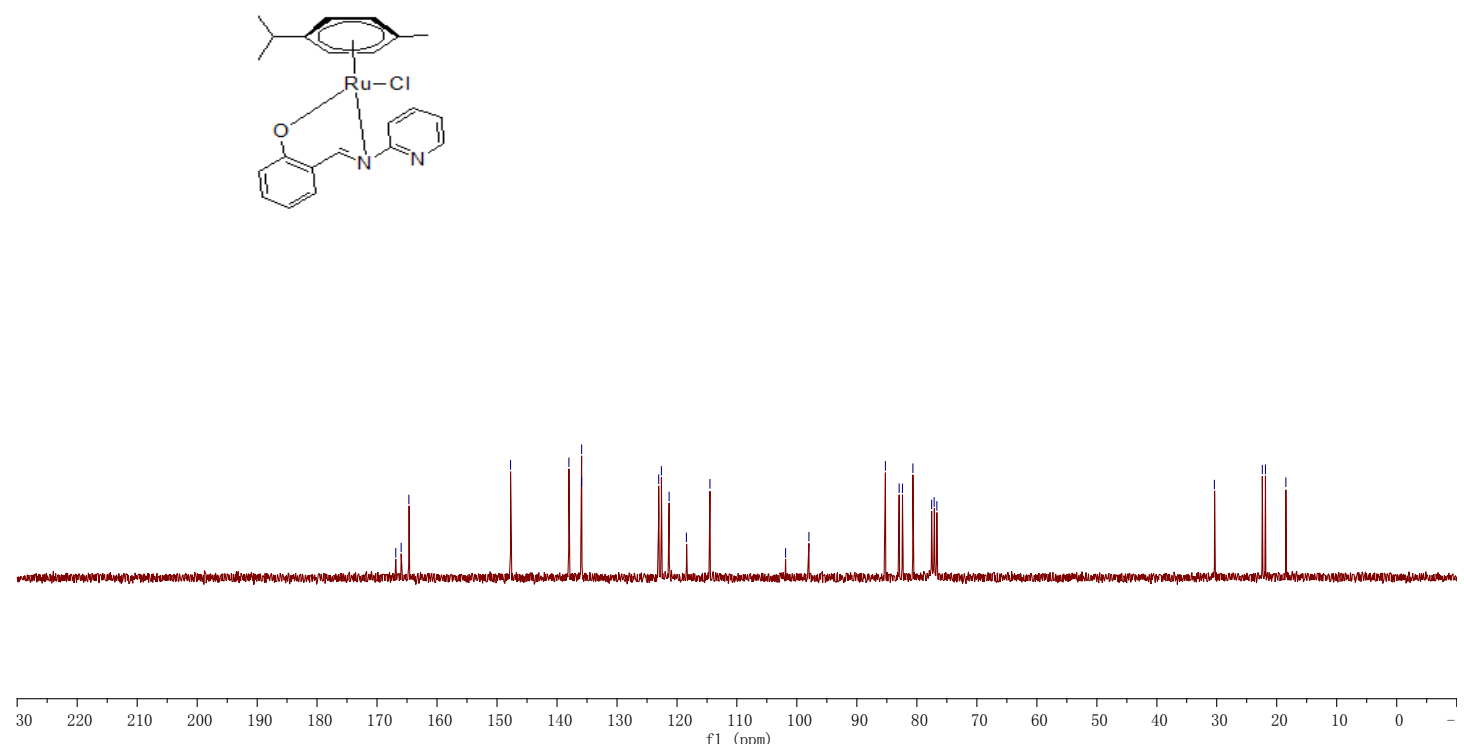

Figure S28. The ${ }^{13} \mathrm{C}$ NMR of half-sandwich ruthenium complex 2 d 


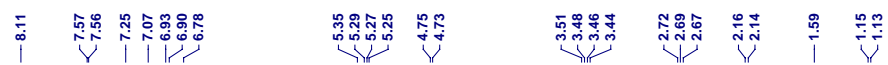
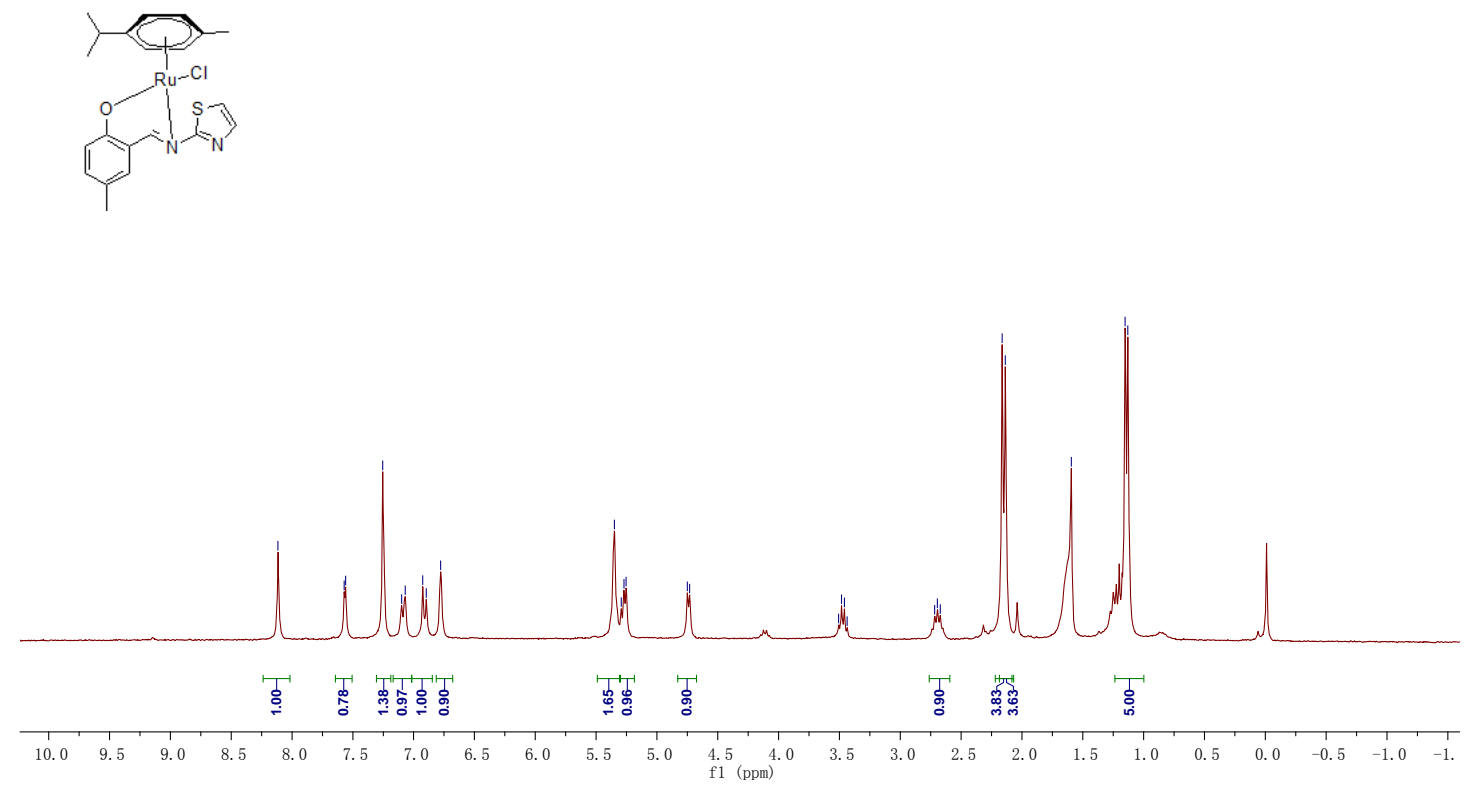

Figure S29. The ${ }^{1} \mathrm{H}$ NMR of half-sandwich ruthenium complex $2 \mathbf{e}$

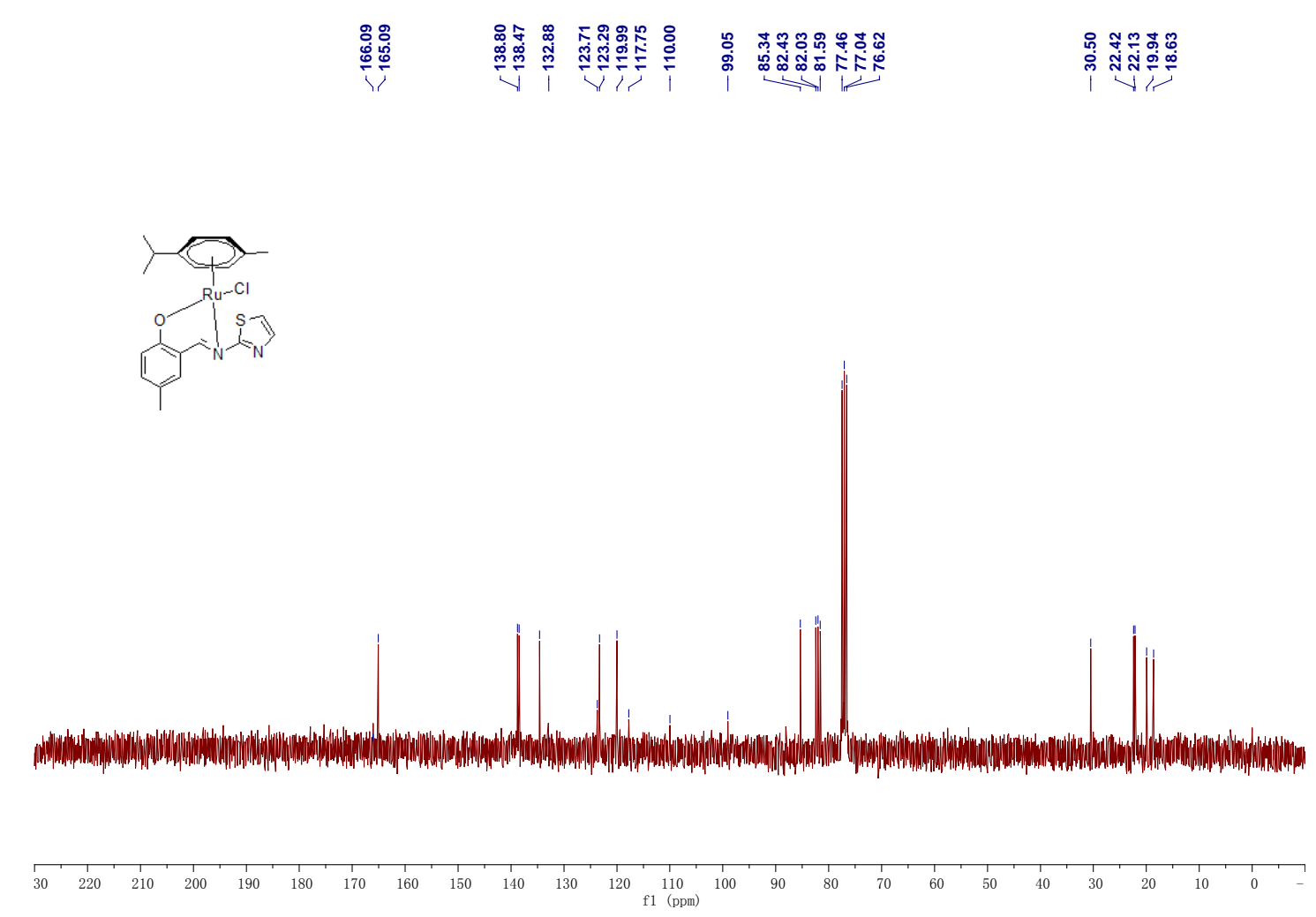

Figure S30. The ${ }^{13} \mathrm{C}$ NMR of half-sandwich ruthenium complex $2 \mathbf{e}$ 


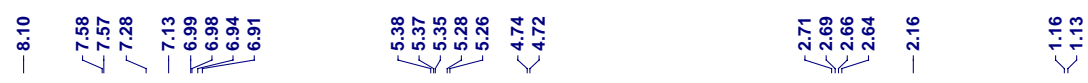
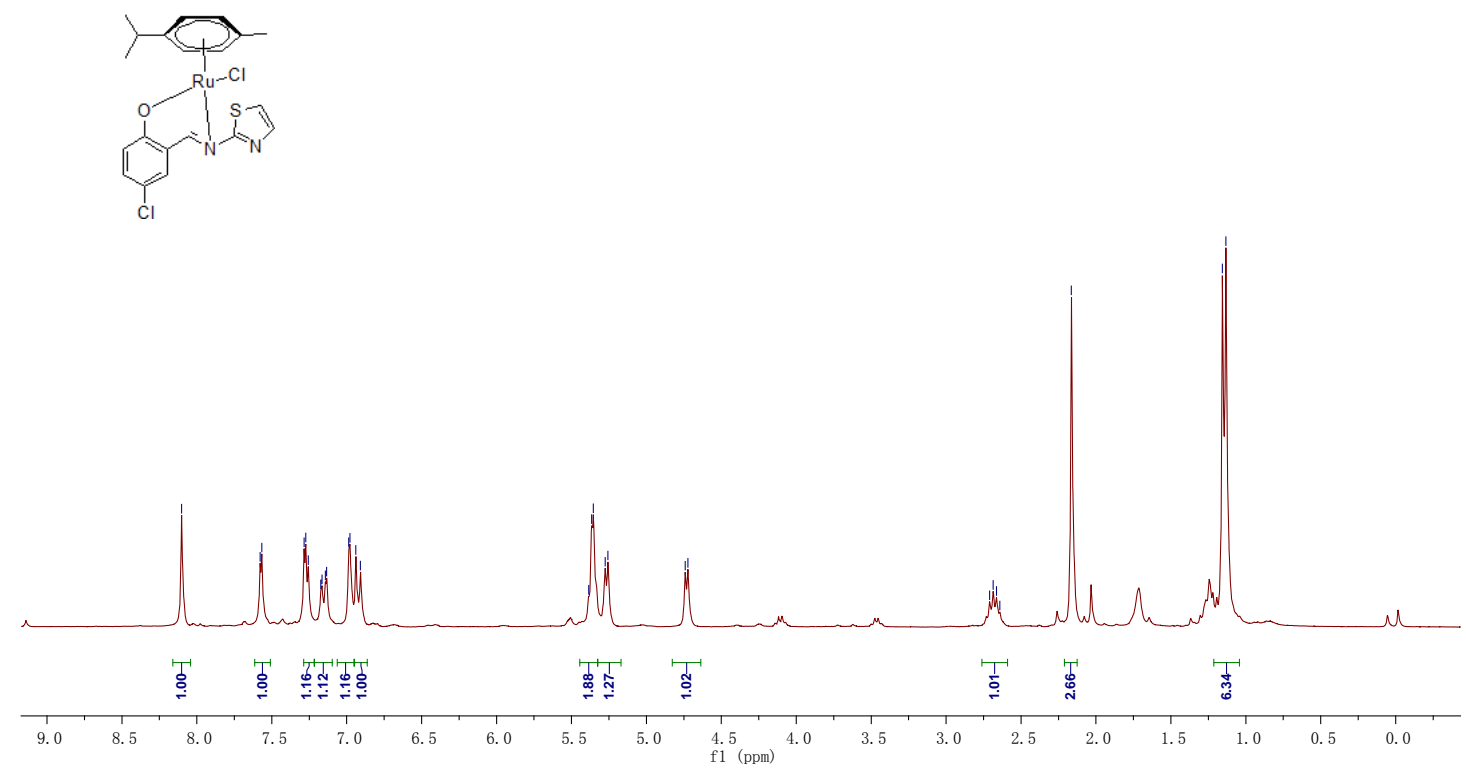

Figure S31. The ${ }^{1} \mathrm{H}$ NMR of half-sandwich ruthenium complex $2 \mathbf{2 f}$

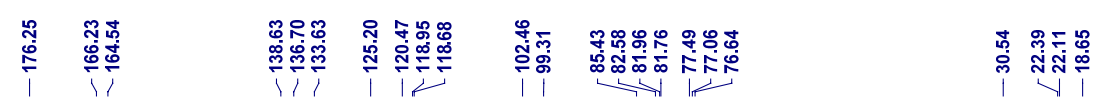
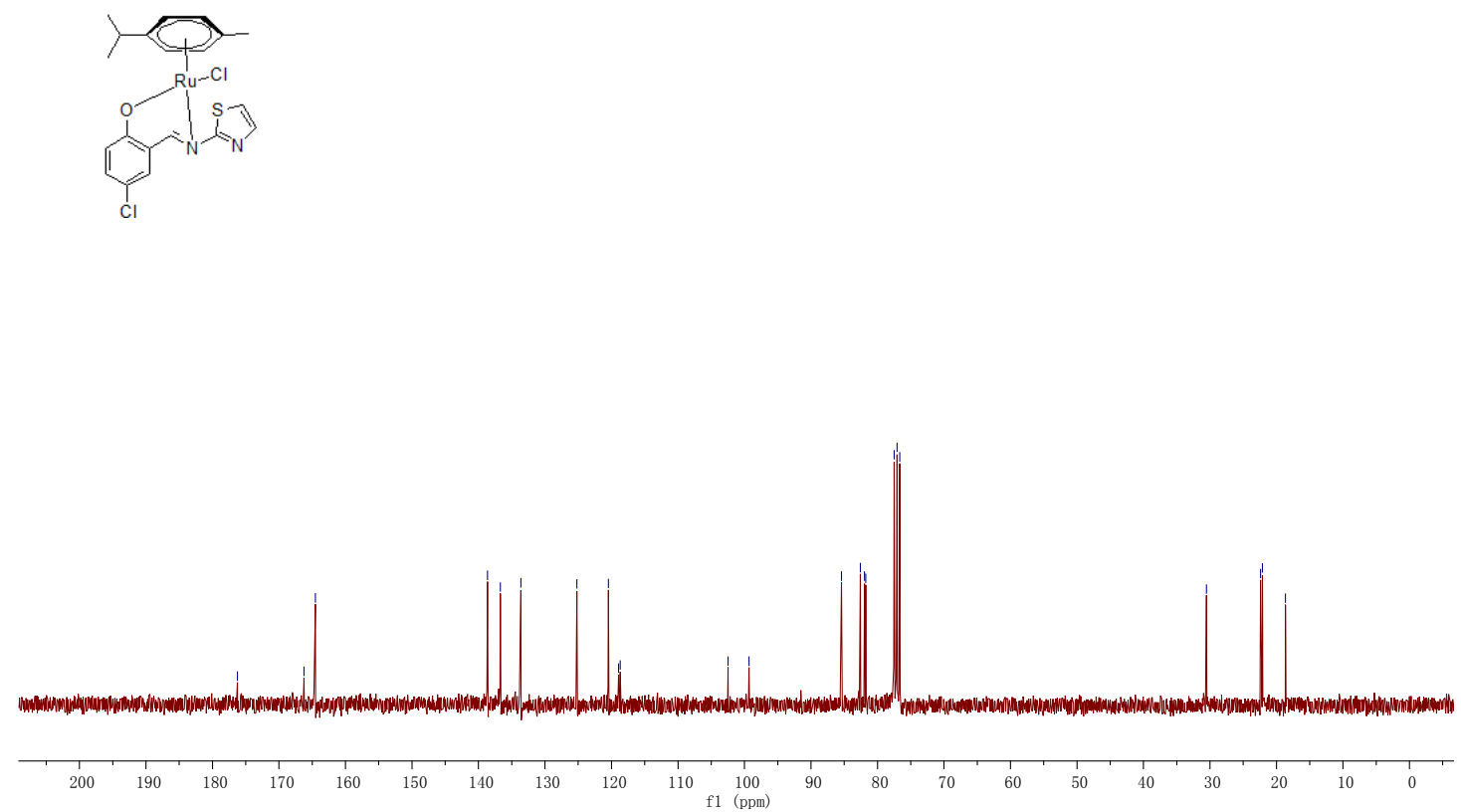

Figure S32. The ${ }^{13} \mathrm{C}$ NMR of half-sandwich ruthenium complex $\mathbf{2 f}$ 

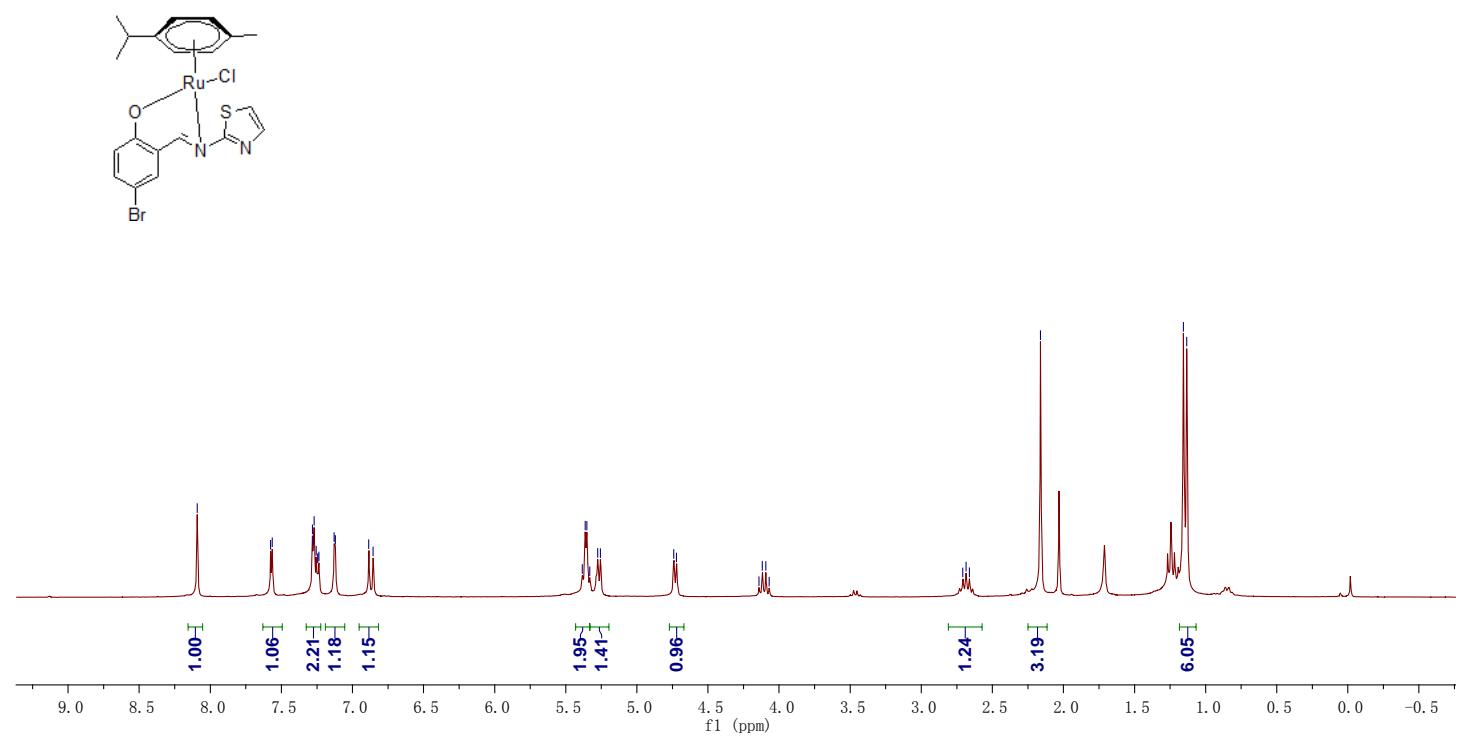

Figure S33. The ${ }^{1} \mathrm{H}$ NMR of half-sandwich ruthenium complex $\mathbf{2 g}$
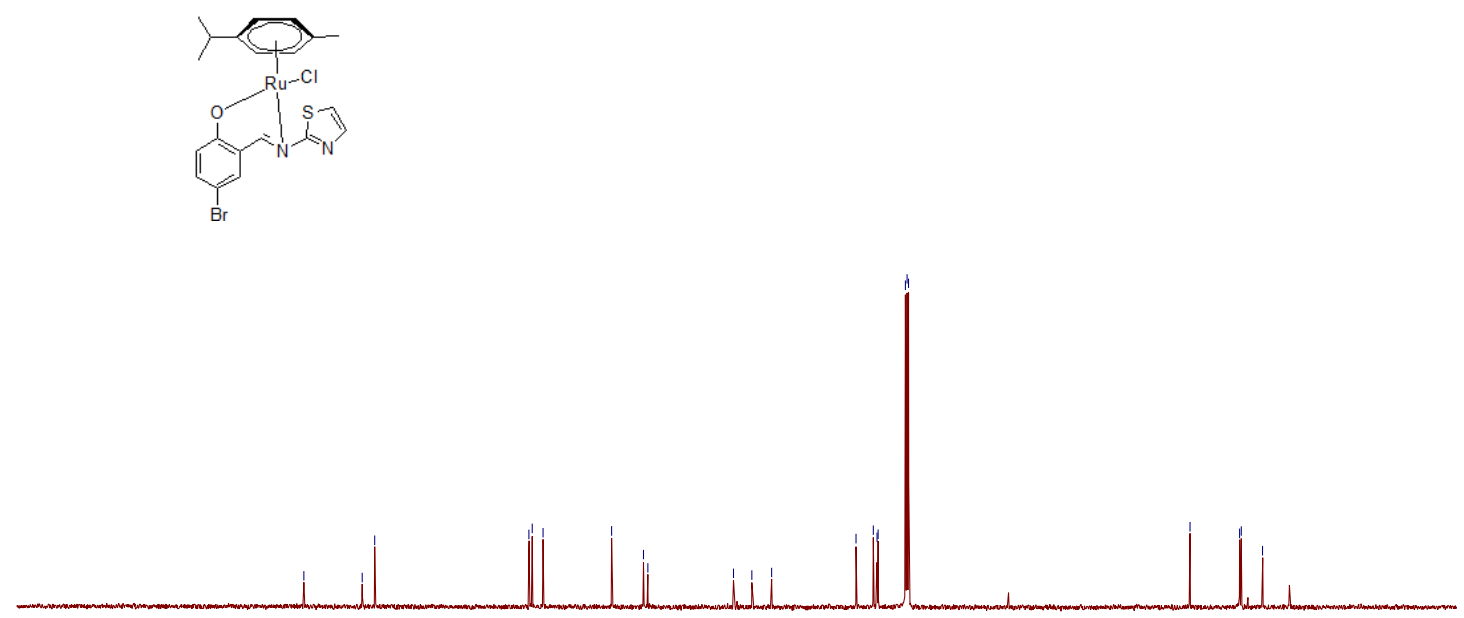

Figure S34. The ${ }^{13} \mathrm{C}$ NMR of half-sandwich ruthenium complex $\mathbf{2 g}$ 


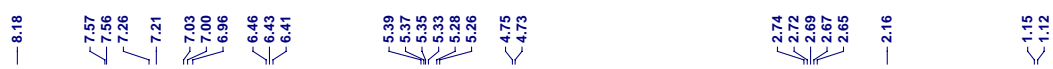
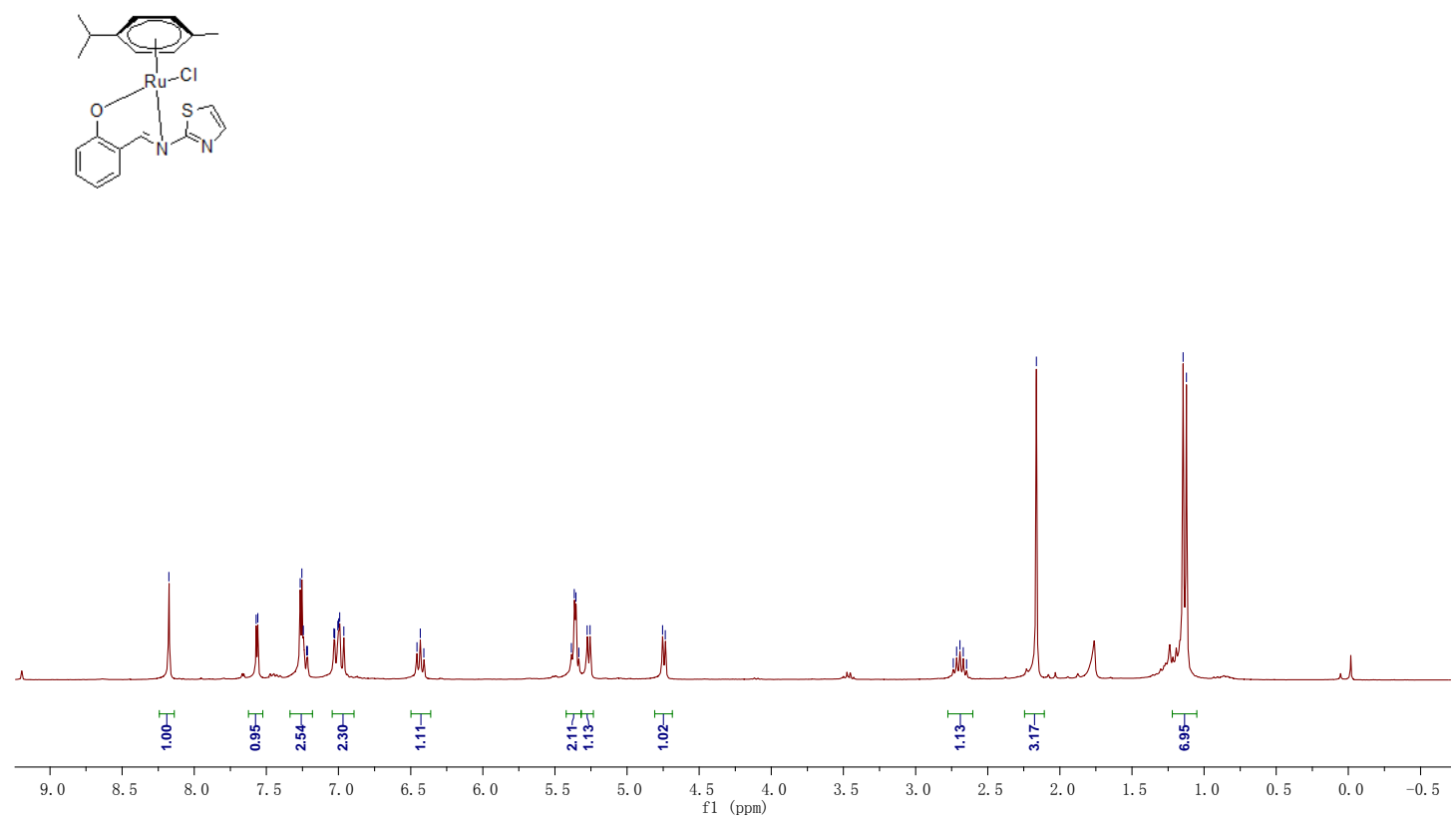

Figure S35. The ${ }^{1} \mathrm{H}$ NMR of half-sandwich ruthenium complex $\mathbf{2 h}$

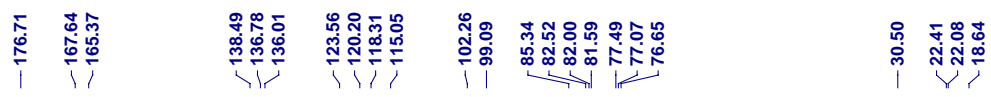
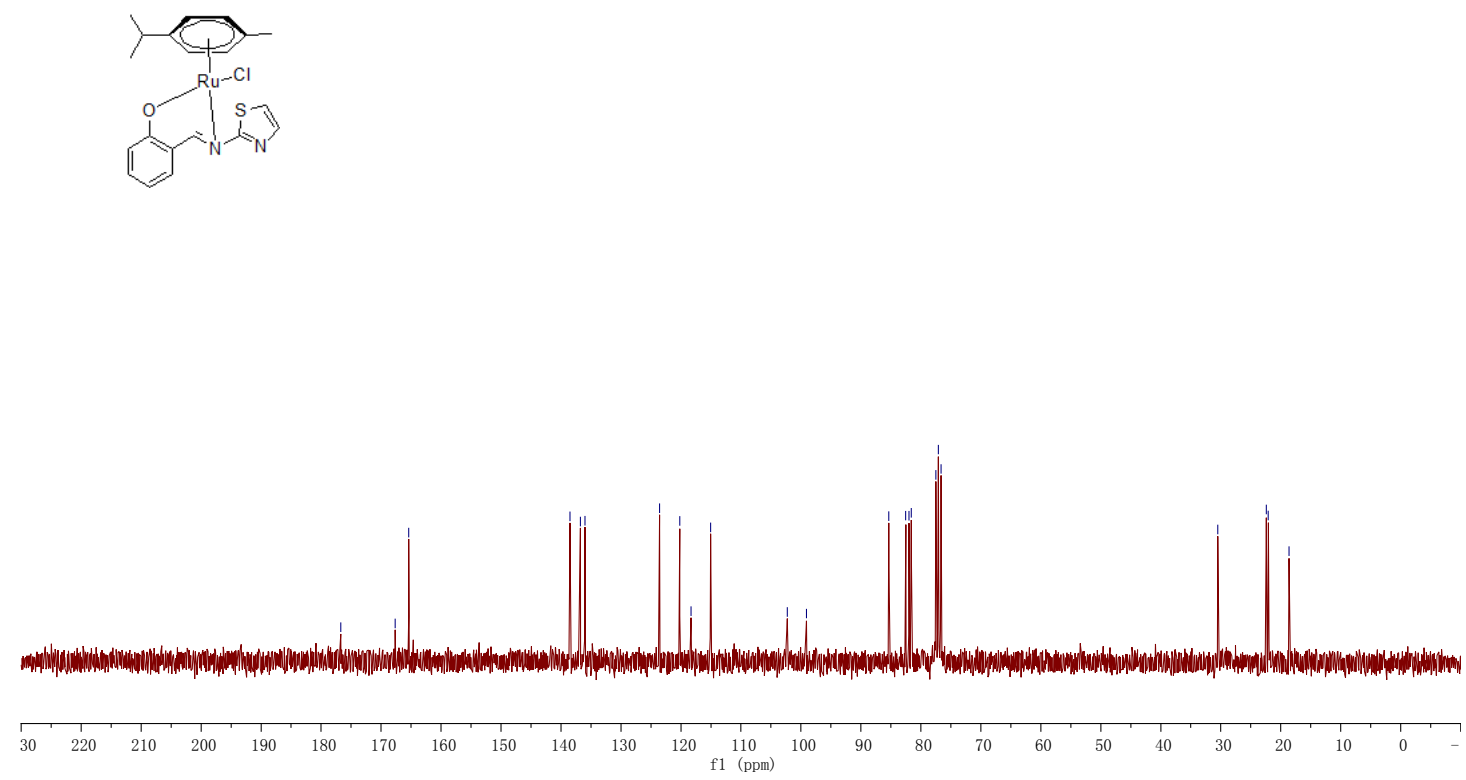

Figure S36. The ${ }^{13} \mathrm{C}$ NMR of half-sandwich ruthenium complex $\mathbf{2 h}$ 


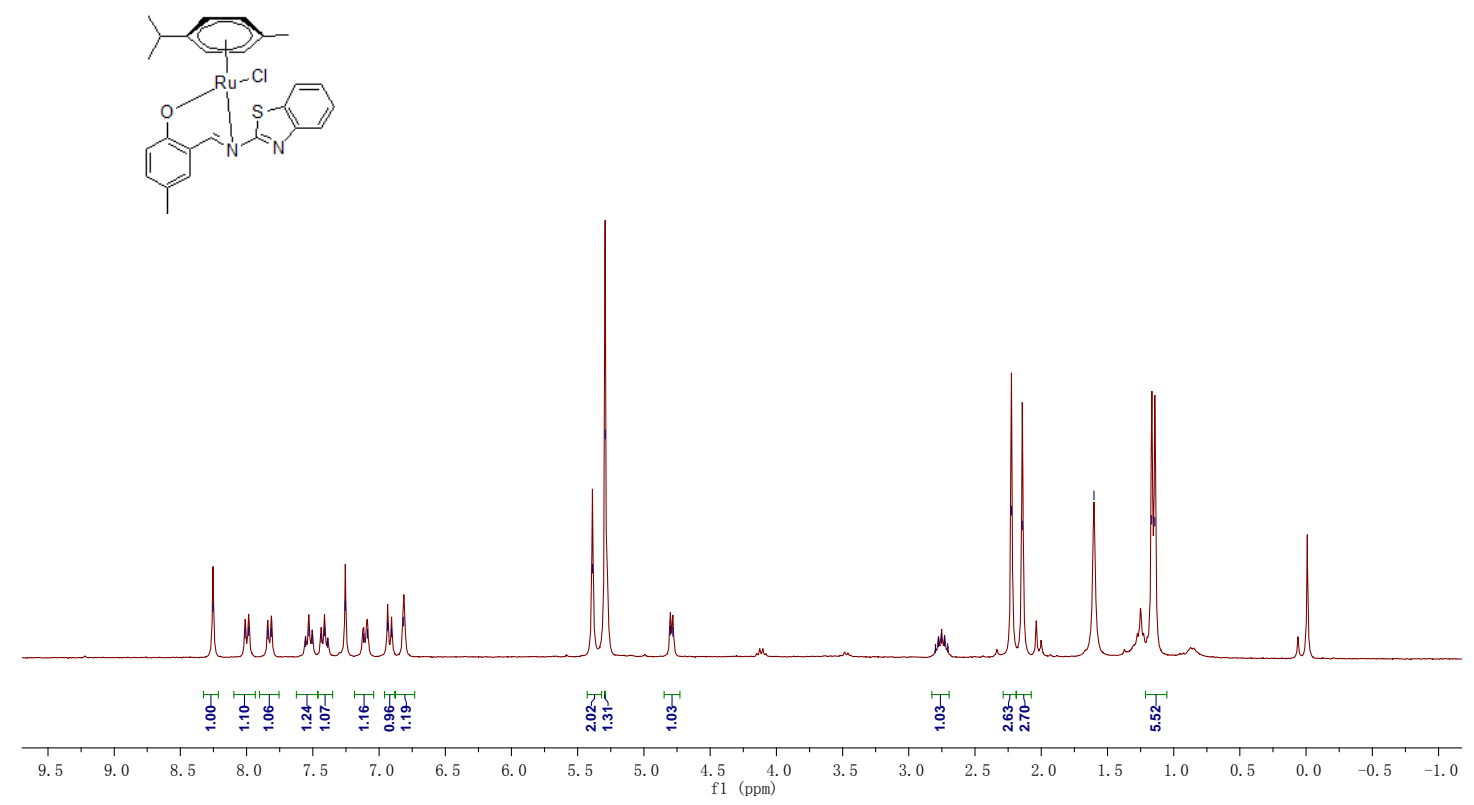

Figure S37. The ${ }^{1} \mathrm{H}$ NMR of half-sandwich ruthenium complex $\mathbf{2 i}$

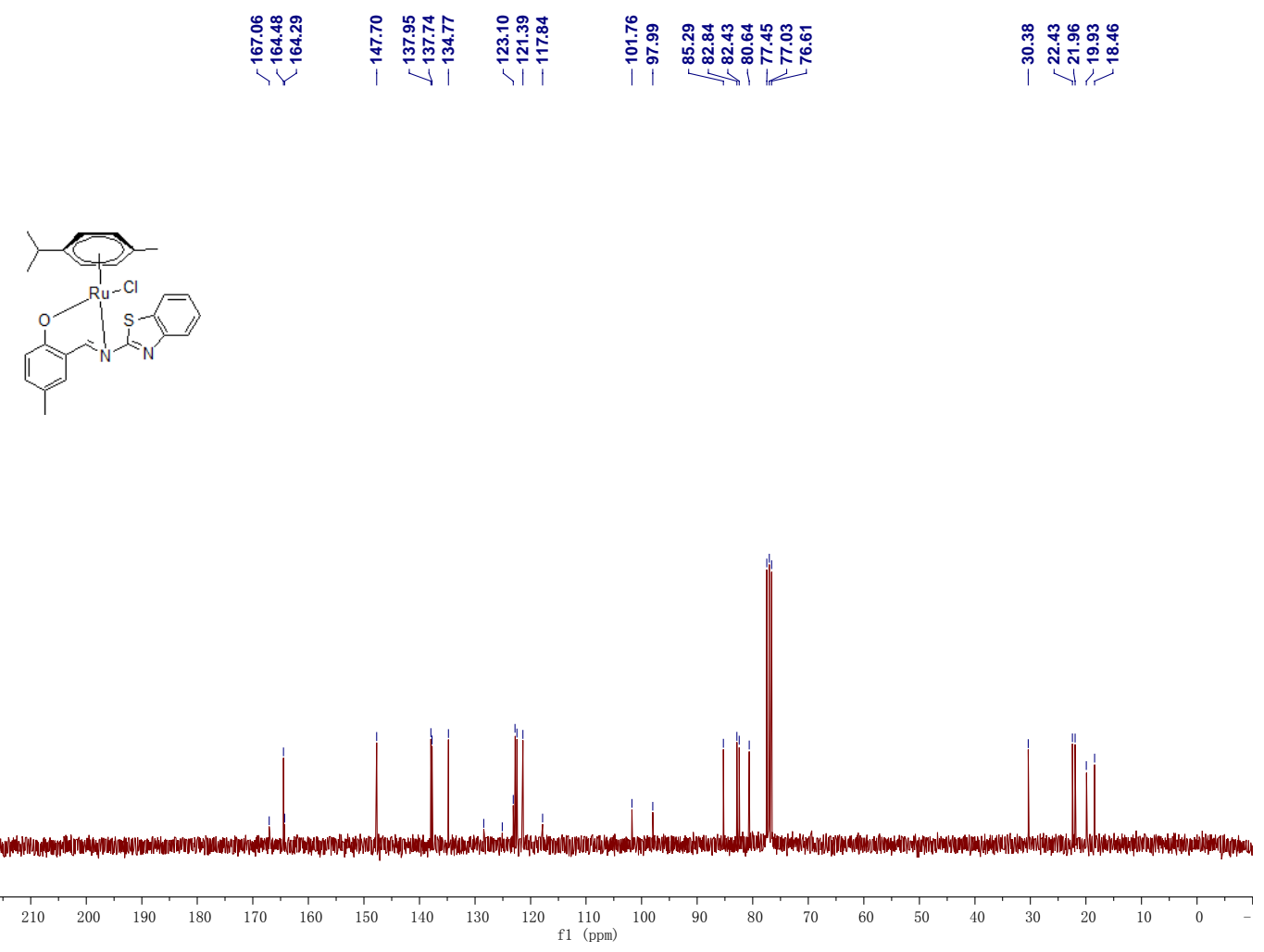

Figure S38. The ${ }^{13} \mathrm{C}$ NMR of half-sandwich ruthenium complex $\mathbf{2 i}$ 


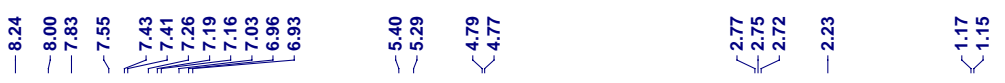
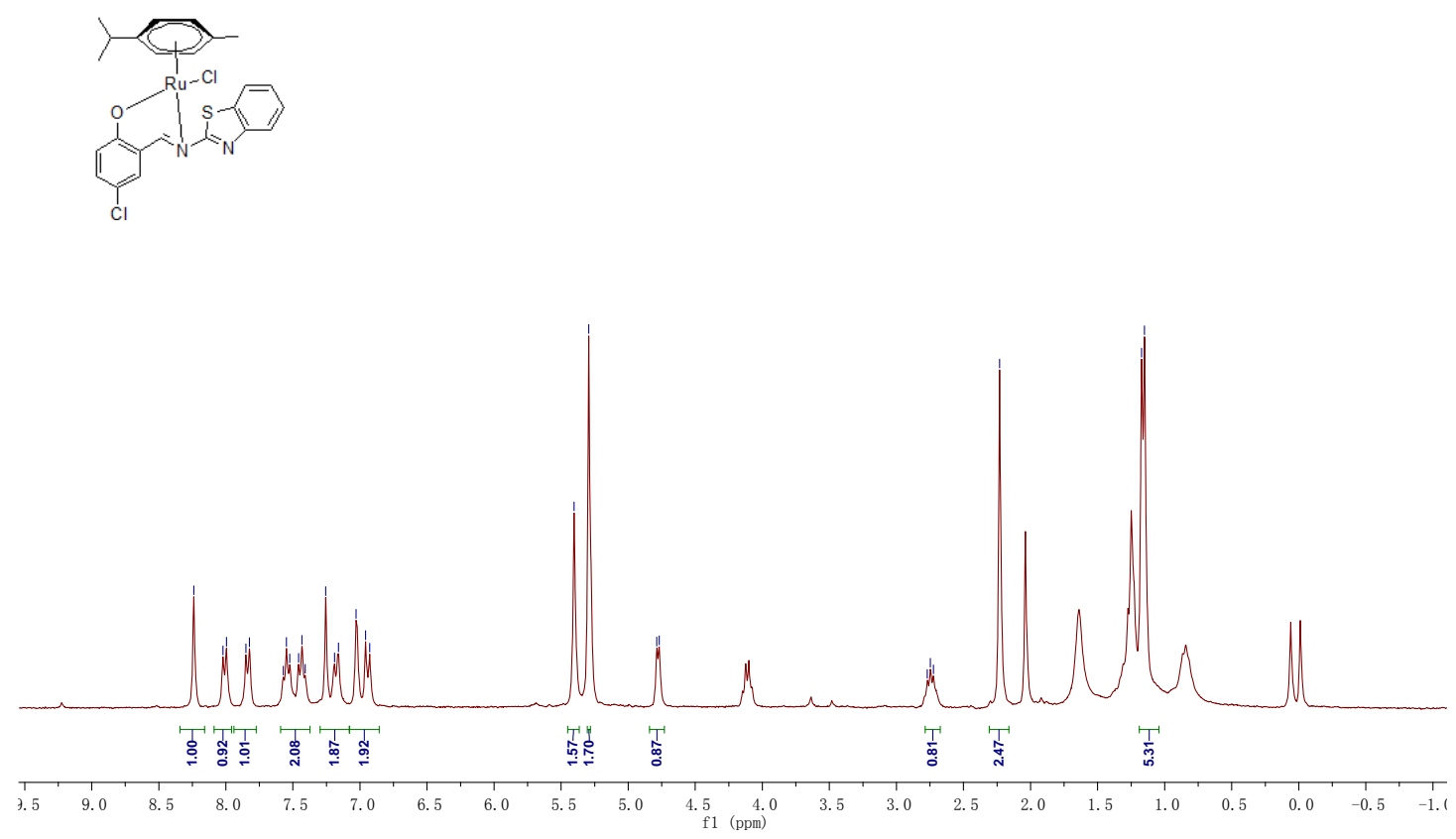

Figure S39. The ${ }^{1} \mathrm{H}$ NMR of half-sandwich ruthenium complex $\mathbf{2} \mathbf{j}$

点
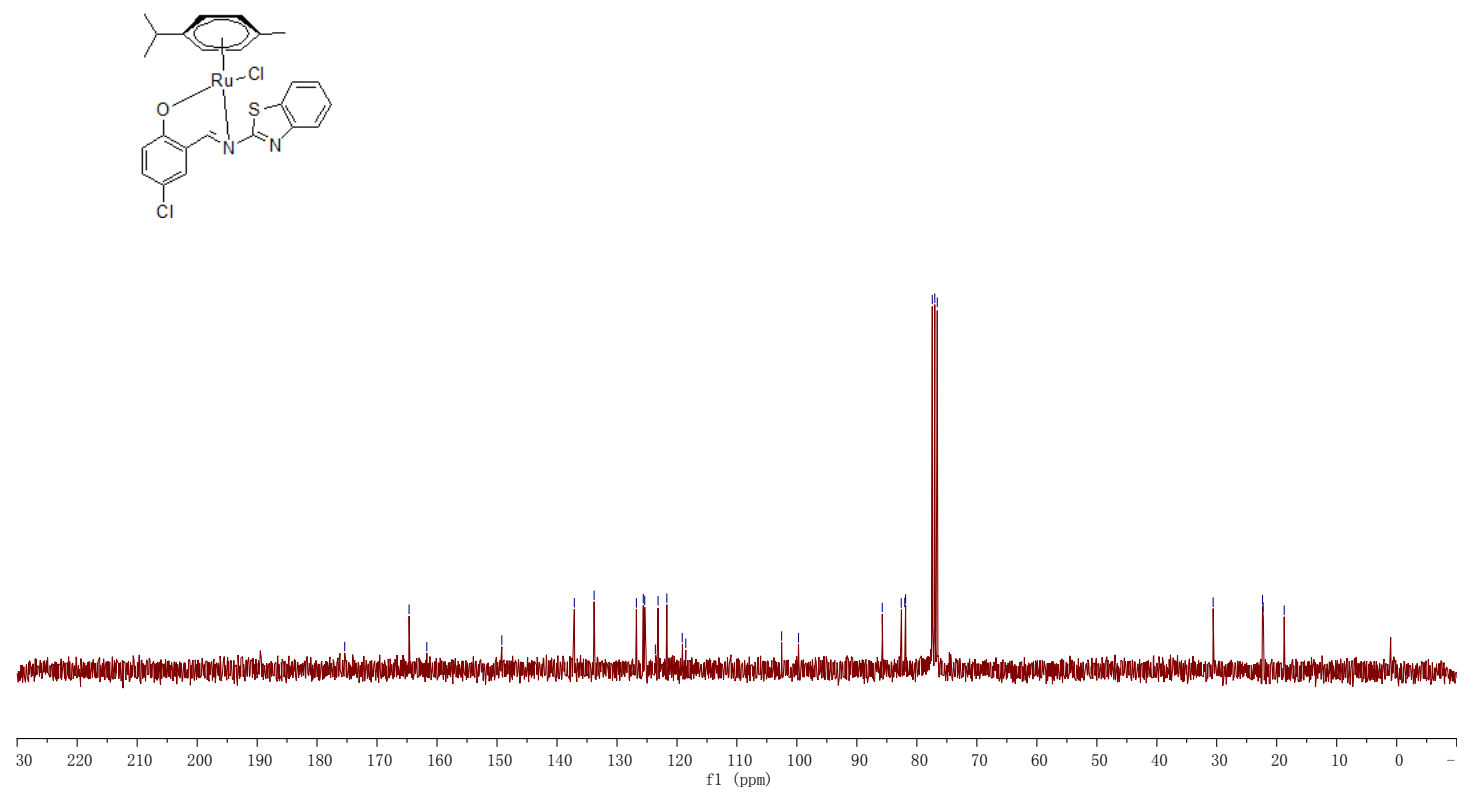

Figure S40. The ${ }^{13} \mathrm{C}$ NMR of half-sandwich ruthenium complex $\mathbf{2 j}$ 

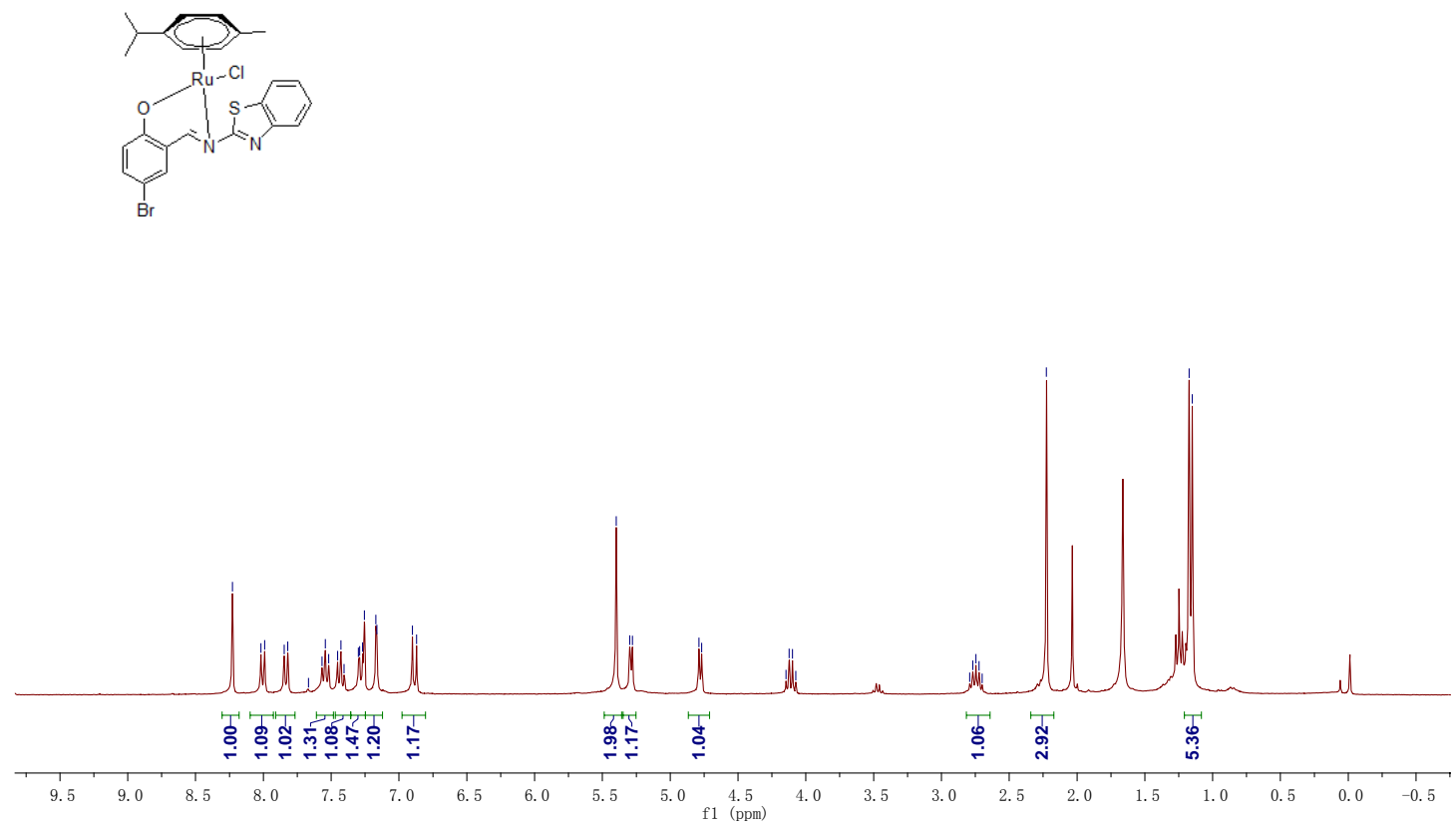

Figure S41. The ${ }^{1} \mathrm{H}$ NMR of half-sandwich ruthenium complex $\mathbf{2 k}$

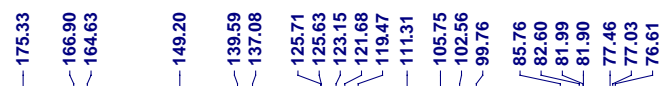

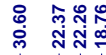
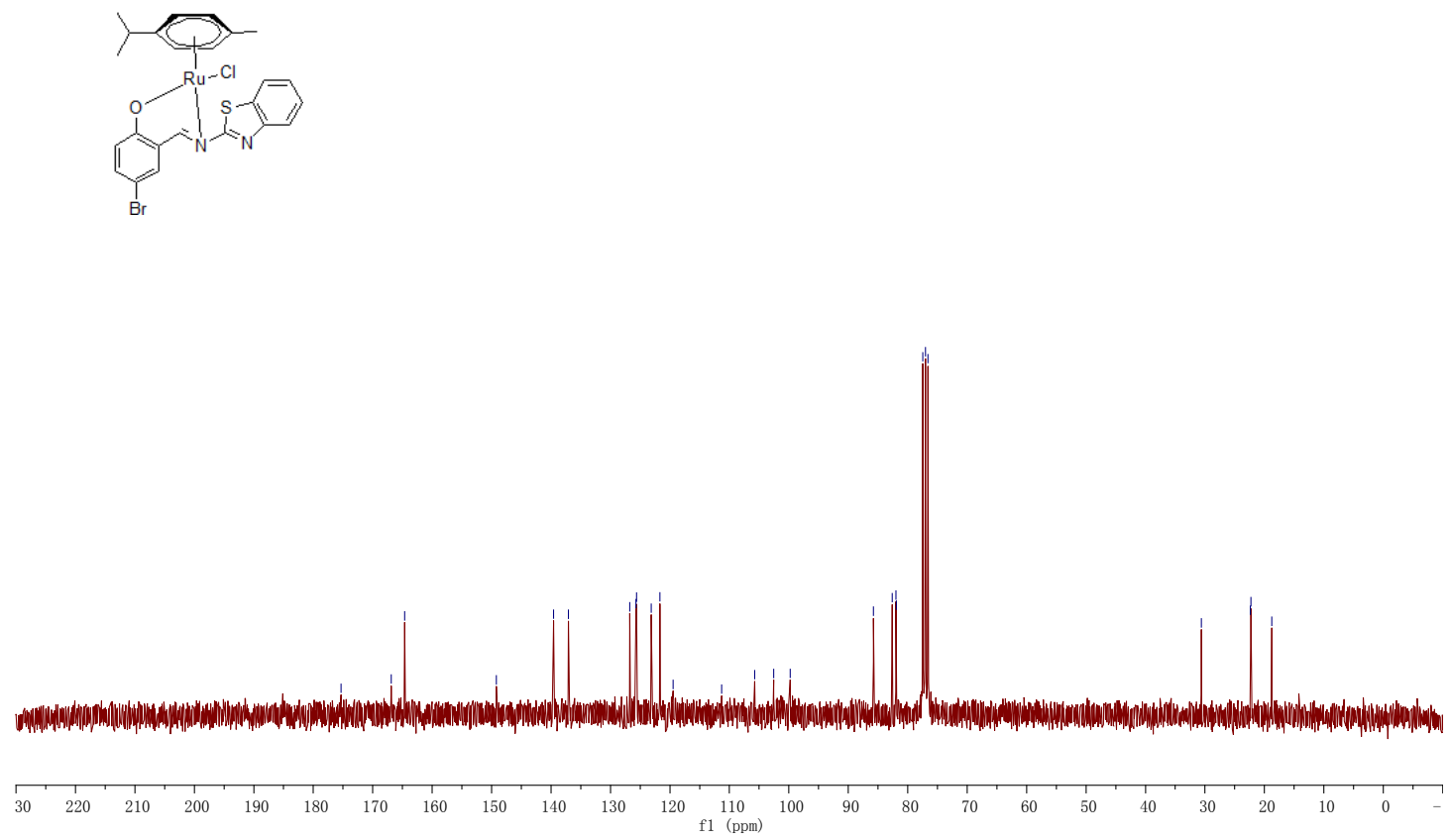

Figure S42. The ${ }^{13} \mathrm{C}$ NMR of half-sandwich ruthenium complex $\mathbf{2 k}$ 

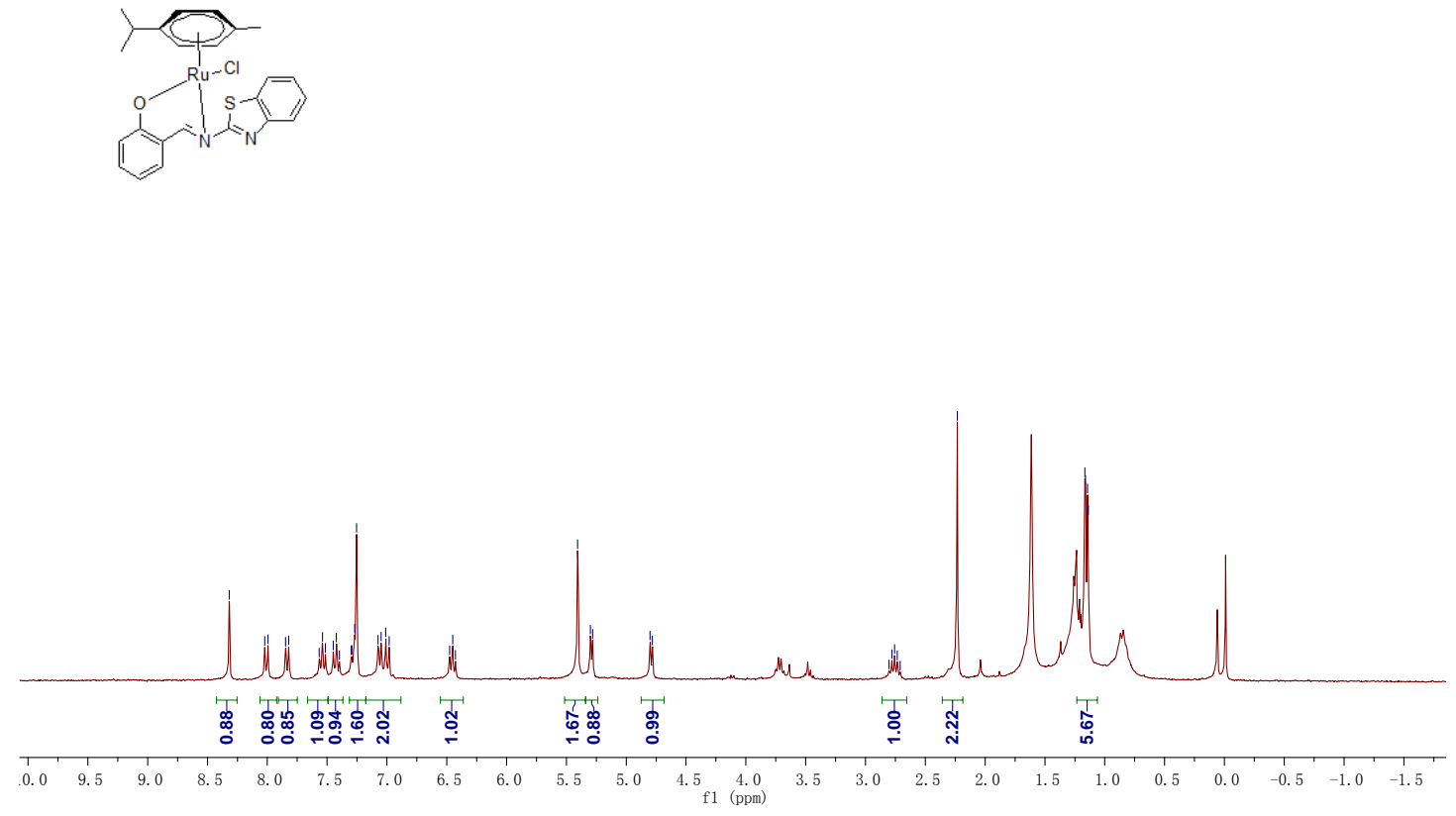

Figure S43. The ${ }^{1} \mathrm{H}$ NMR of half-sandwich ruthenium complex 2 l
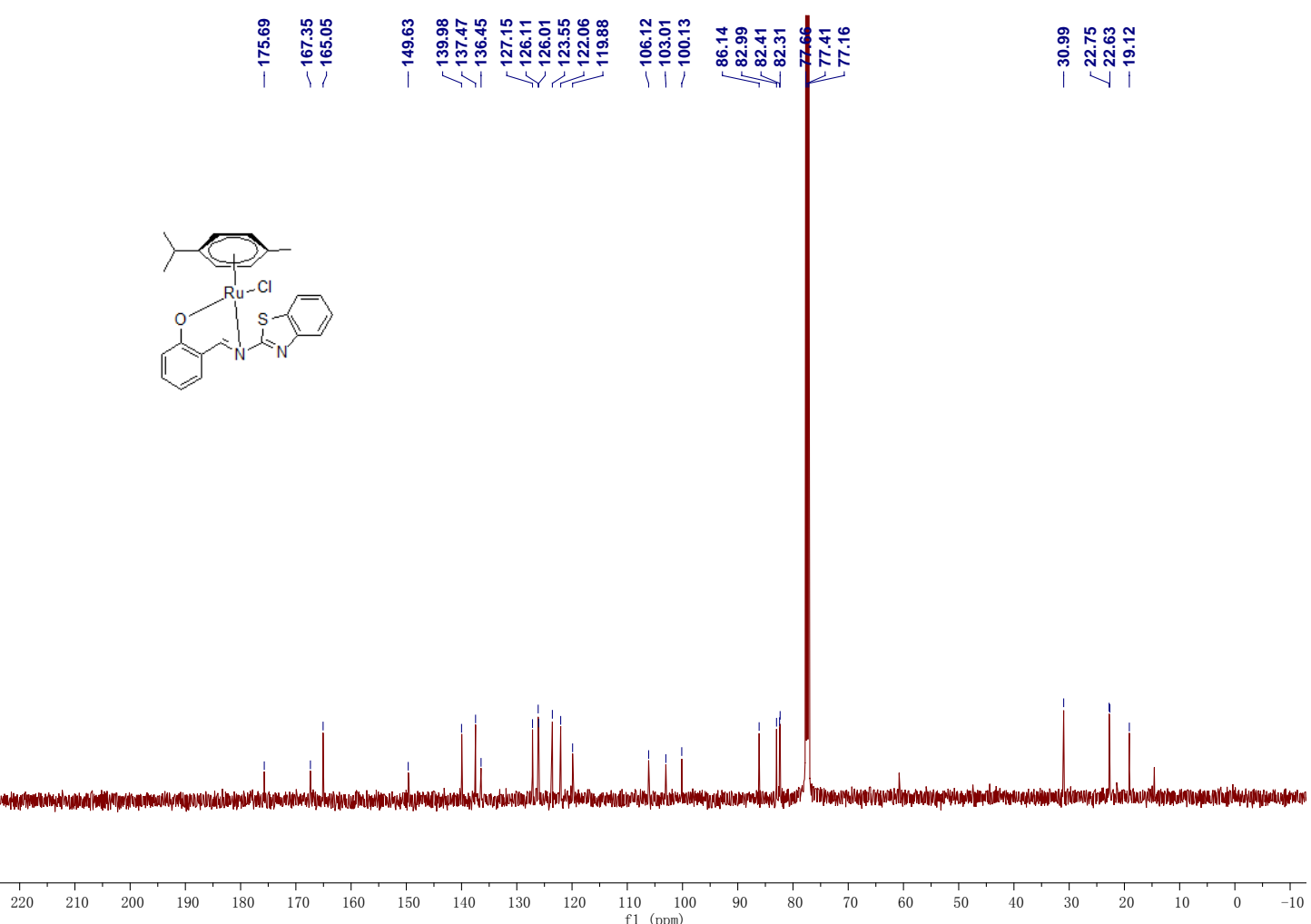

Figure S44. The ${ }^{13} \mathrm{C}$ NMR of half-sandwich ruthenium complex 2 l 
3.
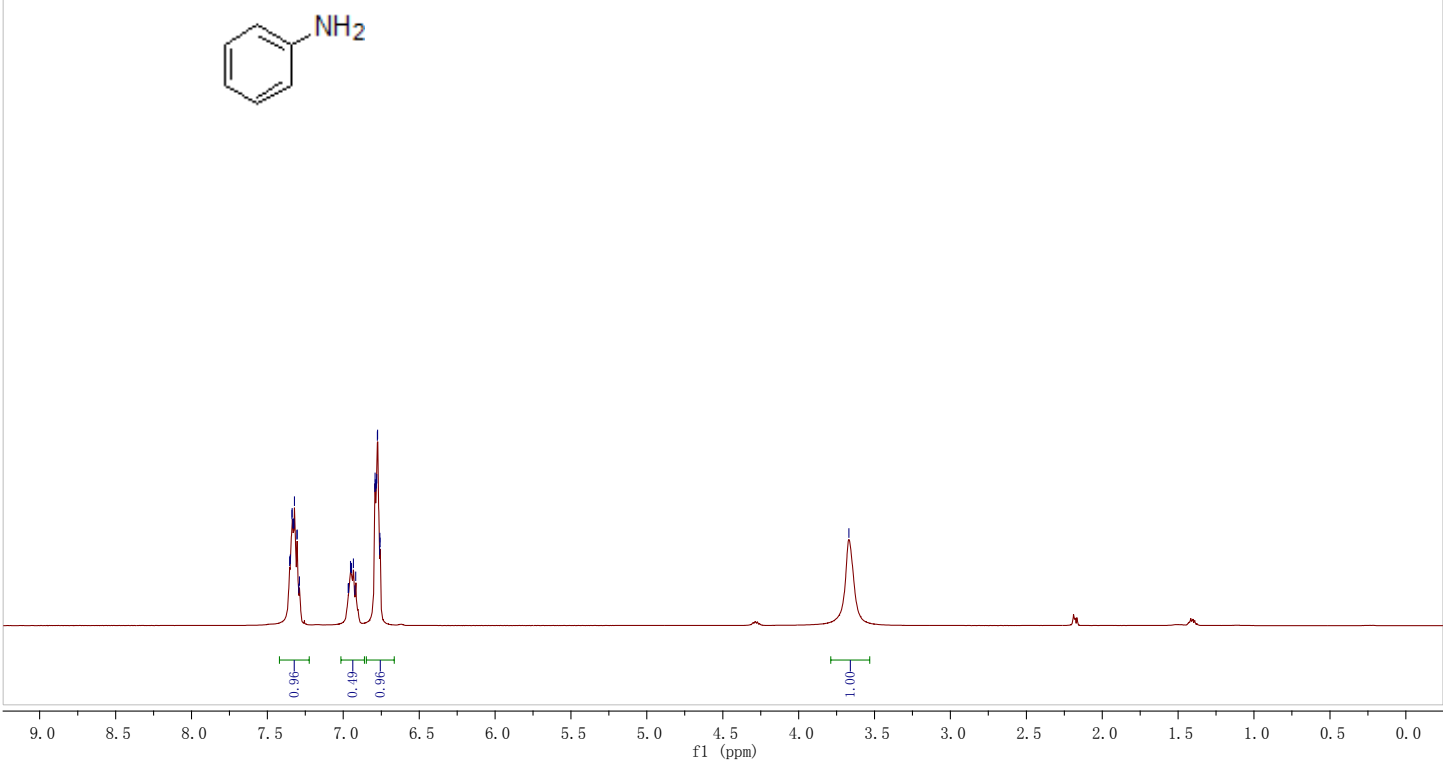

Figure S45. The ${ }^{1} \mathrm{H}$ NMR of Aniline

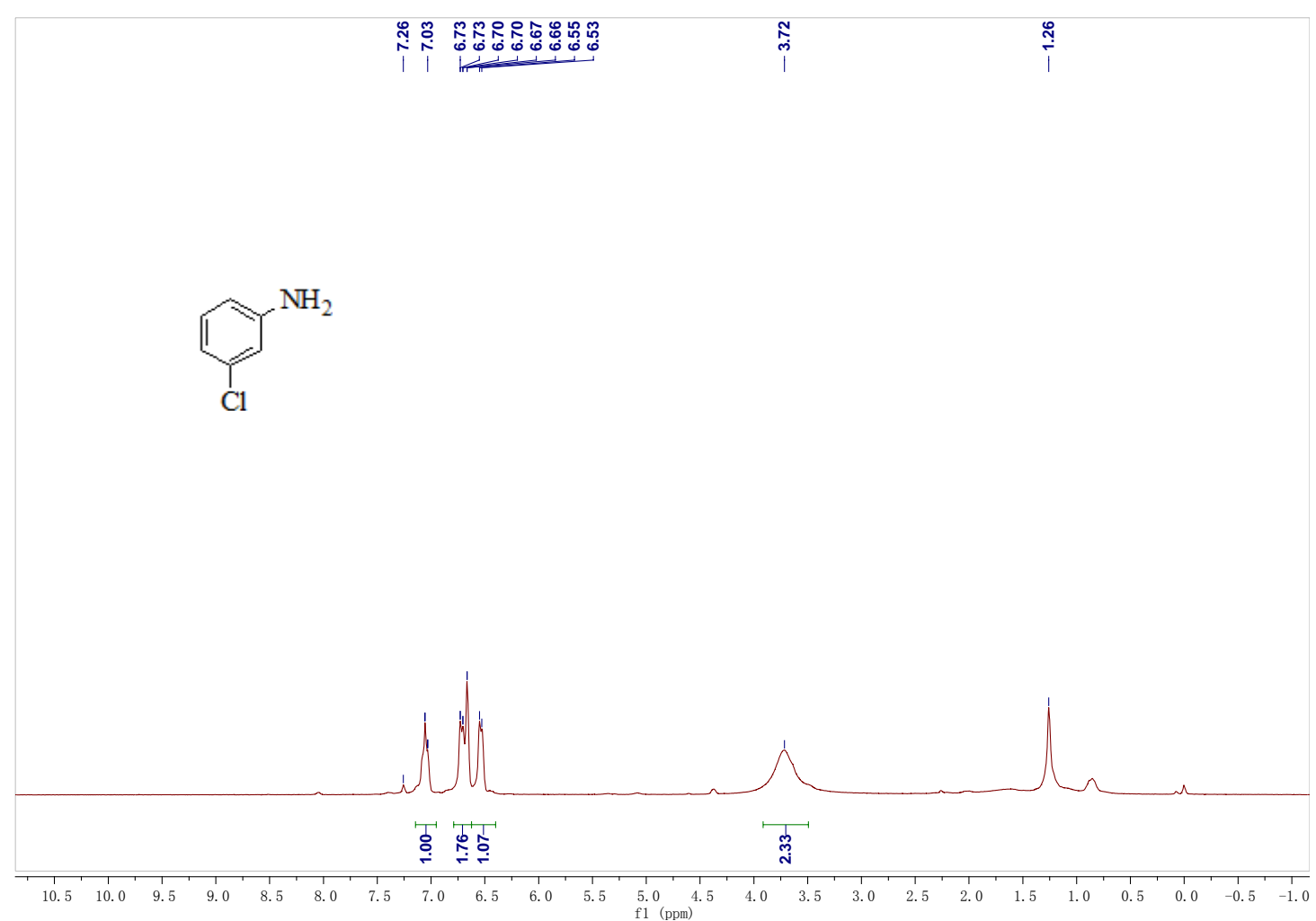

Figure S46. The ${ }^{1} \mathrm{H}$ NMR of 3-Chloroaniline 


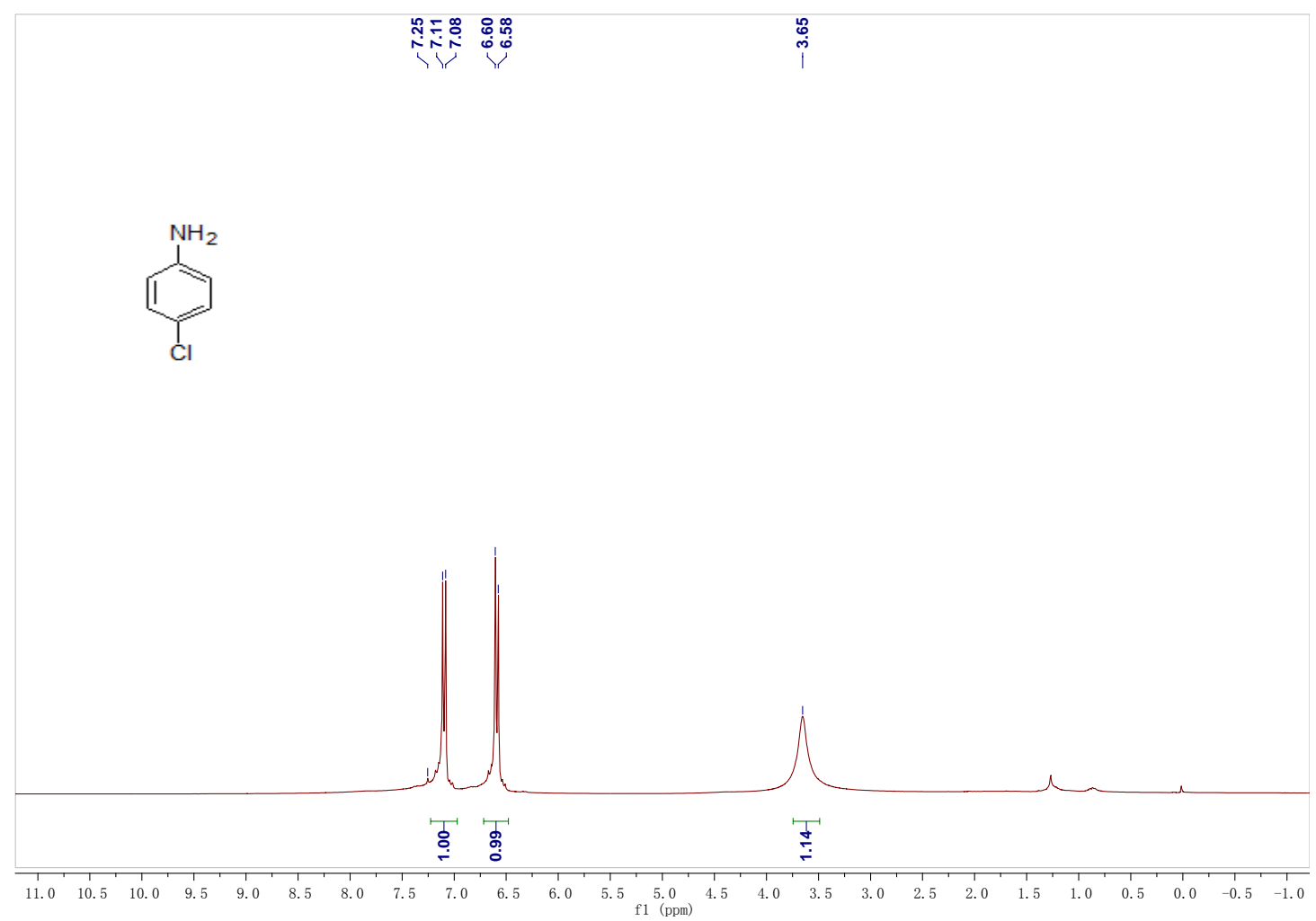

Figure S47. The ${ }^{1} \mathrm{H}$ NMR of 3.4-Chloroaniline

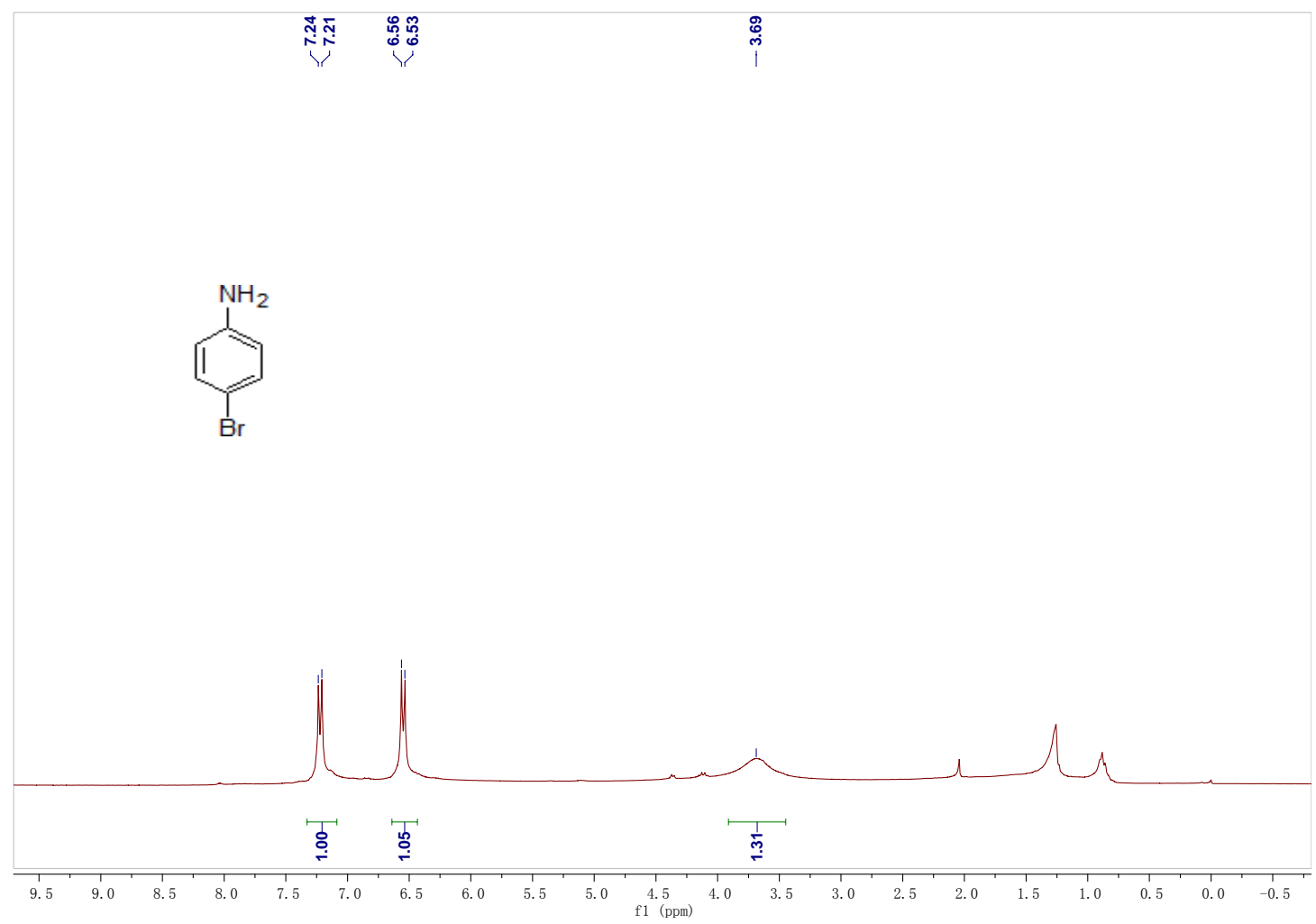

Figure S48. The ${ }^{1} \mathrm{H}$ NMR of 4-bromoaniline 


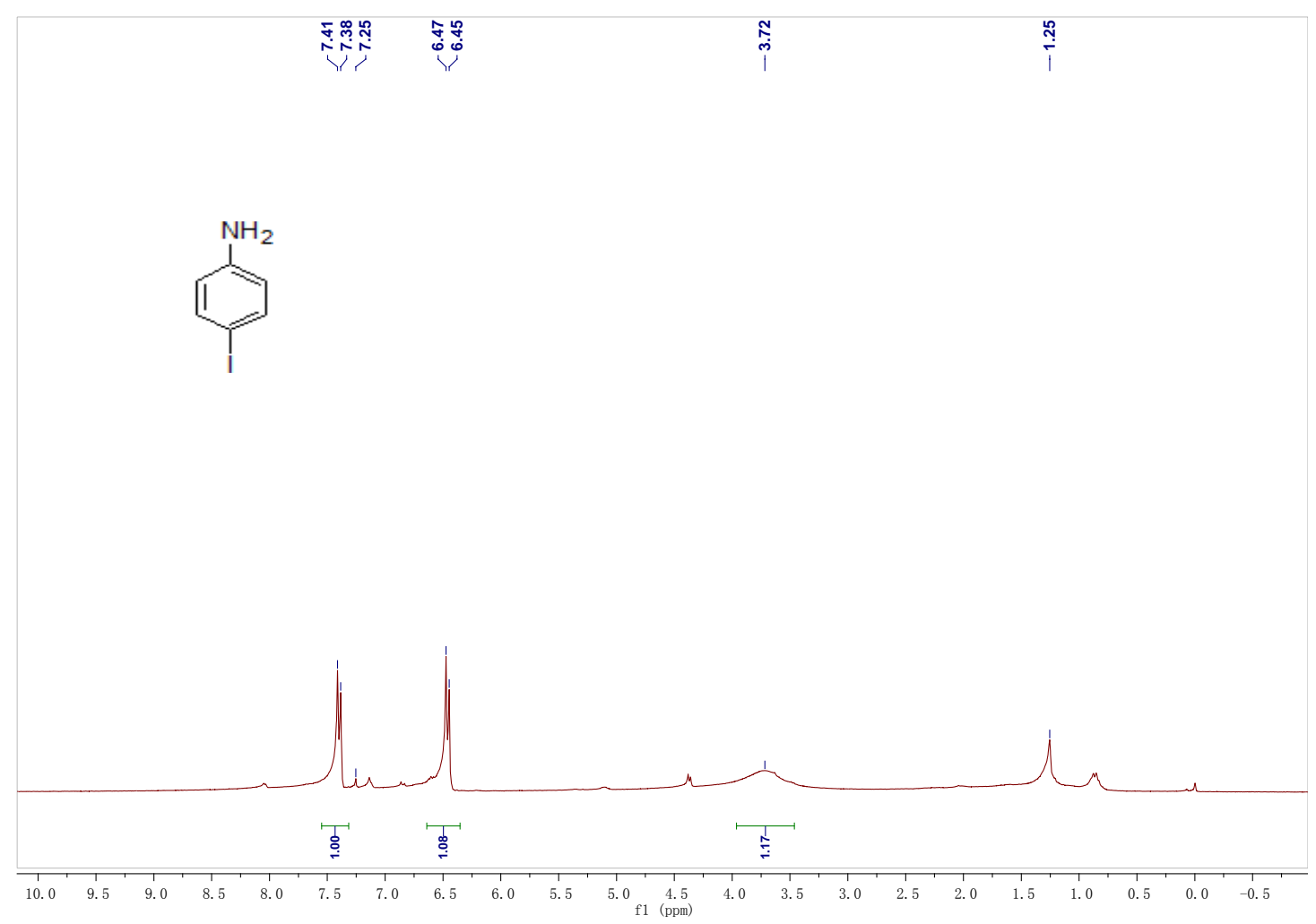

Figure S49. The ${ }^{1} \mathrm{H}$ NMR of 4-iodoaniline

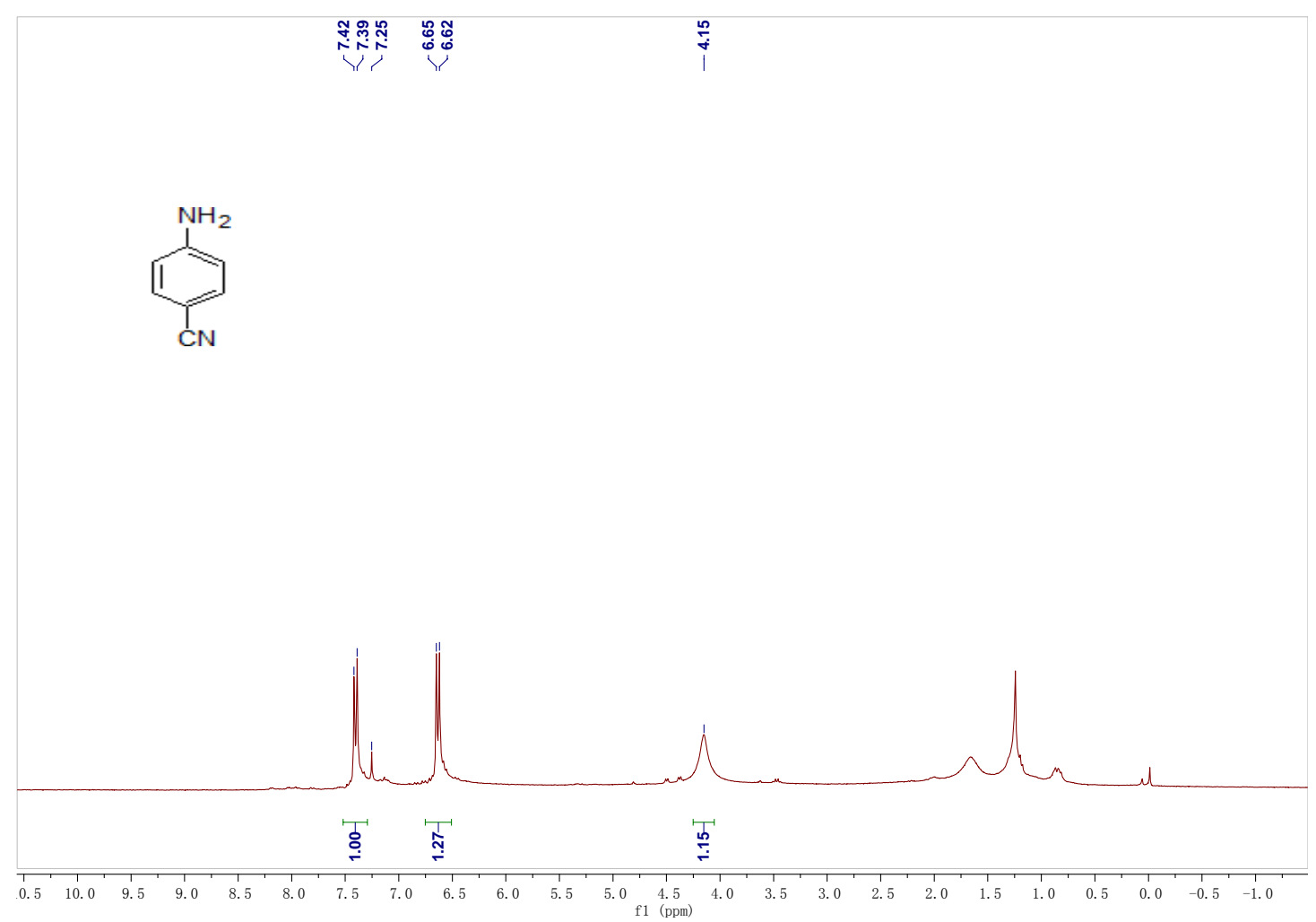

Figure S50. The ${ }^{1} \mathrm{H}$ NMR of 4-Cyanoaniline 


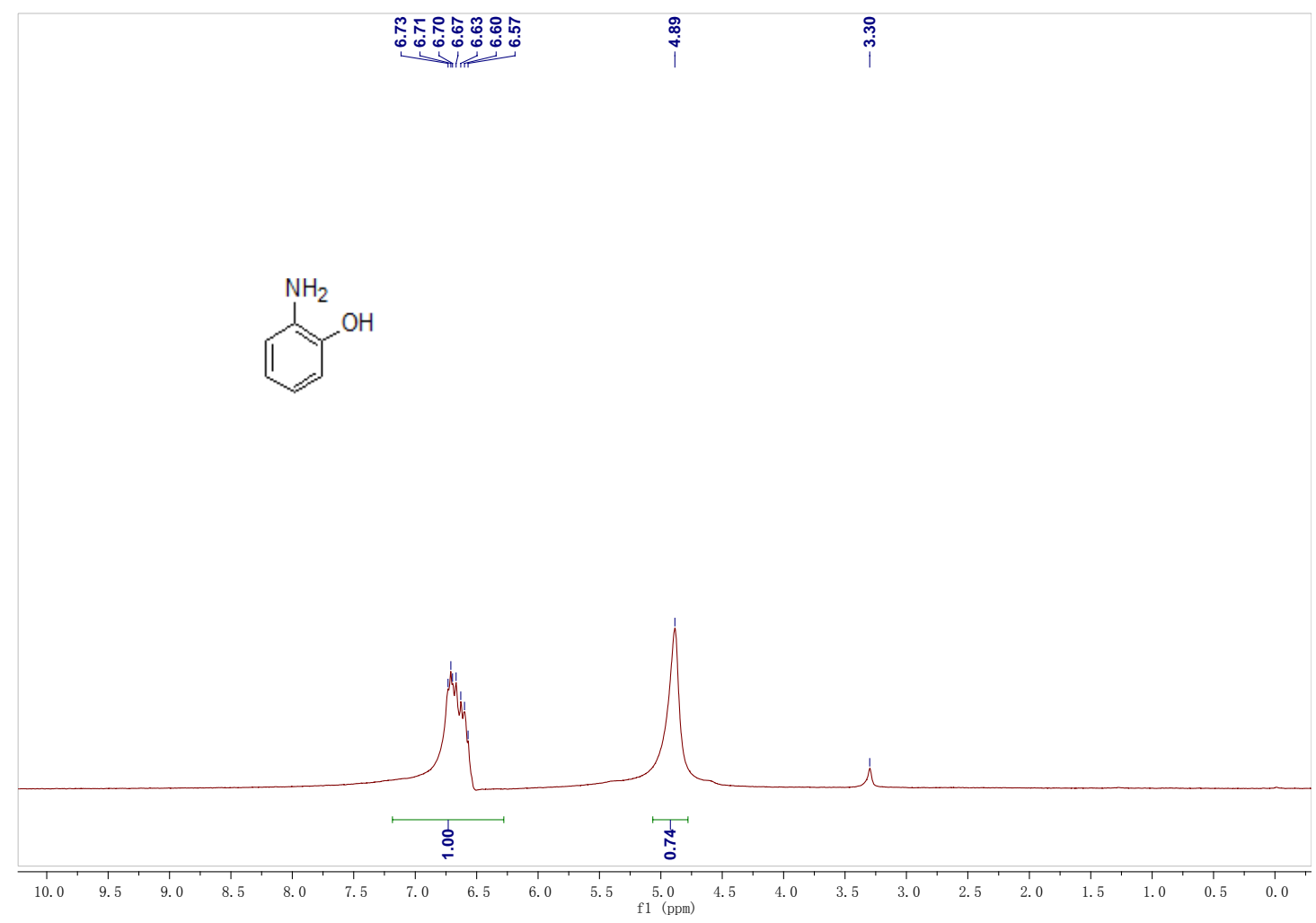

Figure S51. The ${ }^{1} \mathrm{H}$ NMR of 2-aminophenol

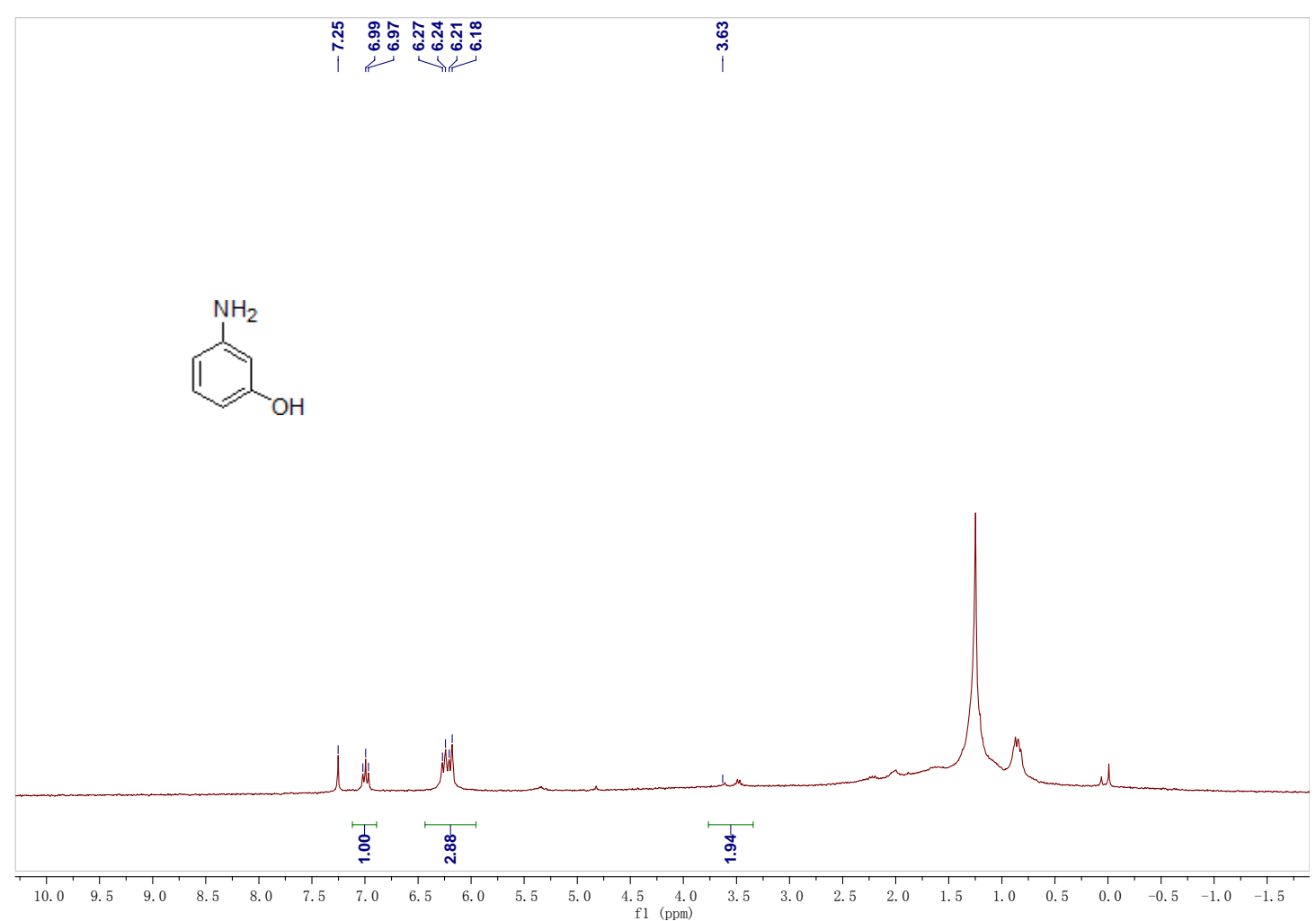

Figure S52. The ${ }^{1} \mathrm{H}$ NMR of 3-aminophenol 


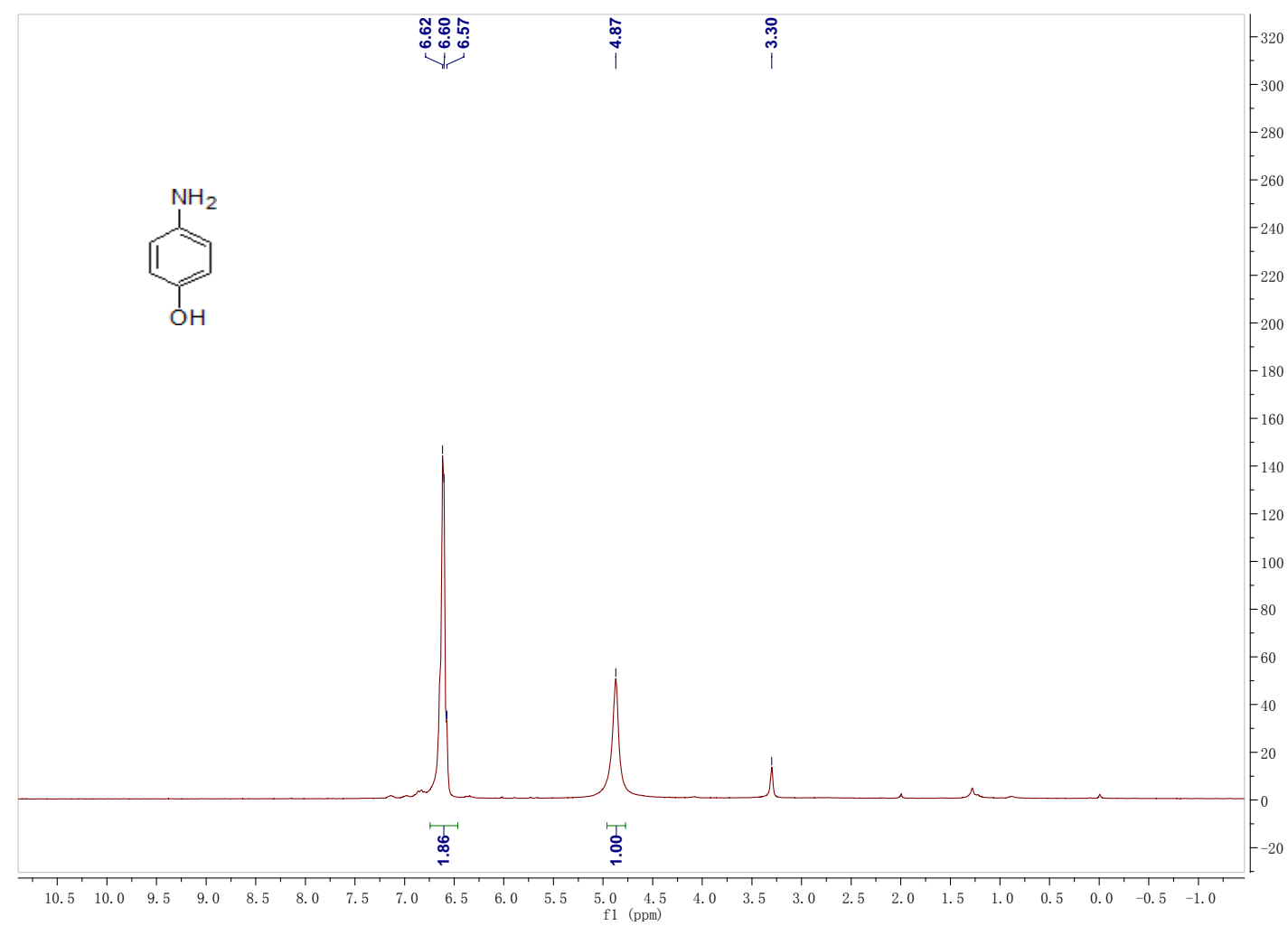

Figure S53. The ${ }^{1} \mathrm{H}$ NMR of 4-aminophenol

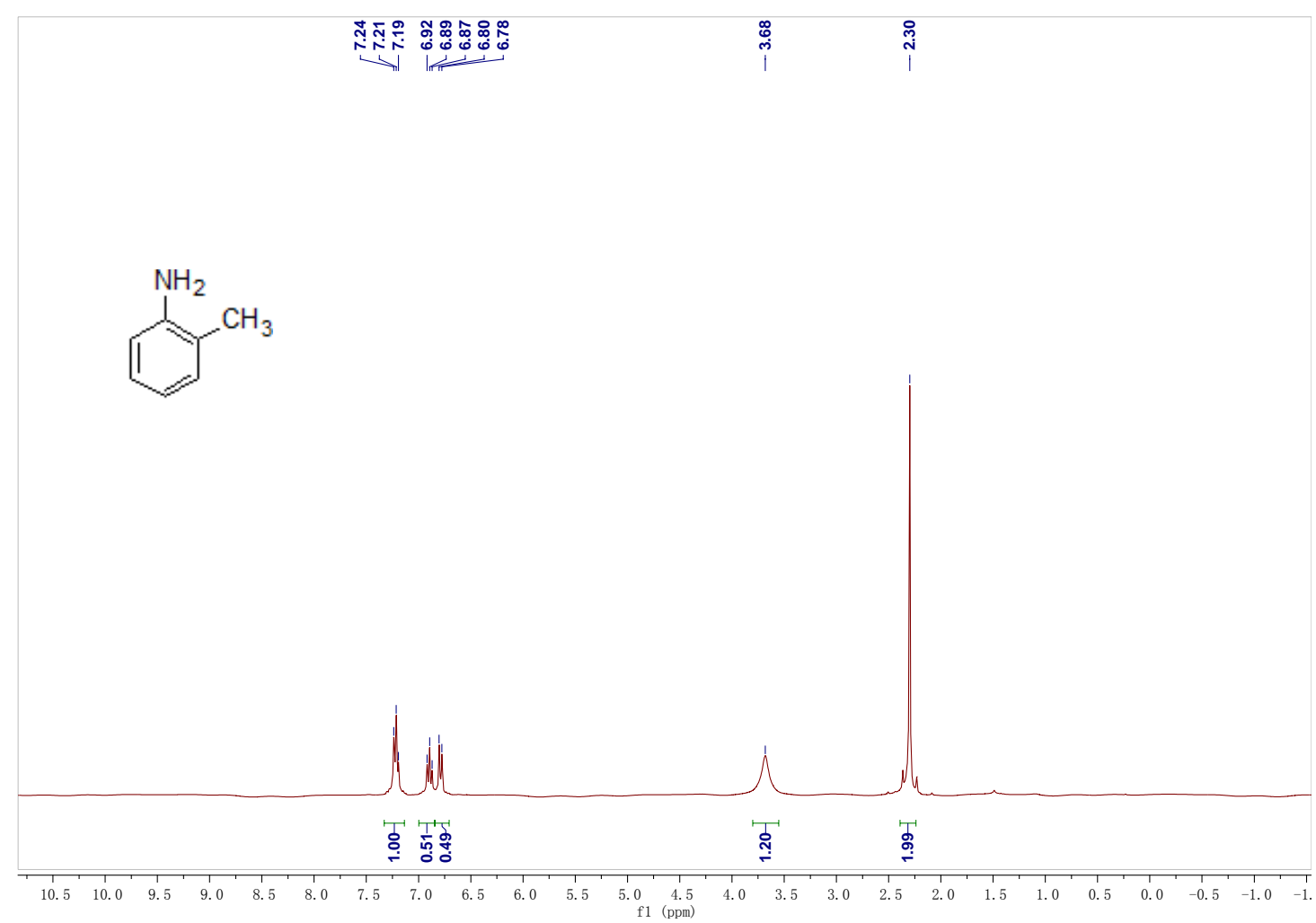

Figure S54. The ${ }^{1} \mathrm{H}$ NMR of 2-tuluidine 


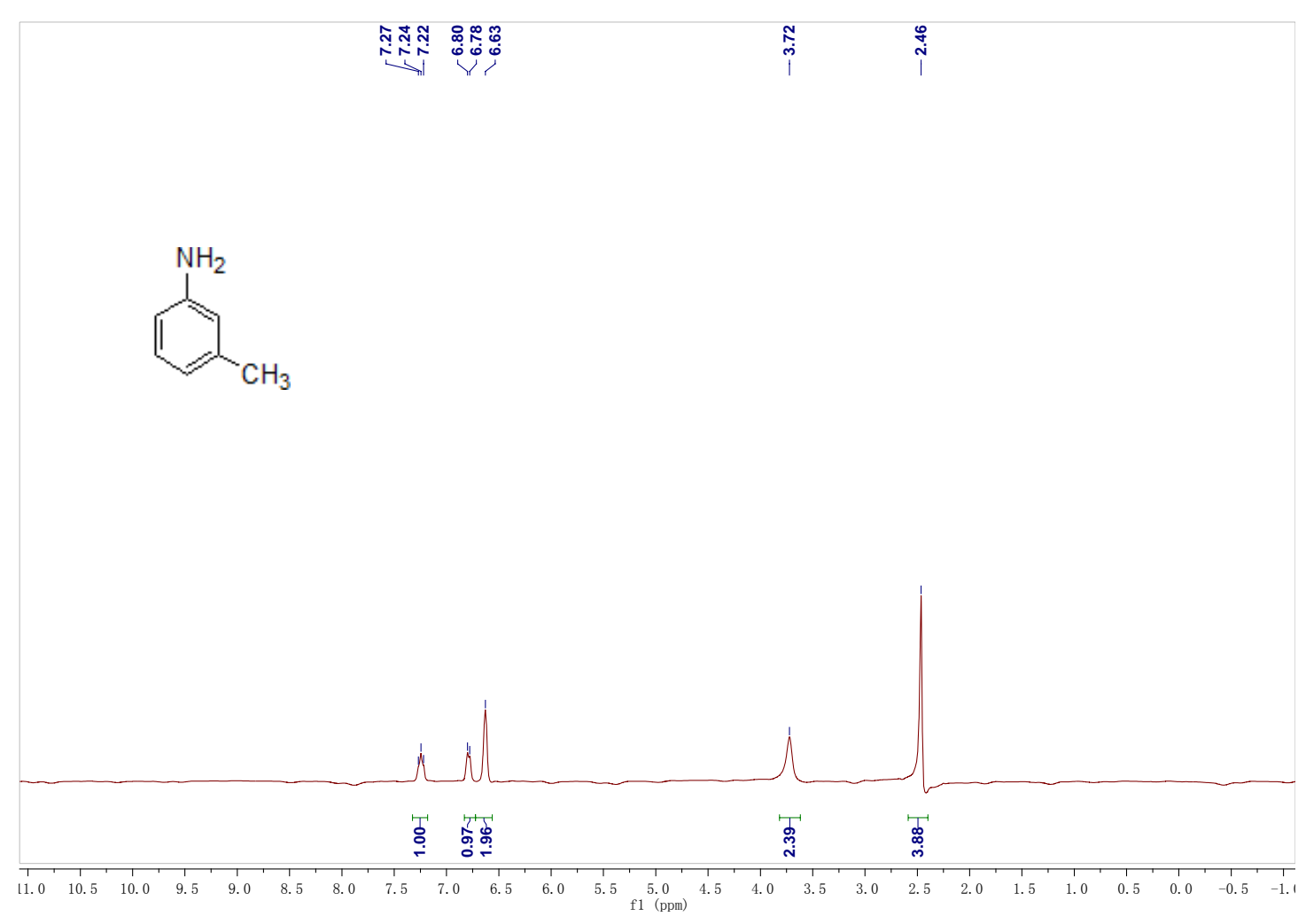

Figure S55. The ${ }^{1} \mathrm{H}$ NMR of 3-tuluidine

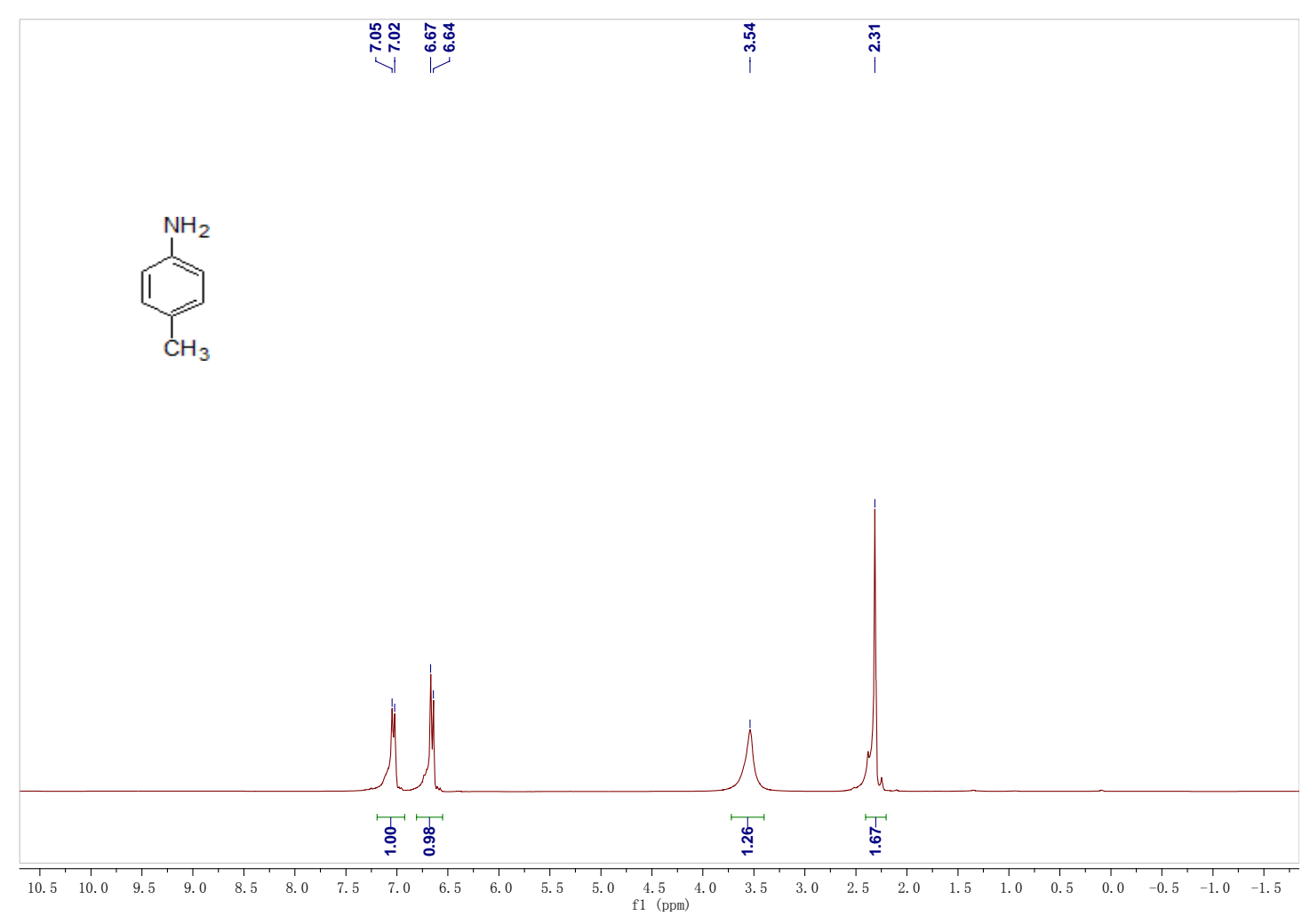

Figure S56. The ${ }^{1} \mathrm{H}$ NMR of 4-toluidine 


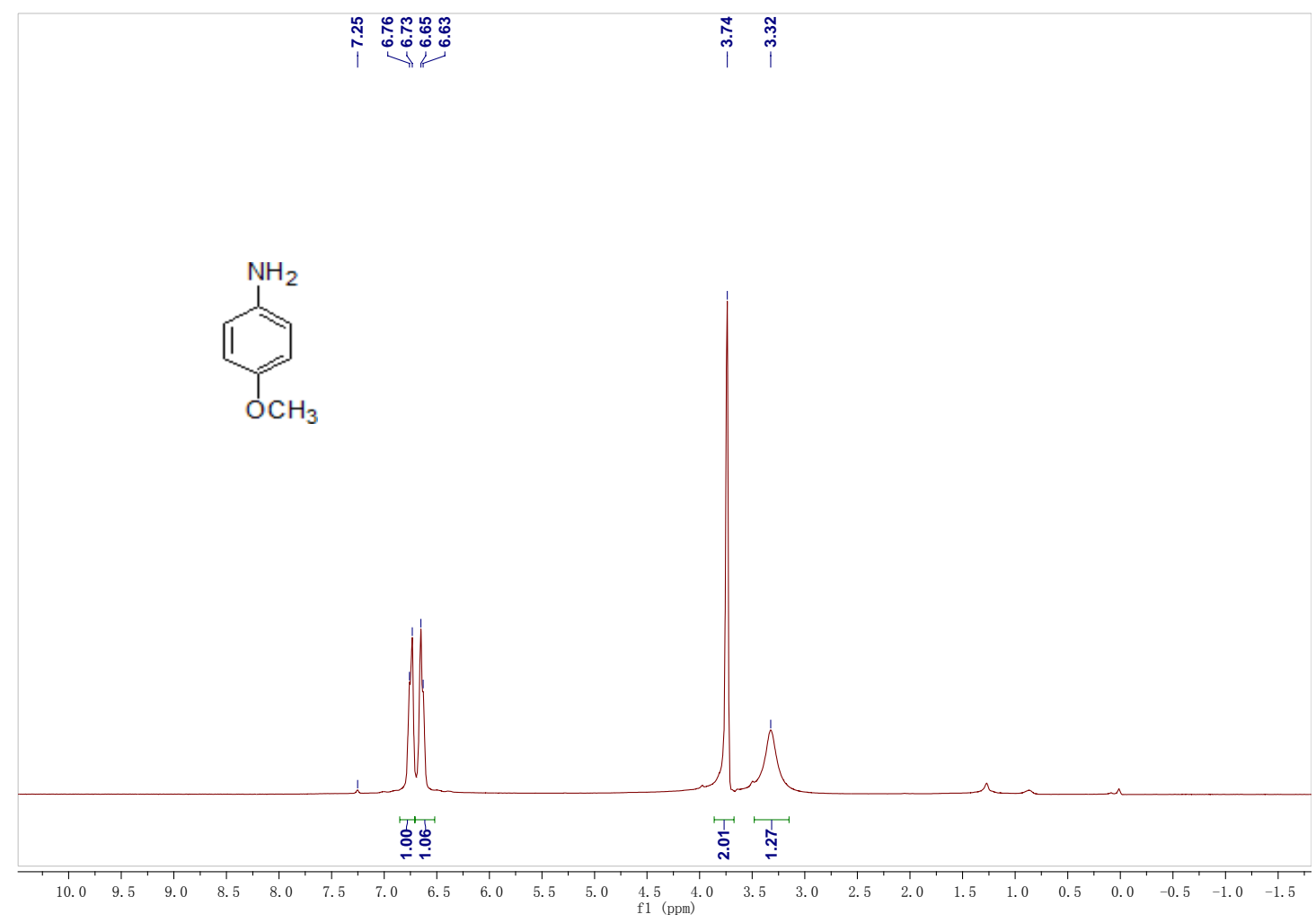

Figure S57. The ${ }^{1} \mathrm{H}$ NMR of $p$-anisidine

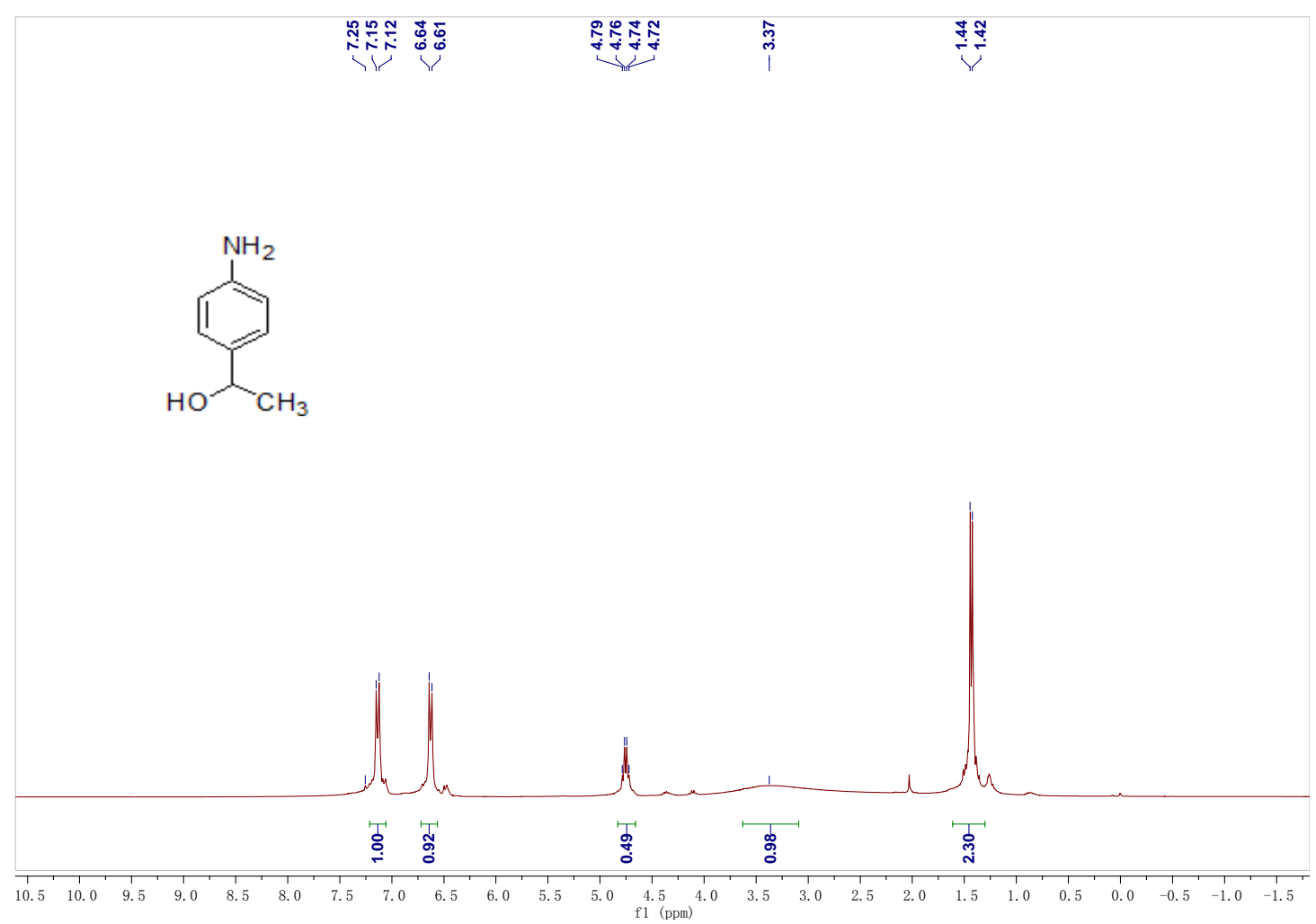

Figure S58. The ${ }^{1} \mathrm{H}$ NMR of 1-(4-aminophenyl)ethanol 


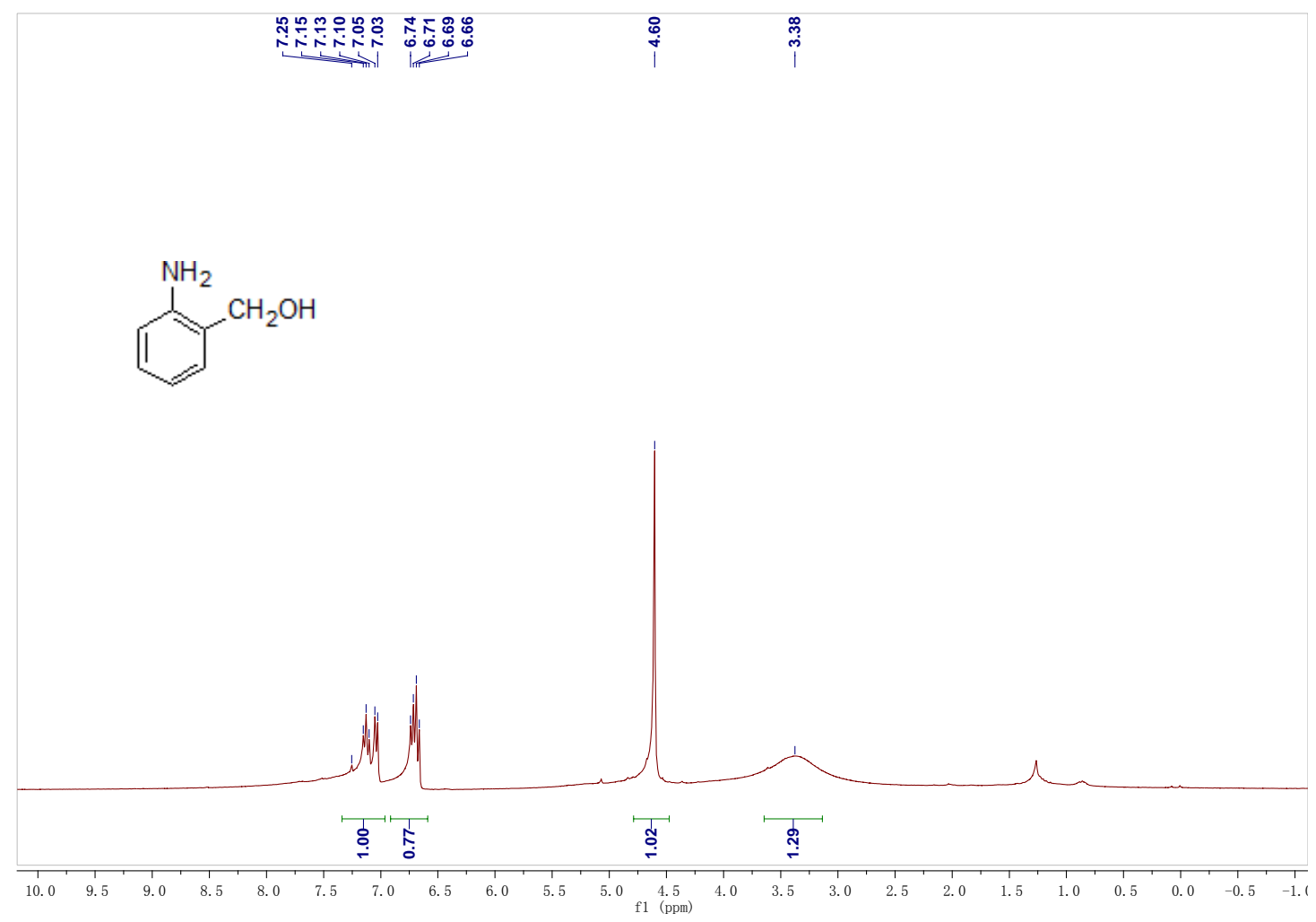

Figure S59. The ${ }^{1} \mathrm{H}$ NMR of (2-aminophenyl)methanol

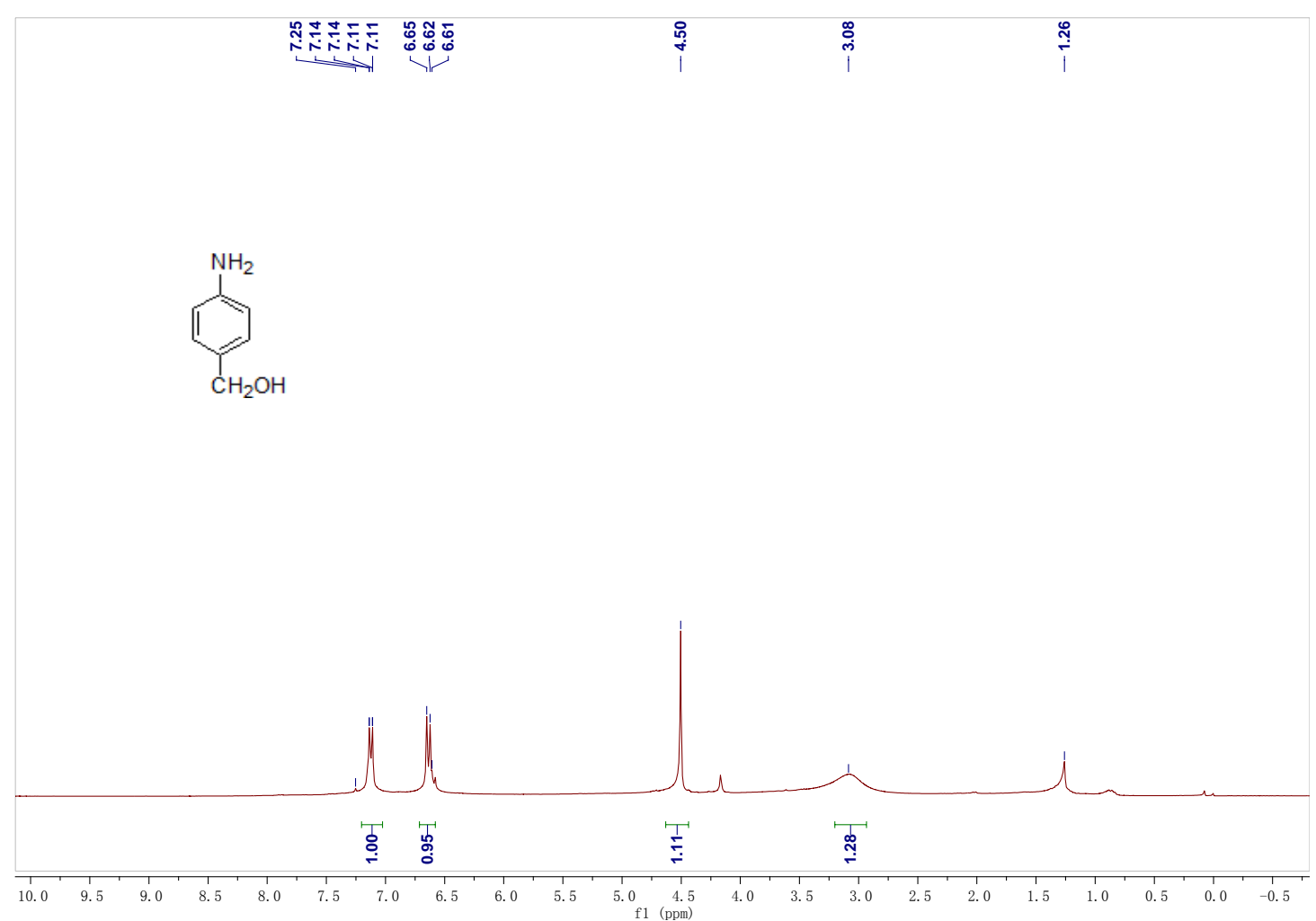

Figure S60. The ${ }^{1} \mathrm{H}$ NMR of (4-aminophenyl)methanol 


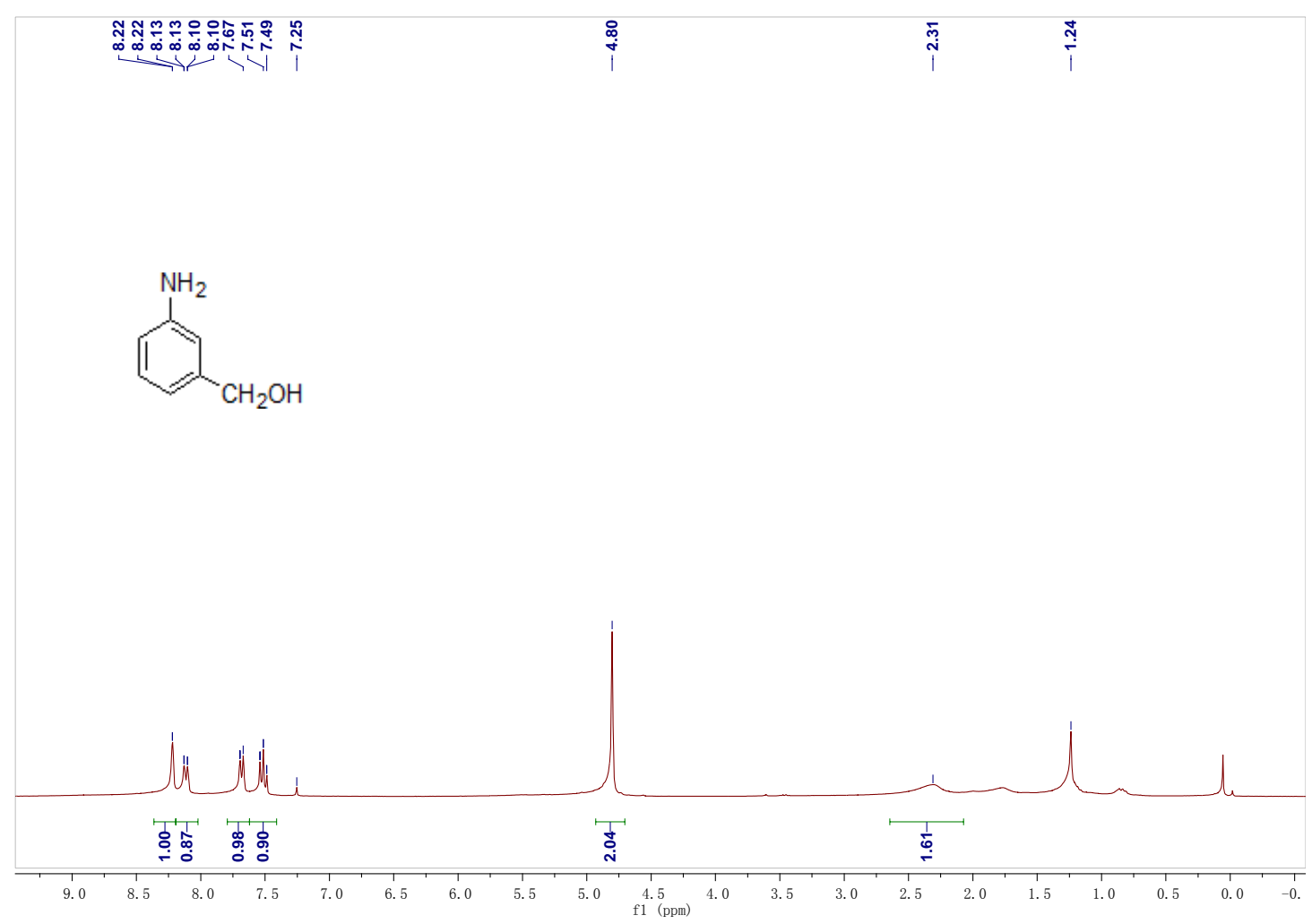

Figure S61. The ${ }^{1} \mathrm{H}$ NMR of (3-aminophenyl)methanol

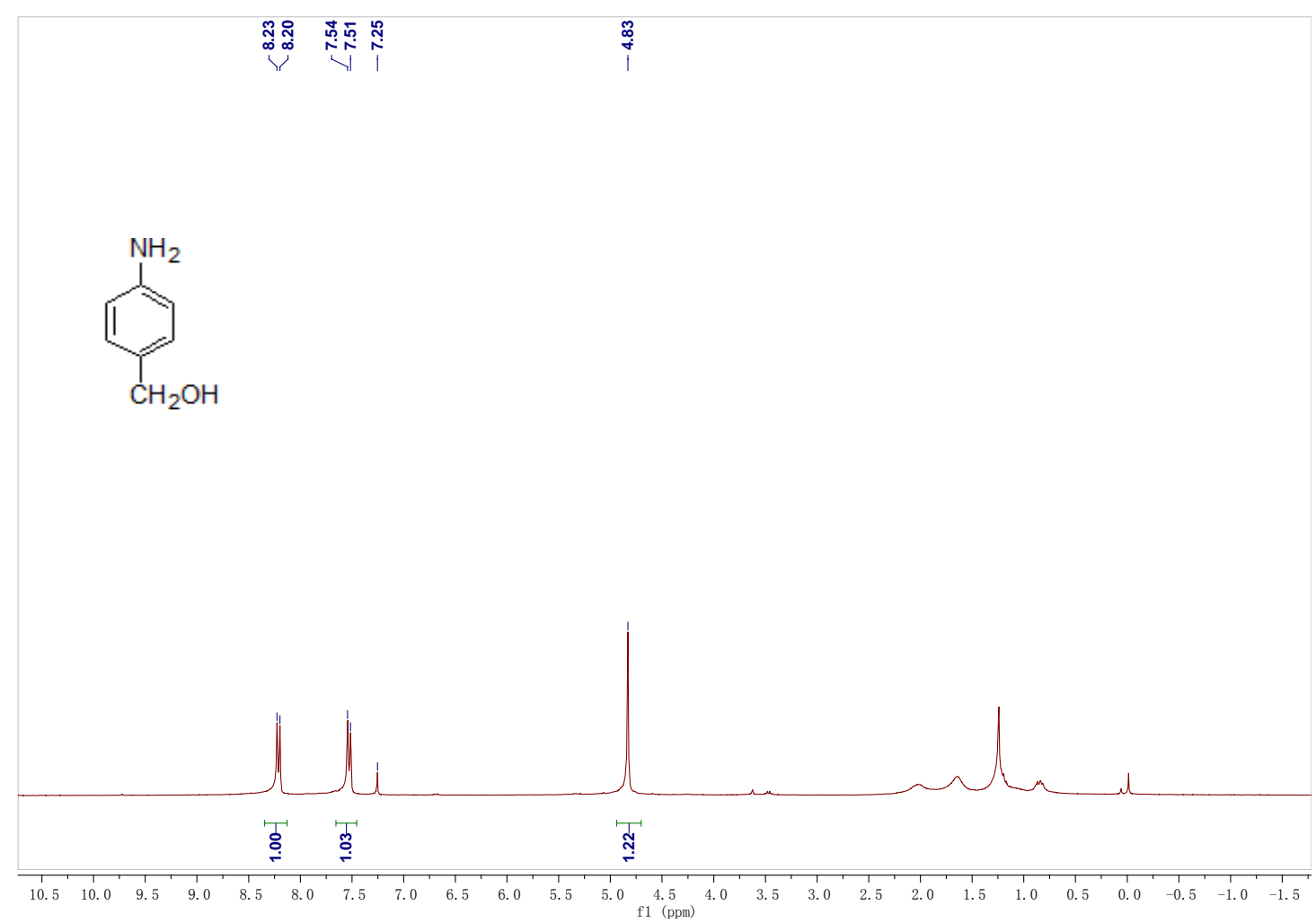

Figure S62. The ${ }^{1} \mathrm{H}$ NMR of (4-aminophenyl)methanol 


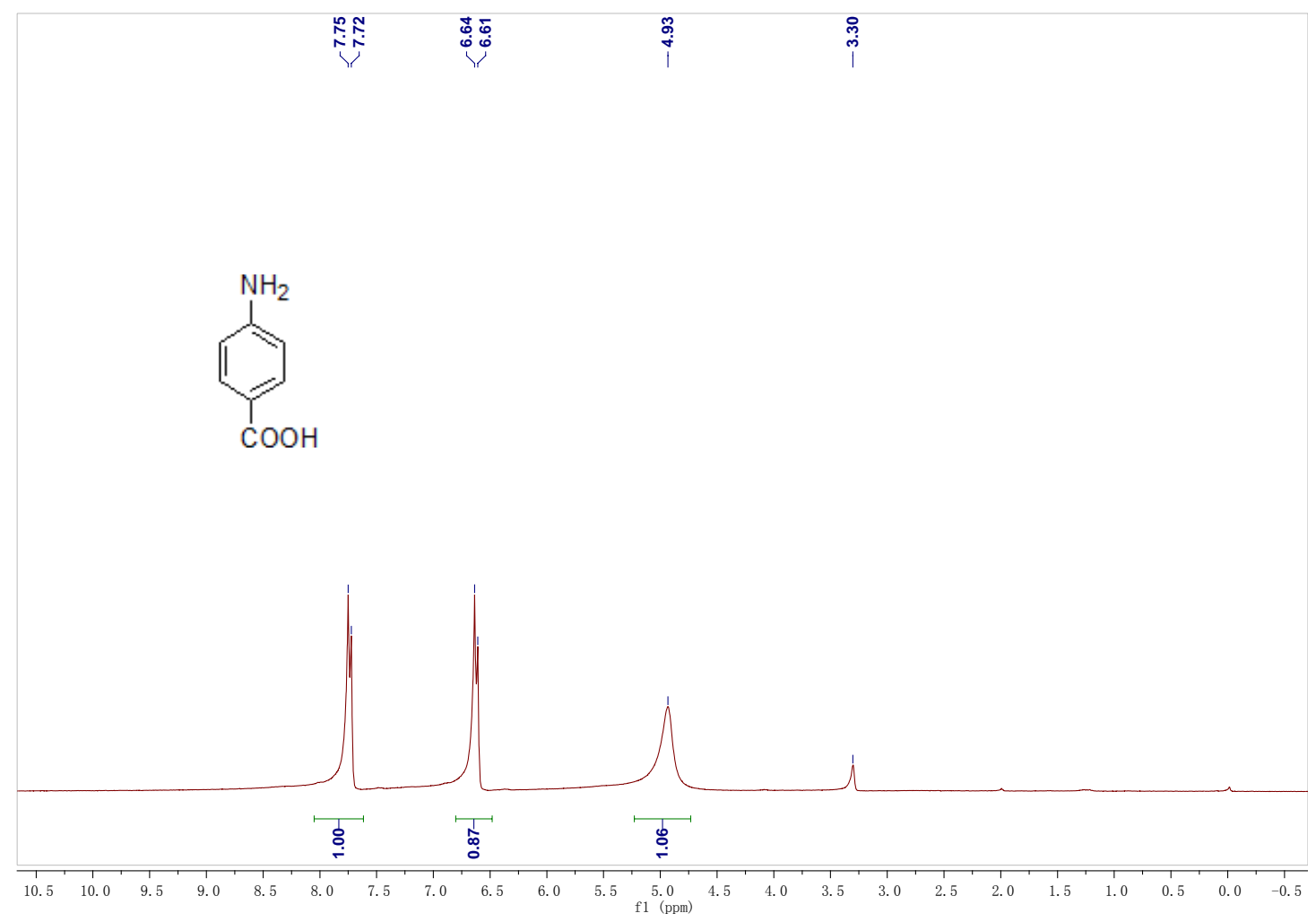

Figure S63. The ${ }^{1} \mathrm{H}$ NMR of 4-aminobenzoic acid

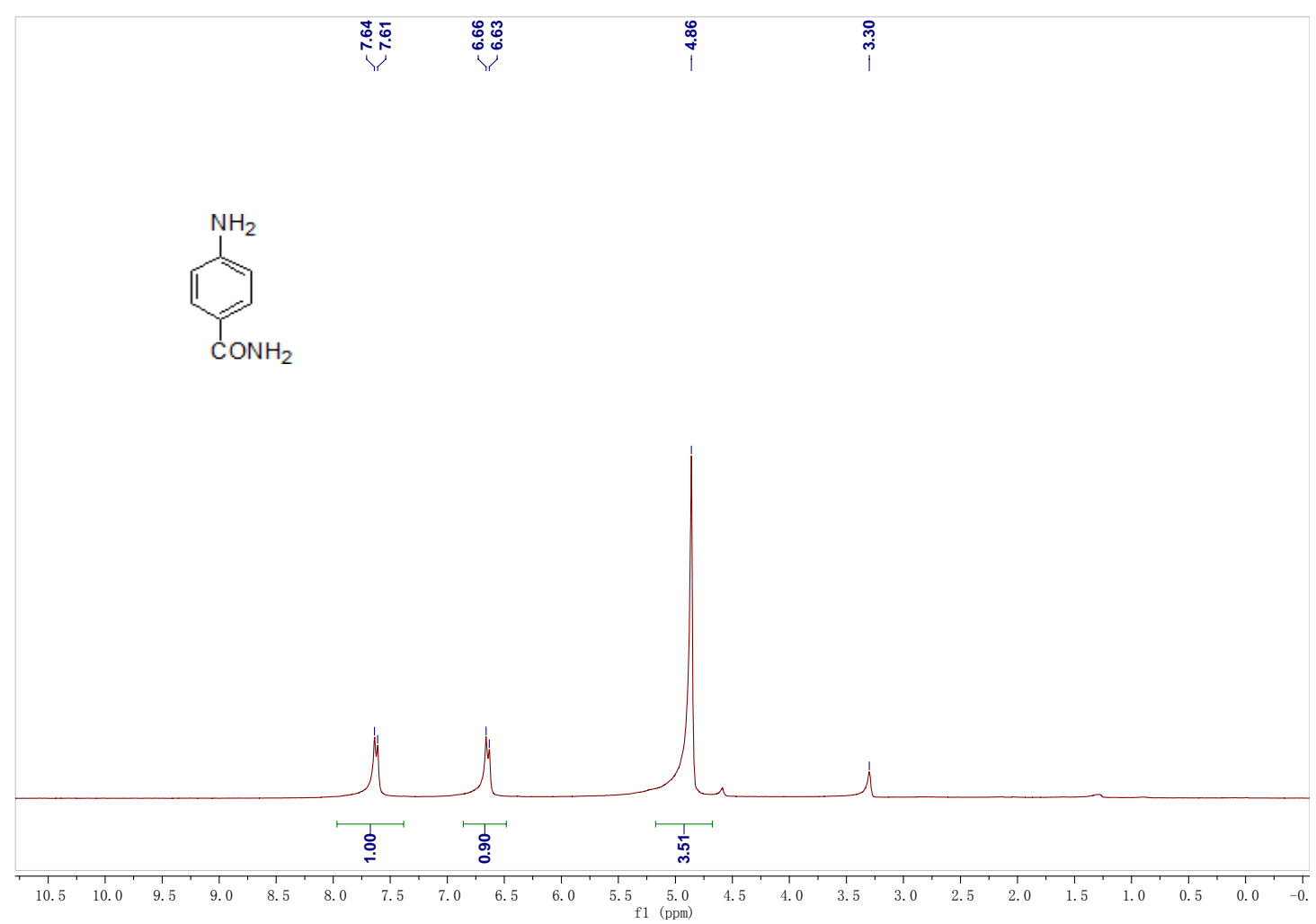

Figure S64. The ${ }^{1} \mathrm{H}$ NMR of 4-Aminobenzamide 


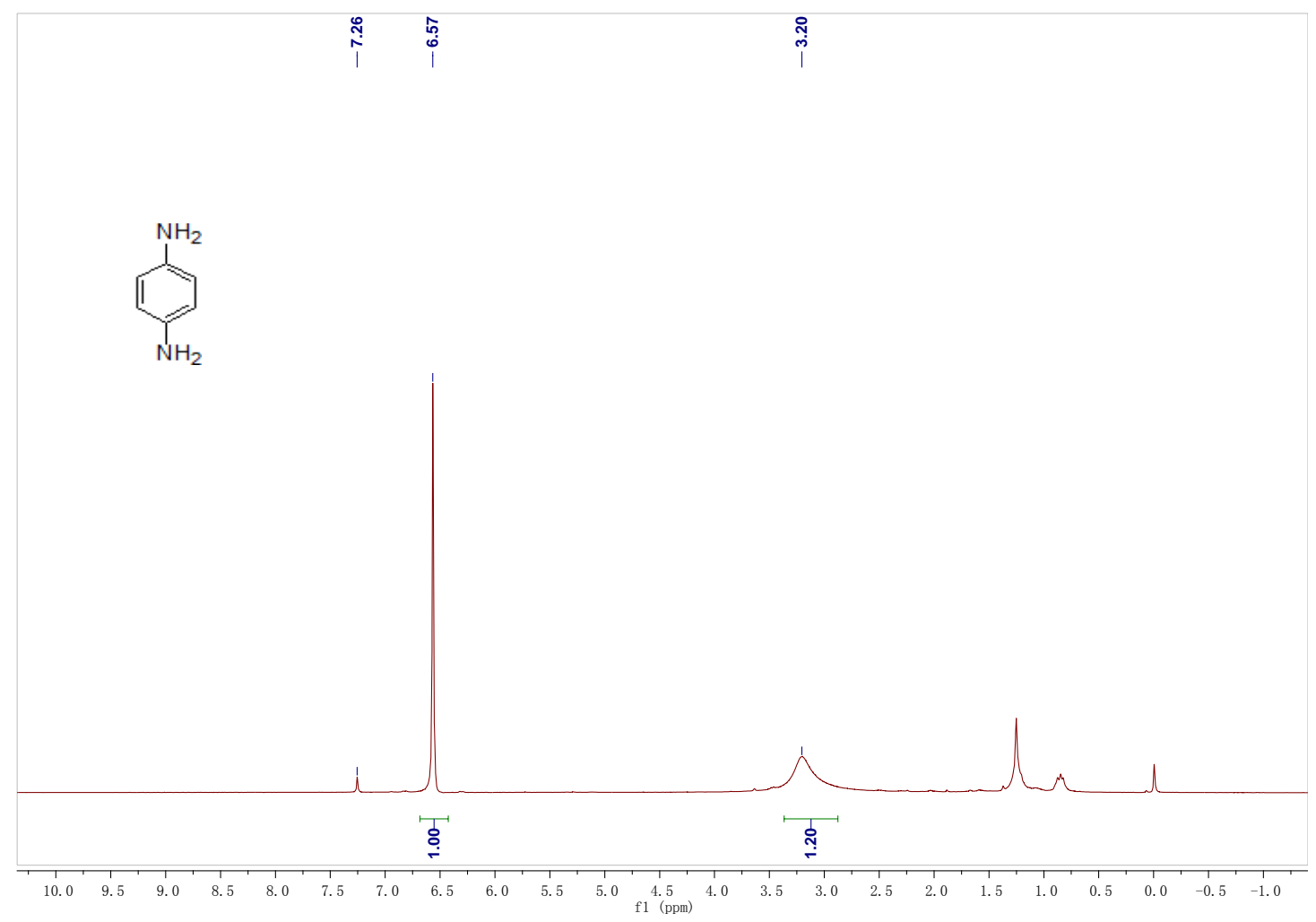

Figure S65. The ${ }^{1} \mathrm{H}$ NMR of 1,4-Phenylenediamine

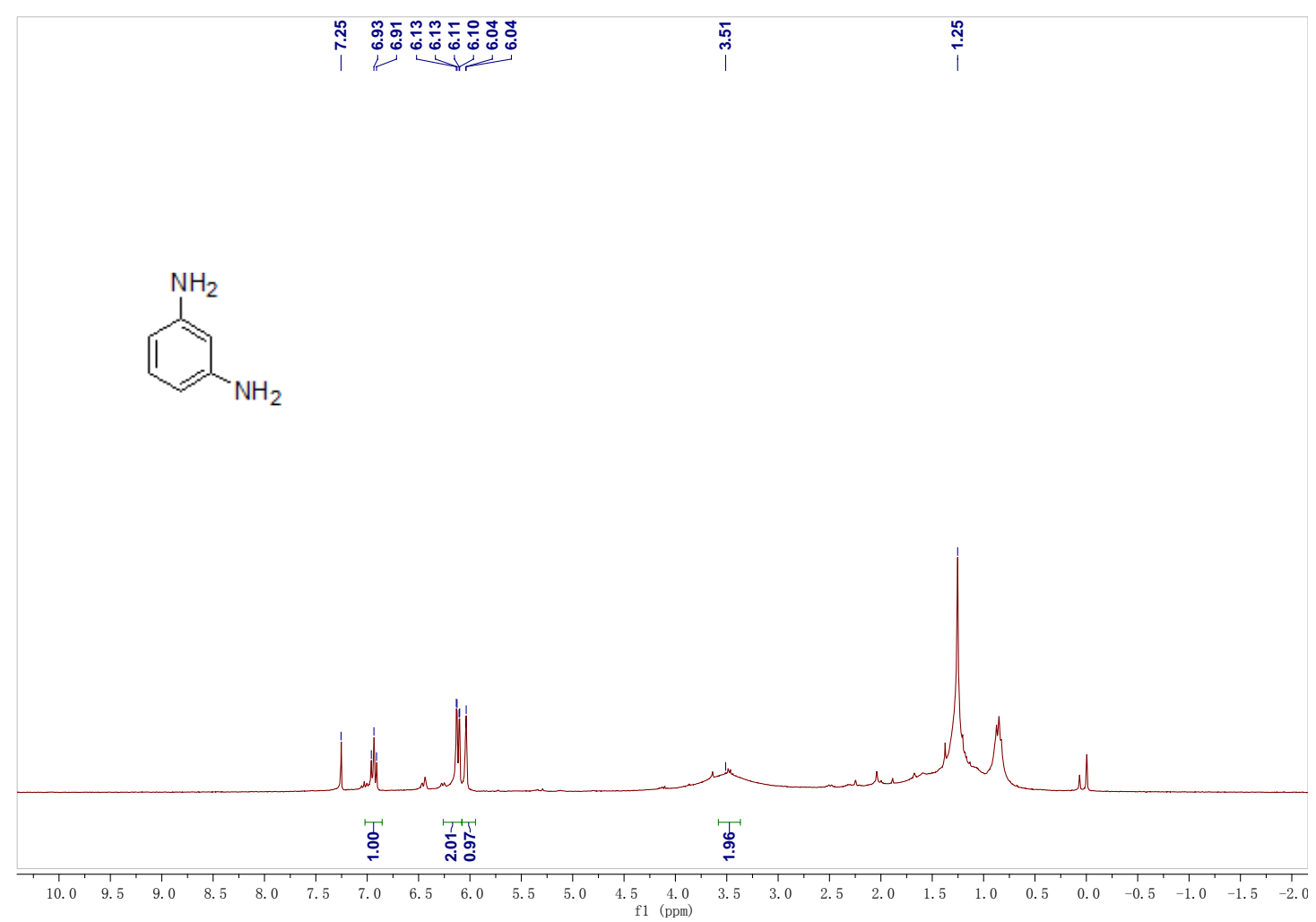

Figure S66. The ${ }^{1} \mathrm{H}$ NMR of 1,3-Phenylenediamine 


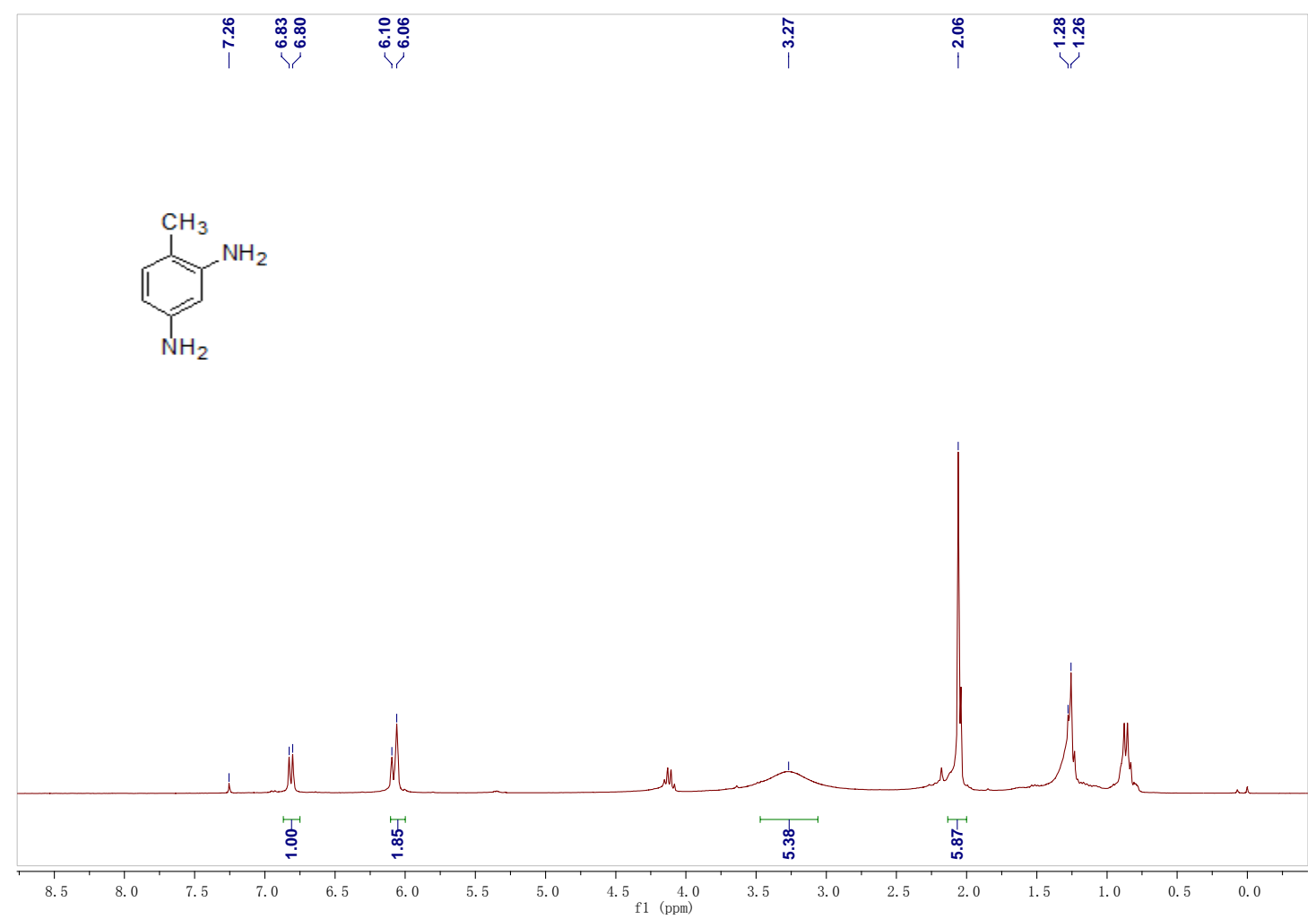

Figure S67. The ${ }^{1} \mathrm{H}$ NMR of 2,4-diaminotoluene

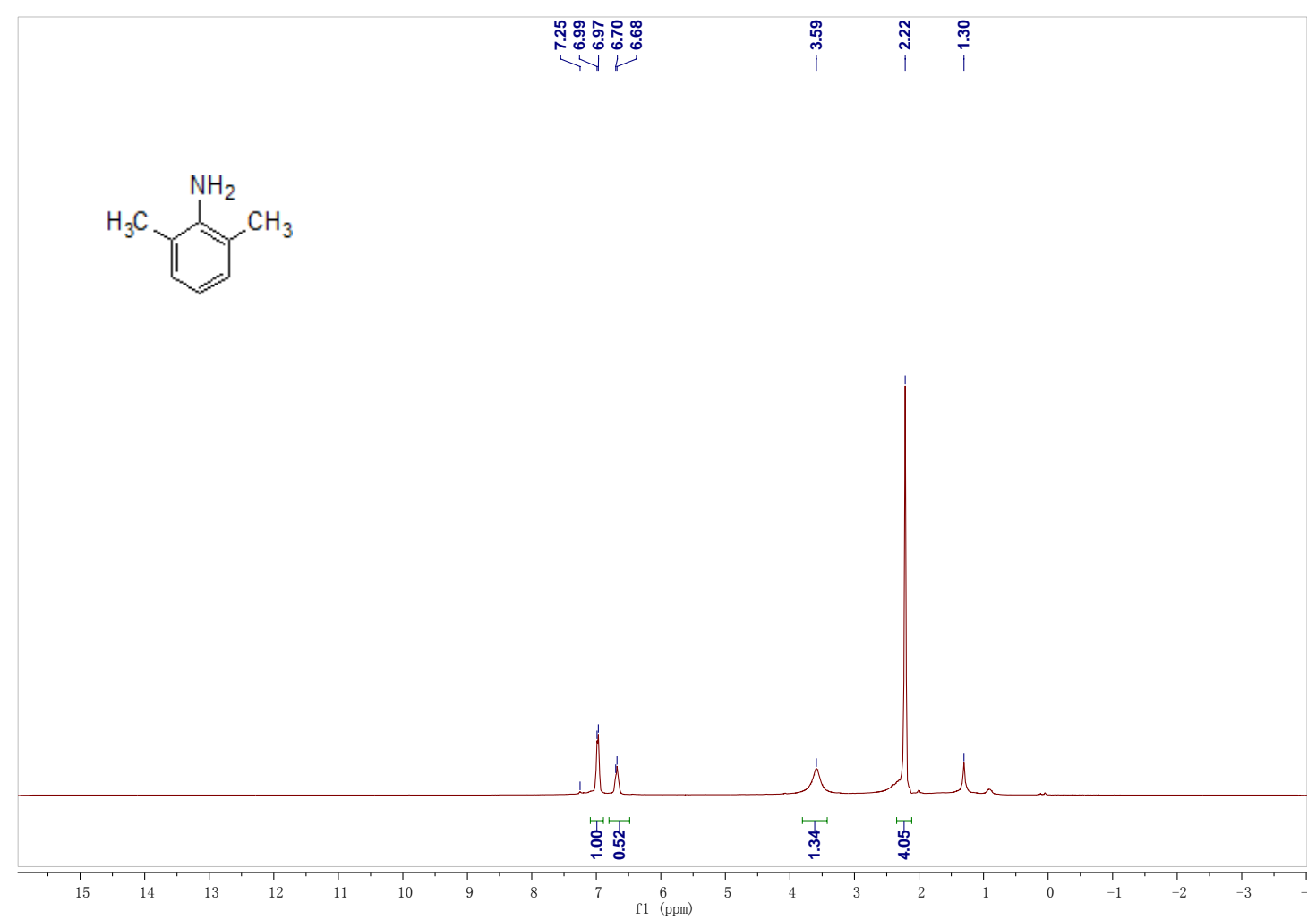

Figure S68. The ${ }^{1} \mathrm{H}$ NMR of 2,6-dimethylaniline 


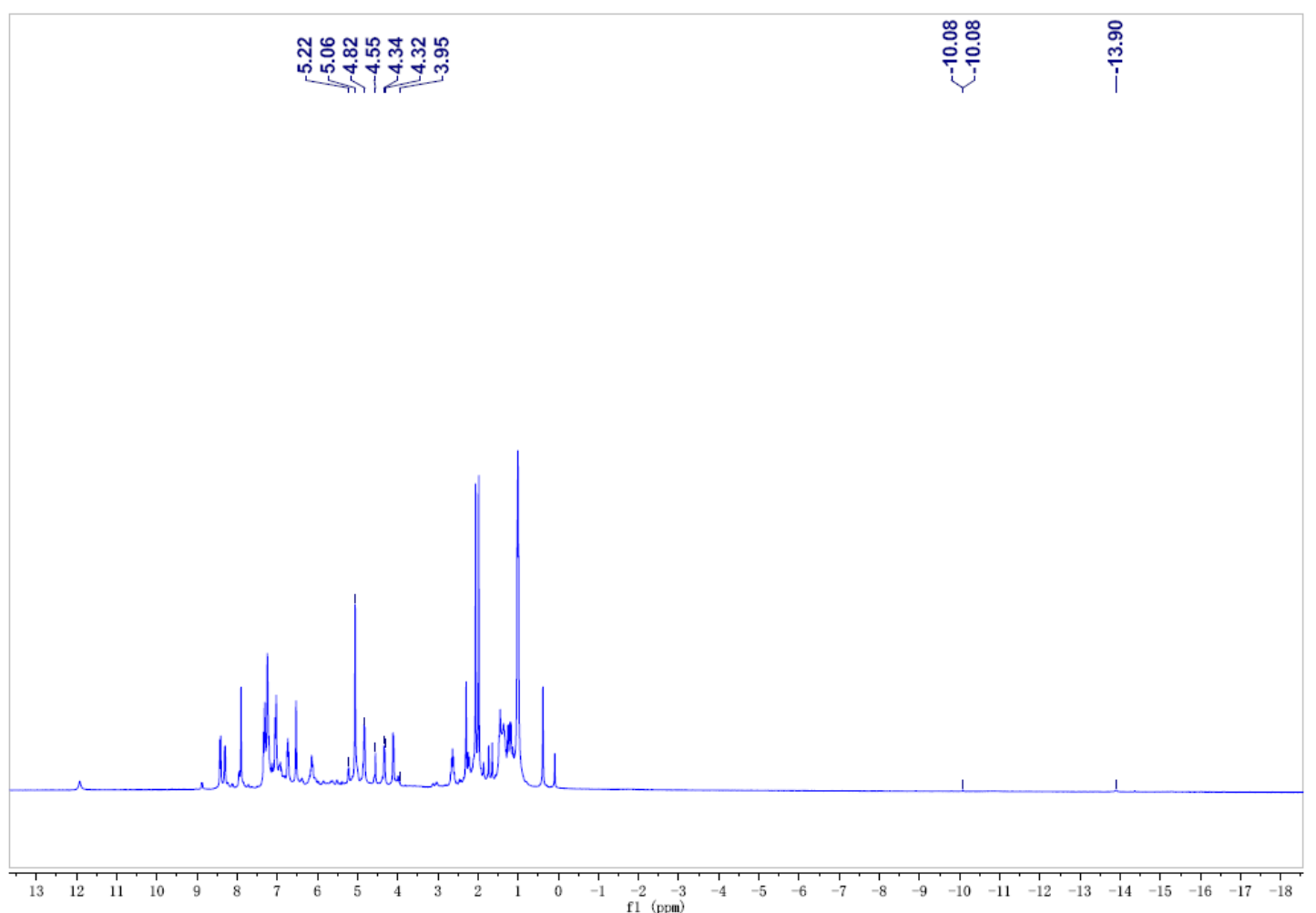

Figure S69. The in situ ${ }^{1} \mathrm{H}$ NMR of complex $\mathbf{2 b}$ reaction with $\mathrm{NaBH}_{4}$ 